Aus der

ABTEILUNG GASTROENTEROLOGIE UND ENDOKRINOLOGIE

(PROF. DR. MED. DR. H.C. G. RAMADORI)

im ZENTRUM INNERE MEDIZIN

der MEDIZINISCHEN FAKULTÄT

der UNIVERSITÄT GÖTTINGEN

\title{
Effekt von Amiodaron auf periphere Parameter der Schilddrüsenhormonaktivität bei kardiologischen Patienten mit AICD
}

\author{
INAUGURAL-DISSERTATION \\ zur Erlangung des Doktorgrades \\ der Medizinischen Fakultät \\ der Georg-August-Universität zu Göttingen
}

\author{
vorgelegt von \\ CHRISTOPH WÜNSCHE
}

aus

Dresden

Göttingen 2010 
Dekan: Prof. Dr. med. C. Frömmel

I. Berichterstatter: Prof. Dr. med. M. Hüfner

II. Berichterstatter: Priv.-Doz. Dr. med. Vollmann

III. Berichterstatter: Prof. Dr. med. Oppermann

Tag der mündlichen Prüfung: 12. 4. 2011 


\subsection{Amiodaron}

1.1.1. Bedeutung von Amiodaron

1.1.2. Chemische Eigenschaften, Pharmakokinetik und Wirkungen ___ 1

1.1.3. Wirkungen von Amiodaron auf die Schilddrüse___ 3

1.1.3.1. Amiodaronbedingte Hyperthyreose _ 4

1.1.3.2. Amiodaronbedingte Hypothyreose

1.2. Fragestellung___ 8

1.3. Schilddrüsenhormone __ 9

1.3.1. Synthese und Eigenschaften __ 9

1.3.2. Wirkung von Schilddrüsenhormonen auf Rezeptorebene__ 10

1.3.3. Periphere Wirkung von Schilddrüsenhormonen ___ 11

1.3.3.1. Leber- und Lipidstoffwechsel ___ 11

1.3.3.2. Knochen und Bindegewebe __ 15

1.3.3.3. Muskel und Herz ___ 20

1.3.3.4. Abhängigkeit der gemessenen Parameter von der Schilddrüsenfunktion

(Zusammenfassung) __ 21

2. Material und Methoden ______________________

2.1. Patientenauswahl und Probenentnahme __ 22

2.2. Probenbestimmung _ 24

2.2.1. Quantitative Bestimmung von SHBG

2.2.2. Quantitative Bestimmung von Osteocalcin___ 24

2.2.3. Quantitative Bestimmung von I CTP (Telopeptid)___ 24

2.2.4. Quantitative Bestimmung von CICP (C-terminal Propeptide of Type- I-Collagen) _ _ 25

2.2.5. Quantitative Bestimmung von Prokollagen III ___ 25

2.2.6. Quantitative Bestimmung der Schilddrüsenparameter ___ 25

2.2.7. Quantitative Bestimmung von Ferritin __ 26

2.2.8. Quantitative Bestimmung von Creatinkinase (Gesamt-CK)__ 27

2.2.8.1. Quantitative Bestimmung von CK-MB __ 27

2.2.9. Quantitative Bestimmung der alkalischen Phosphatase (AP) ___ 27

2.2.9.1. Quantitative Bestimmung der Alkalischen Skelett-Phosphatase (bone AP) __ 27

2.2.10. Quantitative Bestimmung der Gamma-Glutamyl-Transferase (GGT) __ 28

2.2.11. Quantitative Bestimmung von Albumin __ 28

2.2.12. Quantitative Bestimmung von Cholesterin __ 28

2.3. Statistische Auswertung__ 29

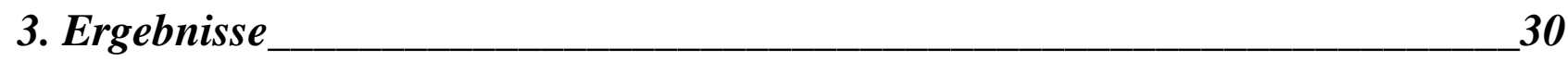

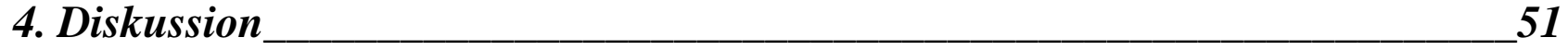

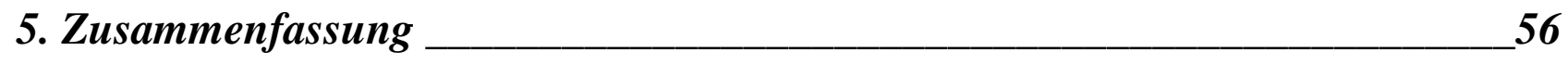

6. Literaturverzeichnis ________________________________ 57

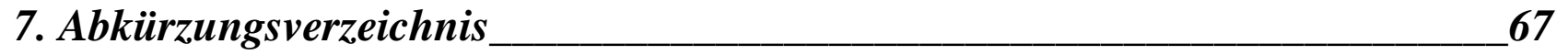




\section{EINLEITUNG}

\subsection{AMIODARON}

\subsubsection{BEDEUTUNG VON AMIODARON}

Amiodaron wurde 1961 in den Labaz-Laboratorien auf der Suche nach einem potenten Koronarvasodilatatoren entwickelt (Charlier 1962, Stäubli und Studer 1981). Bereits nach kurzer Zeit fiel die hervorragende antiarrhythmische Wirkung der Substanz bei Versuchstieren auf. Amiodaron stellt heute eines der potentesten Antiarrhythmika dar. Es ist bei fast allen Herzrhythmusstörungen wirksam und wird heute in der Akuttherapie bei therapieresistentem Kammerflimmern oder bei Kammertachykardien intravenös appliziert. Auch zur Kardioversion bei Vorhofflimmern bzw. zur Rezidivprophylaxe per os wird die Substanz seit Jahren erfolgreich eingesetzt. Insbesondere gilt dies auch für Patienten mit Herzinsuffizienz. So senkt Amiodaron das Risiko des plötzlichen Herztodes um 29\% bzw. des kardiovaskulären Todes um 18\% (Piccini et al. 2009).

\subsubsection{Chemische Eigenschaften, Pharmakokinetik Und Wirkungen}

Amiodaron ist ein Diethylaminobenzofuran. Die Substanz ist stark lipophil und besitzt als Gemeinsamkeit mit vielen anderen Antiarrhythmika eine Diethylaminogruppe. Auffällig ist der hohe Gehalt an organischem Jod. Er entspricht $37 \%$ des Molekulargewichtes (Fachinformation Sanofi Cordarex Infusionslösung 1998, Rao et al. 1986). Der in der Struktur von Amiodaron befindliche zweifach jodierte Benzolring weist auf eine Gemeinsamkeit mit Schilddrüsenhormonen hin (Späth 1992). Abbildung 1 zeigt den Vergleich der Strukturformel von Amiodaron und Desethylamiodaron mit Thyroxin (T4) und Trijodthyronin (T3). Desethylamiodaron (DEA) ist der Hauptmetabolit und gleicht bezüglich der Pharmakokinetik und Wirkung ungefähr dem Amiodaron mit einer allerdings noch längeren Halbwertszeit. Amiodaron weist eine Eliminationshalbwertszeit von 56 Tagen und sein Metabolit Desethylamiodaron eine extrem lange Halbwertszeit von 129 Tagen auf. Der Hauptausscheidungsweg erfolgt über die Leber und die Galle (Kaufmann et al. 2000, Späth 1992). Wichtig zur Beurteilung der Pharmakokinetik ist die Fähigkeit der Substanz, sich stark im Gewebe zu verteilen. Es besteht, sowohl bei Amiodaron selbst als auch bei DEA, ein 30bis 50-mal größerer Verteilungsraum als bei anderen Antiarrhythmika. Hierbei bestehen gewebespezifische Unterschiede, auch ist die Verteilungsgeschwindigkeit in die verschiedenen Kompartimente unterschiedlich. So ist die Konzentration von Amiodaron im 
Fettgewebe (41\%), in der Lunge (10\%), im Skelettmuskel (22\%) und der Leber (19\%) besonders hoch (Adams et al. 1985).

Am Herzen zeigt der Metabolit Desethylamiodaron eine bis zu dreifach höhere Konzentration als Amiodaron selbst. Amiodaron ist bei therapeutischem Serumspiegel an Alpha- und BetaLipoproteine gebunden. Hierbei handelt es sich um Albumin und Alpha -1- Acidglykoprotein (sog. Akute-Phase-Protein). Amiodaron geht dabei zu 99,5\% eine Eiweißbindung ein (freie Fraktion 0,5\%) und bei Desethylamiodaron sind es 98,2\% (freie Fraktion 1,8\%) (Späth 1992, Natter und Talajic 1988, Kates et al. 1988, Lalloz et al. 1984). Das Proteinbindungsverhalten wird durch die Amiodaronkonzentration im Serum beeinflusst (Schmidberger 1988).

Die Wirkung von Amiodaron basiert auf der Hemmung verschiedener Ionenströme. Als Klasse-III-Antiarrhythmikum besteht hauptsächlich eine Blockade der Kaliumkanäle. Es kommt zur Verlängerung der kardialen Repolarisation im Aktionspotential der Herzmuskelzelle und damit zur Verlängerung der Aktionspotentialdauer (Lewalter et al. 2002). Weitere Wirkungen sind die Hemmung der adrenergen kardialen Rezeptoren sowie die Abschwächung der sympathischen Effekte am Herz-Kreislauf-System. Dies wird insbesondere durch die Abschwächung von katecholamininduziertem Anstieg von Blutdruck, Herzfrequenz und damit verbundenem hohen Sauerstoffverbrauch erreicht. Diese Wirkung ist bedingt durch Verminderung von präsynaptischer Freisetzung sympathomimetischer Transmitter bzw. nicht-kompetitiver Hemmung der Alpha-, Beta-1- und Beta-2- Rezeptoren. Ferner führt der Einsatz von Amiodaron zur Abnahme der Anzahl der Beta-AdrenoRezeptoren des Herzens und zur Hemmung der T3-Wirkung auf die Adreno-RezeptorExpression des Herzens, was tierexperimentell nachgewiesen wurde (Franklin und Sheppard 1993). Weitere wichtige Wirkungen sind Hemmung der Aktivierung der Adenylzyklase, Vasodilatation mit Blutdruckabfall sowie Koronardilatation (Späth 1992).

Des Weiteren führt die Substanz zur Hemmung der Konversion von T4 zu T3 in der Leber und im Herzen. Die kardiale Wirkung des Präparats spiegelt direkte Interaktionen der Substanz mit nuklearen Rezeptoren für T3 wider (Franklin und Sheppard 1993). So wurde in einer Studie von Wiersinga 2008 festgestellt, dass der kardiale Effekt von Amiodaron teilweise durch Hypothyreose-ähnliches Verhalten am Herzen hervorgerufen wird. Es kommt dabei zum inhibitorischen Effekt der Bindung von T3 an Thyroid-Rezeptor - alpha-1 und Thyroid-Rezeptor - beta-1 und bei der Expression von T3-abhängigen Genen. Dies zeigte sich durch signifikante Ähnlichkeit bei der Expression von bestimmten Genen im Herzen von hypothyreoten Versuchstieren im Vergleich mit amiodaron-behandelten Tieren. Diese Ähnlichkeit existierte bei der Transkription von Ionen-Kanal-Genen nicht in dieser Weise 
(Wiersinga 2008). Es ist daher nötig, Schilddrüsenhormone und deren Rezeptoren im Folgenden näher zu betrachten (s. Kap. 1.2.)<smiles>CCCCCCN(CCCCCC)CCCOc1c(I)cc(C(=O)c2c(C)oc3ccccc23)cc1I</smiles>

Amiodaron<smiles>CCCNCCOc1c(I)cc(C(=O)c2c(C)oc3ccccc23)cc1I</smiles>

Desethylamiodaron<smiles>NC(Cc1cc(I)c(Oc2cc(I)c(O)c(I)c2)c(I)c1)C(=O)O</smiles>

Thyroxin<smiles>NC(Cc1cc(I)c(Oc2ccc(O)c(I)c2)c(I)c1)C(=O)O</smiles>

Trijodthyronin

Abb.1 Vergleich der Strukturformeln von Amiodaron, Desethylamiodaron, Thyroxin (T4) und Trijodthyronin (T3)

\subsubsection{WIRKUNGEN VON AMIODARON AUF DIE SCHILDDRÜSE}

Die Einflüsse von Amiodaron auf das Schilddrüsensystem sind strukturbedingt, aber auch dem extrem hohen Jodgehalt der Verbindung zuzuschreiben. Die meisten der mit Amiodaron behandelten Patienten behalten unter der Therapie ihre euthyreote Stoffwechsellage bei. Allerdings kommt es bei etwa 50\% der Patienten zu Veränderungen von Schilddrüsenfunktionsparametern (Heufelder und Wiersinga 1999). Es handelt sich dabei 
meist um obligatorische, d.h. erwartungsgemäße, regelmäßige und ohne therapeutische Konsequenzen bleibende Effekte von Amiodaron auf das Schilddrüsenhormonsystem.

In der Hypophyse und im peripheren Gewebe wird T4 in aktives T3 umgewandelt. Für die hierfür notwendige Dejodierung von T4 sind Dejodasen notwendig. Es sind Typ I-, II- und III- 5-Dejodasen beteiligt. Typ I- 5-Dejodase und Typ II- 5'-Dejodase katalysiert die Konversion von T4 in aktives T3, Typ III hingegen baut T4 zum inaktiven rT3 ab (Pfannenstiel et al. 1999 a). Amiodaron hemmt die Aktivität der Typ I- 5-Dejodase im peripheren Gewebe und der Typ I-5 'Dejodase in der Hypophyse (Kaufmann et al. 2000, Burger et al. 1976). Demzufolge kommt es zu einem Anstieg von T4 und fT4 und zu einer Erniedrigung von aktivem T3. Das fT4 steigt dabei um ca. 40\% und der fT3-Spiegel sinkt um ca. $50 \%$ (T3 um 10 bis 25\%). Das Thyroxin steigt bei ca. $40 \%$ der Patienten bis in hyperthyreote Bereiche an.

Die zentrale Konversionshemmung von fT4 zu fT3 führt durch ein vermindertes negatives Feedback in der Hypophyse und im Thalamus zu einer Erhöhung des TSH in den oberen Normbereich oder darüber (Kaufmann et al. 2000). Diese TSH-Erhöhung normalisiert sich nach längerer Behandlung (ca. 3 Monate) mit Amiodaron und kann sogar in einen erniedrigten TSH-Spiegel umschlagen (Heufelder und Wiersinga 1999). Auch wird die Aufnahme von fT3 und fT4 in die peripheren Zellen durch Amiodaron gehemmt, was ebenfalls zu leicht erhöhten fT4- Spiegeln beiträgt (Kaufmann et al. 2000).

Bei bis zu 15\% der Patienten kommt es zu einer manifesten Amiodaron-induzierten Hypooder Hyperthyreose (Newman et al. 1998).

\subsubsection{AMIODARON-BEDINGTE HYPERTHYREOSE}

Der Jodgehalt von Amiodaron beträgt 37\%. Dies bedeutet bei einer Dauertherapie von 200 $\mathrm{mg} / \mathrm{d}$ eine tägliche Jodzufuhr von $75 \mathrm{mg}$. Davon werden ca $6 \mathrm{mg} / \mathrm{d}$ als freies Jodid in die Zirkulation abgegeben. Der normale Tagesbedarf des Organismus an Jod beträgt 150-250 Mikrogramm. Der intrathyreoidale Jodgehalt steigt bei euthyreoten Personen unter chronischer Behandlung mit Amiodaron um das Vierfache an (Heufelder und Wiersinga 1999, Wiersinga 1997). Eine jodinduzierte Hyperthyreose im Verlauf einer Amiodarontherapie wird als Typ-I - Hyperthyreose bezeichnet. Sie wird meist durch autonome mikro- und makrofollikuläre Veränderungen der Schilddrüse (z.B. multinoduläre Struma) verursacht, welche häufiger in Jodmangelgebieten vorkommen. In Jodmangelgebieten überwiegt deshalb die Amiodaron-induzierte Hyperthyreose (Nolte et al.1995, Martino et al. 1984). Die Follikel passen sich einer gesteigerten Jodzufuhr nicht an 
und produzieren mehr Schilddrüsenhormone (Heufelder und Wiersinga 1999, Studer et al. 1978).

Eine Typ-I-Hyperthyreose kann im Gegensatz zur Amiodaron-bedingten Hypothyreose, welche meist innerhalb der ersten 18 Monate der Amiodarontherapie auftritt, während der gesamten Amiodaroneinnahmezeit manifest werden (Spelsberg et al. 2000).

Neben der Typ-I-Hyperthyreose gibt es die Typ-II-Hyperthyreose. Hierbei kommt es zur gesteigerten Freisetzung von präformierten Schilddrüsenhormonen. Dies kann auf dem Boden einer destruierenden Thyreoiditis geschehen, welche durch medikamentenbedingte zytotoxische Effekte auf die Thyreozyten hervorgerufen wird. Durch die Zerstörung von Schilddrüsenfollikeln wird neben den Schilddrüsenhormonen auch Thyreoglobulin ausgeschwemmt. Das ist eine Erklärung für die häufige Erhöhung des Thyreoglobulinspiegels bei Typ-II- Hyperthyreose.

\subsubsection{AMIODARON-BEDINGTE HYPOTHYREOSE}

Sowohl bei der Amiodaron-induzierten Hyperthyreose als auch bei der Hypothyreose kann der hohe Jodgehalt eine ursächliche Rolle spielen. Physiologisch existiert ein Autoregulationsmechanismus der Schilddrüse, welcher nach seinen Erstbeschreibern als Wolff- Chaikoff- Effekt bezeichnet wird. Wenn es durch Überschwemmung des Organismus mit Jod zur Überschreitung einer bestimmten Jodid-Konzentration im Plasma kommt, führt das zu einer akuten Hemmung des Einbaus von Jodid in organische Verbindungen und damit zur Hemmung der Hormonsynthese (Nolte et al. 1995). Außerdem wird die Sekretion von Schilddrüsenhormonen akut blockiert. Innerhalb von ca. zwei Wochen adaptiert sich der Organismus an diese hohe Jodexposition und der Hemmeffekt geht wieder verloren (Pfannenstiel et al.1999a). Kommt es zur Überforderung dieses Autoregulationsmechanismus, d.h., die Hemmung des Jodid Einbaus persistiert, resultiert eine manifeste Jod-induzierte Hypothyreose (Hörmann 1997, Stäubli und Studer 1981).

Selten kommt es auch zu einer immunogenen Eigenwirkung von Amiodaron mit Wirkung von antithyreoidalen Antikörpern (Safran et al. 1988). Meist werden bereits vorliegende subklinische Immunthyreopathien ausgelöst (Martino et al. 1994). So kann Amiodaron eine immunogene Thyreoiditis (z.B. Hashimoto-Thyreoiditis) mit initialer Hyperthyreose und später Hypothyreose hervorrufen (durch Läsion der Thyreozyten mit anschließender Zirkulation der Hormone) (Hörmann 1997). 
Die Inzidenz, an einer Amiodaron-bedingten Hypothyreose zu erkranken, ist in Ländern mit hoher Jodzufuhr häufiger (13\%) und in Ländern mit Jodmangel niedriger (6\%) (Newman et al. 1998).

Hypothyreose - ähnliche Effekte unter Amiodaroneinnahme wurden bereits in den 70er und 80er Jahren an Ratten und Kaninchen untersucht, aber auch an Menschen beobachtet (Burger et al. 1976, Wiegand et al. 1986). Man ging damals von einer Inhibition der Hormonsynthese durch die starke Jodbelastung durch Amiodaron (Burger et al. 1976) und von einem Absinken von T3 aufgrund der Hemmung der Konversion von T4 in T3 auch in den peripheren Zellen durch Amiodaron (Pekary et al. 1986, Sogol et al. 1983) aus. Durch Gewebekulturen von Hypophyse, Leber und Myokard wurde ein dritter Mechanismus als Ursache für die durch Amiodaron ausgelösten Hypothyreose-ähnlichen Effekte untersucht, nämlich die Bindung von Amiodaron bzw. Desethylamiodaron am T3-Rezeptor und die daraus folgende kompetitive oder nicht-kompetitive Hemmung (Latham et al.1987, Franklyn et al.1985).

In den 90er Jahren folgte dann durch Paradies et al. eine In-vivo-Untersuchung an Ratten zur Klärung des kompetitiven Antagonismus von Amiodaron zu T3 auf Rezeptorebene. Um den hypothyreoten Effekt der gehemmten Konversion von T4 zu T3 auszuschalten, wurden die Ratten thyreoidektomiert und T3 direkt substituiert. Eine Gruppe von Ratten bekam zusätzlich zu T3 Amiodaron verabreicht. Es stellte sich heraus, dass in dieser Gruppe ein Hypothyreoseähnlicher Effekt zu verzeichnen war. Hohe T3-Dosen dämpften den Hypothyreose-ähnlichen Effekt wieder und verursachten schließlich eine hyperthyreote Stoffwechsellage. Zur Beurteilung dieser Stoffwechsellage wurden folgende Parameter verwendet: Körpergewicht, links-ventrikuläres Herzgewicht, Schilddrüsenhormonkonzentration im Plasma und MHC (Myosin heavy chains) des Herzmuskels (Paradies et al. 1991). Weitere Untersuchungen folgten, in welchen auch eine Spezifizierung des Antagonismus von Amiodaron bzw. Desethylamiodaron auf bestimmte Rezeptor-Subtypen vorgenommen wurde. So wurde eine kompetitive Inhibition von Desethylamiodaron auf den Alpha-1-T3-Rezeptor in vitro festgestellt (van Beeren et al. 1995).

Bakker et al. stellten 1994 fest, dass neben dem kompetitiven Antagonismus von Desethylamiodaron auf T3-Rezeptoren auch ein nicht-kompetitiver Antagonismus auf die Beta-1-T3- Rezeptoren besteht. Hierbei wirkt Desethylamiodaron, nicht aber Amiodaron selbst als Inhibitor und hemmt die Bindung von T3 an Beta-1-T3-Rezeptoren. Desethylamiodaron interagiert dabei vornehmlich mit dem nicht besetzten Rezeptor. Die Untersuchung wurde von Bakker et al. mit klonierten Schilddrüsenhormonrezeptoren der Ratte durchgeführt (Bakker et al. 1994). Van Beeren et al. verwendeten für eine ähnliche 
Untersuchung von Hühnern stammende Alpha-1-T3-Rezeptoren in einem E.coli-System (van Beeren et al. 1995).

Drvota et al. stellten 1995 fest, dass der Antagonismus je nach Amiodaronkonzentration am Beta-1-Schilddrüsenhormon-Rezeptor von „,nicht kompetitiv“ zu „kompetitiv“ bei hohen Amiodaronkonzentrationen wechselt. Ein Vergleich mit anderen Antiarrhythmika (Metoprolol, Sotalol, Verapamil, Propafenon, Disopyramid, Lignocaine) zeigte, dass nur Amiodaron bzw. Desethylamiodaron einen antagonistischen Effekt auf Beta-1Schilddrüsenhormon-Rezeptoren hat. Die Untersuchungen wurden in vitro an menschlichen Beta-1-Schilddrüsenhormon-Rezeptoren (hThRß1), kloniert aus einer menschlichen Brustkrebszellreihe, vorgenommen (Drvota et al. 1995).

Verschiedene weitere Studien bestätigten diese Resultate (Bogazzi et al. 2001).

Der nicht kompetitive Antagonismus wurde also festgestellt, aber erst in einer Studie von van Beeren et al. 1999 wurde untersucht, an welcher Stelle das Desethylamiodaron die nicht kompetitive Bindung am TR-Beta-1-Rezeptor eingeht. Van Beeren et al. fanden heraus, dass diese Bindungsstelle an der äußeren Hülle des Rezeptorproteins die Region überlappt, an welcher auch Co-Aktivatoren und Co-Repressoren am TR-Beta-1-Rezeptor binden (van Beeren et al. 1999).

Im Jahr 2000 wurde ebenfalls von van Beeren et al. gezeigt, dass DEA die Interaktion des CoAktivators GRIP1 (glucocorticoid receptor interacting protein 1) mit dem TR-Beta-1Rezeptor behindert und als Ursache für die Hypothyreose-ähnlichen Effekte mitverantwortlich sein kann (van Beeren et al. 2000). 


\subsection{Fragestellung}

Amiodaron ist wie oben beschrieben ein hochpotentes Antiarrhythmikum mit betarezeptorantagonist-ähnlichem Effekt. Es kommt zu einer Verlängerung der Repolarisationszeit in der Herzmuskelzelle, wie dies bei Hypothyrose bekannt ist. Amiodaron besitzt nicht nur einen hohen Jodgehalt, sondern auch eine starke Strukturähnlichkeit mit den Schilddrüsenhormonen Thyroxin (T4) und Trijodthyronin (T3) (Lewalter et al 2002, Späth 1992).

Auf Grund der strukturellen Ähnlichkeit von Amiodaron mit Schilddrüsenhormonen bestand der Verdacht, dass Amiodaron und sein Hauptmetabolit Desethylamiodaron als Antagonist an den organspezifischen Alpha- und Beta-Schilddrüsenhormonrezeptoren der peripheren Organe wirkt. Dies hätte an den entsprechenden Zielzellen und -organen eine Stoffwechsellage wie bei Hypothyreose zur Folge. Dies wurde tierexperimentell an Ratten bzw. in vitro an menschlischen und tierischen Gewebekulturen auch nachgewiesen (Paradies et al. 1991, Bakker et al. 1994, van Beeren et al. 1995, Drvota et al. 1995, Wiersinga 2008). Es wurde sowohl ein kompetitiver als auch ein nicht-kompetitiver Antagonismus am Beta-1und Alpha-1-Schilddrüsenhormonrezeptor festgestellt. Eine In-vivo-Untersuchung am Menschen fehlte bisher. Die peripheren Schilddrüsenhormon-Rezeptortypen sind quantitativ unterschiedlich in verschiedenen Geweben repräsentiert. In vorliegender Studie werden verschiedene Proteine und Enzyme als Repräsentanten unterschiedlicher Gewebe und Organe untersucht. Das Verhalten bei Hypothyreose ist bei diesen Parametern bereits bekannt. Im Rahmen der Studie wird nun ein Vergleich diesbezüglich mit Amiodaron angestellt. 


\subsection{SCHILDDRÜSENHORMONE}

\subsubsection{SYNTHESE UND EIGENSCHAFTEN}

Bei der Synthese von Schilddrüsenhormonen kommt es zunächst zur Aufnahme von Jodid über $\mathrm{Na}^{+} /$Jodid-Symporter in die Zelle. Dort erfolgt der Transport zur apikalen Zellmembran und die Jodierung von Thyreoglobulin unter Mitwirkung von Thyreoidperoxidase (TPO).

Als Zwischenprodukte entstehen die Hormonvorläufer 3-Monojodtyrosin (MIT) und 3,5Dijodtyrosin (DIT). Daraus entsteht $\mathrm{T} 4$ (Tetrajodthyronin $=$ Thyroxin) durch Kopplungsreaktion aus 2 DIT-Molekülen. T3 entsteht einerseits durch die Verbindung von DIT und MIT, vor allem aber durch intra- und extrathyreoidale enzymatische Dejodierung aus T4. Hierbei wird T4 durch 3 verschiedene Dejodasen metabolisiert.

Die Typ-I - 5'-Dejodase ist hierbei das wichtigste Enzym, welches in der Schilddrüse, in Leber, Niere, Hypophyse sowie im ZNS die Umwandlung von T4 zu T3 und den Abbau von rT3 zu 3,3'- T2 vornimmt. Außerdem ist die Typ-II - 5'-Dejodase an der Dejodierung von T4 zu aktivem T3 beteiligt. Sie wird vor allem bei Hypothyreose im ZNS, der Hypophyse und in der Plazenta exprimiert. Das inaktive rT3 entsteht unter Einwirkung von Typ-III - 5 Dejodase aus Thyroxin. Außerdem kommt es unter Mitwirkung dieser Dejodase zum Abbau von T3 zu 3,3'- T2 (Hüfner und Grussendorf 1980, Pfannenstiel et al. 1999 a).

Die Schilddrüse sezerniert ca. 100 Mikrogramm T4 pro Tag, welches zu 99,9\% an Transportproteine gebunden im Serum vorkommt. Hierbei spielen in absteigender Affinität insbesondere Thyroxin bindendes Globulin (TBG), Transthyretin (= Praealbumin) und Albumin eine Rolle. Schilddrüsenhormone werden durch passive Aufnahme und möglicherweise auch über einen energieabhängigen aktiven Carrier in die Zielzelle aufgenommen. An Transportproteine, insbesondere an TBG gebundenes T4, kann nicht in die Zelle aufgenommen werden und steht demzufolge in dieser Form für die Wirkung in der Körperperipherie nicht zur Verfügung (Pfannenstiel et al.1999 a). Der Anteil an freiem T4 beträgt nur $0,03 \%$. T3 besitzt eine ca. 10- bis 20-fach geringere Affinität zu TBG als Thyroxin. Deshalb liegt der Anteil des freien, am Stoffwechsel beteiligten fT3 bei 0,3\%. Für Transthyretin fehlt die Bindungsfähigkeit zu T3 ganz. Allerdings resultiert daraus für T3 auch nur eine Halbwertszeit von 19 Stunden statt 5 bis 8 Tagen wie bei T4. Das biologisch inaktive rT3 zeigt eine noch geringere Bindungsaffinität an Proteine und hat eine Halbwertszeit von ca. 4 Stunden. An T3 werden in der Schilddrüse nur ca. 10 Mikrogramm pro Tag sezerniert. Der Rest (ca. 30 Mikrogramm T3 und 35 Mikrogramm rT3) wird in der Peripherie durch Umwandlung von T4 in T3 produziert (Pfannenstiel et al. 1999 a). 


\subsubsection{WIRKUNG VON SCHILDDRÜSENHORMONEN AUF REZEPTOREBENE}

Die Vermittlung der Schilddrüsenhormonwirkung erfolgt durch intranukleäre Schilddrüsenhormonrezeptoren. 1967 wurde von Tata und Williams-Ashman eine durch Schilddrüsenhormone induzierte mRNA bzw. Proteinsynthese nachgewiesen (Tata und Williams-Ashman 1967). Schilddrüsenhormonrezeptoren gehören zur Familie der Steroidrezeptoren. Dieser Rezeptorentyp, dem auch die Glukokortikoid-, Mineralokortikoid-, Progesteron-, Vitamin-D- und Retinsäurerezeptoren angehören, wirkt als ligandenabhängiger Transkriptionsfaktor mit zentraler DNS-Bindungsdomäne sowie zwei sog. Zinkfingern und einer C-terminalen Ligandenbindungsdomäne (Evans 1988).

T3 als die physiologisch aktive Form tritt in den Zellkern ein und bindet dort an den T3Rezeptor. Der Rezeptor-Hormonkomplex erkennt bestimmte Nukleotidsequenzen, die sog. „thyroid hormone response elements “.

Das Rezeptorprotein wird über die Zinkfinger mit der DNS-bindenden Domäne an die „thyroid hormone response elements“ des Zielgens gebunden. Zur Stabilisierung dieser Bindung dienen andere nukleäre Proteine, sog. Co-Faktoren, welche mit dem Hormonrezeptorkomplex Heterodimere bilden (Lazar 1993).

Als Heterodimerisierungspartner können neben den verschiedenen SchilddrüsenHormonrezeptoren auch andere Steroid-Proteine dienen, die summiert als TRAPs (TR auxiliary protein) bezeichnet werden (Darling et al. 1991).

In der Zelle werden Schilddrüsenhormone an spezifische nukleäre Rezeptoren gebunden. Es sind inzwischen fünf verschiedene Schilddrüsenhormonrezeptoren bekannt ( TR-beta-1, TRbeta-2, TR-alpha-1, TR-alpha-2 mit 2 Untertypen ).

1986 konnten 2 Gene identifiziert werden, die für spezifische Schilddrüsenhormorzeptoren TR-alpha und TR-beta codieren. Hierbei wird T3 mit hoher und T4 mit etwa 10-fach geringerer Affinität gebunden. Bis auf TR-alpha-2 haben alle eine T3-bindende Domäne. Über diese findet die Aktivierung der Rezeptoren statt. Das Gen der Betarezeptoren liegt auf Chromosom 3, das der Alpharezeptoren auf Chromosom 17 (Janssen 1998, Oppenheimer et al. 1996, Pfannenstiel et al. 1999 a).

Die Rezeptortypen sind quantitativ unterschiedlich in verschiedenen Geweben repräsentiert. Während sich in der Leber und Hypophyse hauptsächlich Betarezeptoren exprimieren, kommt im Hirn vor allem TR - alpha -1 vor. Im Herzmuskel sind beide Rezeptortypen vertreten (Janssen 1998 , Brent 1994). 


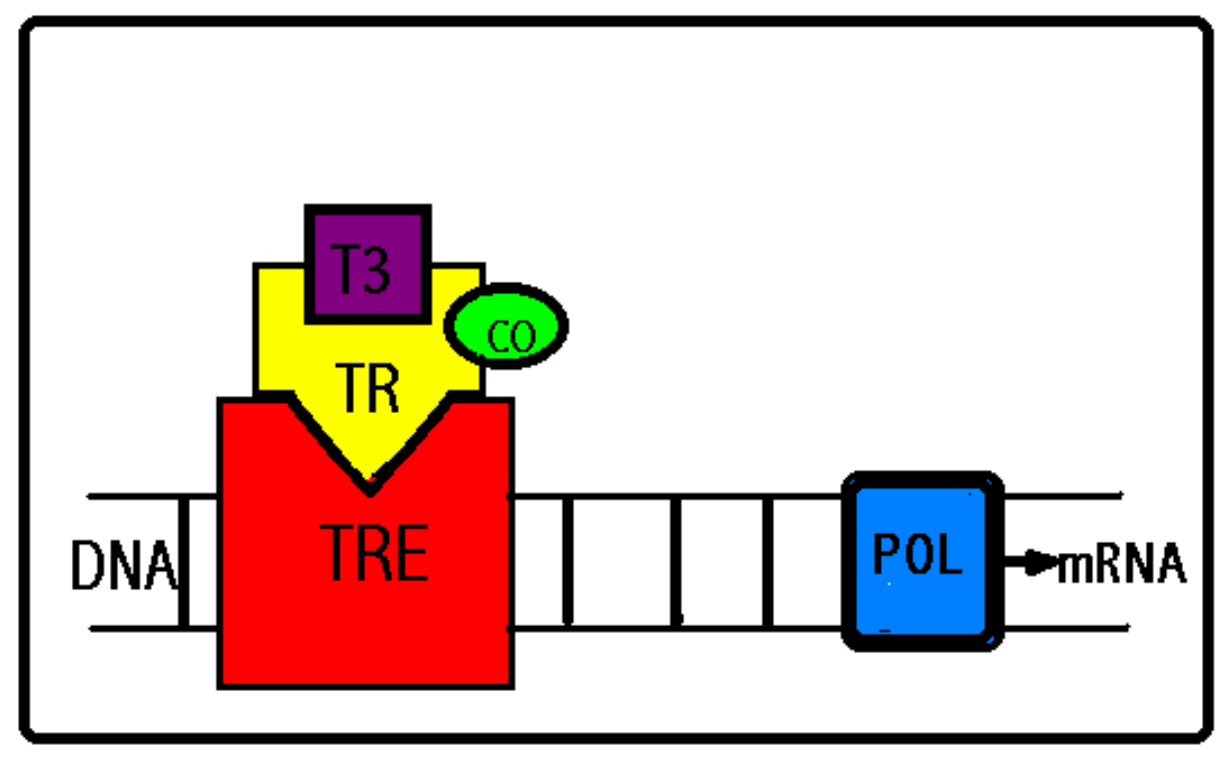

Abb.2 TR Schilddrüsenhormonrezeptor

TRE thyroid-hormone responsive element

POL RNA-Polymerase

CO Co-Aktivator/Repressor

\subsubsection{PERIPHERE WIRKUNG VON SCHILDDRÜSENHORMONEN}

Schilddrüsenhormone wirken in der Peripherie in unterschiedlichen Organen und Stoffwechselprozessen auf verschiedene Art und Weise. In der Studie wird deshalb ein breites Spektrum von Organ- und Stoffwechselprozessen durch entsprechende, die Stoffwechselprozesse repräsentierende, Laborparameter untersucht.

\subsubsection{LEBER- UND LIPIDSTOFFWECHSEL}

\section{Lipid-und Proteinmetbolismus}

Cholesterin gehört innerhalb der Stoffklasse der Lipide zu den Steroiden und macht dabei den größten Anteil aus (Buddecke 1984). Es besteht eine enge Korrelation zwischen dem Lipidstoffwechsel und der Schilddrüsenfunktion (Eckerth 1982, Bastenie 1972). Schilddrüsenhormone beeinflussen den Fettstoffwechsel durch Steigerung der Fettmobilisierung. Es kommt zum Abbau von Speicherfett und in geringem Maße auch zu einer erhöhten Lipidsynthese. Bei Hyperthyreose fallen die Cholesterinwerte ab und bei Hypothyreose wird ein Anstieg verzeichnet (Pfannenstiel et al. 1999 b, Abrams und Grundy 1981).

Der Cholesteringehalt des Serums entsteht neben der Aufnahme durch die Nahrung durch endogene Synthese. Den Hauptanteil bildet hier das endogen synthetisierte Cholesterin 
(Eckerth 1982). Synthese, Abbau und Elimination des Cholesterins werden durch die Schilddrüsenfunktion beeinflusst, nicht jedoch die Absorption im Darm. Schilddrüsenhormone beeinflussen die Synthese von Cholesterin über die Stimulierung des Schlüsselenzyms der Cholesterinsynthese der HMG-CoA-Reduktase. Die Aktivität dieses Enzyms als Ausdruck für verstärkte Cholesterinsyntheserate verhält sich direkt proportional zum Schilddrüsenhormonspiegel. Trotzdem kommt es unter dem Einfluss von Schilddrüsenhormonen insgesamt $\mathrm{zu}$ einem cholesterinsenkenden Effekt durch das Überwiegen der vermehrten Ausscheidung des Cholesterins im Darm und einem stärker stimulierten Abbau in der Leber (Eckerth 1982).

Die Wirkung von Schilddrüsenhormonen auf den Proteinmetabolismus wird u.a. durch Albumin repräsentiert. Albumin ist ein wichtiges Transportprotein mit einem Molekulargewicht von 66,3 Kilodalton. Es wird in der Leber synthetisiert. Stimulierend auf die Albuminsynthese wirkt, neben Glukokortikoiden und anabolen Steroiden, das Thyroxin. Circa 40\% des Albuminpools ist extravasculär, hauptsächlich in Haut und Muskulatur, nur ein geringer Teil in der Leber selbst (ca. 0,3 g), gespeichert. Die Halbwertszeit des Albumins beträgt 19 Tage. Über den Darm (täglich ca. 100 Milligramm) und über die Nieren (täglich 15 Milligramm) wird ein Teil des Albumins ausgeschieden. Der Abbau erfolgt über unterschiedliche Gewebe, insbesondere durch die Kapillarendothelzellen nach Pinozytose. $\mathrm{Zu}$ Hypoalbuminämien kommt es in erster Linie durch Verteilungsstörungen, z.B. durch Vergrößerung des Verteilungsraumes bei Sepsis oder Schock bzw. durch Verlust in den dritten Raum bei Ödemen oder Aszites. Des Weiteren kann es durch Verlust nach außerhalb (z.B. durch Verbrennungen oder verminderte Synthese bei gestörter Leberfunktion und Proteinmangelernährung) zu verminderten Albuminkonzentrationen im Serum kommen.

Bei Nahrungsentzug fällt die Konzentration frühestens nach einer Woche unter den Referenzbereich, der bei Erwachsenen leicht altersabhängig zwischen $30 \mathrm{~g}$ und $53 \mathrm{~g}$ pro Liter liegt. Starker Albuminverlust führt zu verstärkter Synthese, was mit einer CholinesteraseAktivitätserhöhung einhergeht. Erhöhte Albuminwerte kommen praktisch nicht vor, allenfalls relativ durch Exsikkose (Thomas 2000 b).

Bezüglich der Schilddrüse übernimmt Albumin, zusammen mit Präalbumin und TBG (Thyroxinbindendes Globulin), die Funktion des Transportproteins, welches insbesondere T4, aber auch T3 bindet. Amiodaron bindet ebenfalls an Albumin, hat aber keinen Einfluss auf die Verteilung der Bindung von Schilddrüsenhormonen auf deren Bindungsproteine (Lalloz et al. 1984). Wie oben erwähnt, wirkt Thyroxin stimulierend auf die Albuminsynthese. In einer Studie von 1989 wurde ein direkter proportionaler Zusammenhang zwischen fT3/ fT4 und 
Albumin im Serum festgestellt (Shimamoto et al. 1989). Allerdings konnte bei Untersuchungen an Patienten mit Leberzirrhose und hypothyreoter Stoffwechsellage bei erhöhtem TSH eine signifikante Erhöhung des Albuminspiegels im Serum festgestellt werden (Oren et al. 2000).

\section{Gamma- Glutamyltransferase (GGT):}

Auch bezüglich der GGT besteht eine Korrelation zwischen Schilddrüsenhormonen und der Aktivität der Gamma-GT. Die Gamma-GT ist ein heterodimeres Protein, welches zu einer Gruppe von Peptidasen gehört, die den Transfer von Aminosäuren von einem Peptid zu einem anderen durchführt. Gamma-GT spaltet im sog. Gammaglutamat-Zyklus Glutathion in seine Komponenten. Die Gamma-GT ist auf der Zytoplasmamembrane vieler Körperzellen lokalisiert und spielt dort eine Rolle bei der Sezernierung von Glutathion in den ExtrazellulärRaum (Liebermann et al. 1995, Thomas 2000 a).

Die Gamma-GT ist zum größten Teil an Lipoproteine gebunden und entstammt hauptsächlich der Leber. Dort kann die Synthese durch Cholestase, chronischen Alkoholgenuss oder Pharmaka (z.B. Phenytoin) induziert werden. Die Ausscheidung erfolgt vorwiegend über die Galle, ein kleiner Teil über die Nieren.

$\mathrm{Zu}$ einer Gamma-GT-Erhöhung im Serum kann es neben vermehrter Neusynthese durch Medikamente oder Alkohol auch bei Zellmembranschädigung kommen (toxische Substanzen, Ischämie oder Infektion der Hepatozyten, cholestatische Prozesse mit Übertritt von Galle in das Blut) (Thomas 2000 a). Somit ist die Gamma-GT ein leber- und gallengangspezifisches Enzym. Es wurde die Schilddrüsenhormonabhängigkeit der Leber - Gamma-GT von Sulakhe et al. 1990 an Ratten nachgewiesen (Sulakhe et al.1990).

Aber auch Studien von Azizi (1982) oder Couzigou et al. (1984) zeigten, dass die SerumGamma-GT-Aktivität bei Patienten mit Hyperthyreose oft erhöht war, während sie bei Patienten mit Hypothyreose erniedrigt war. Eine Korrelation mit TSH konnte nachgewiesen werden (Azizi 1982, Couzigou et al.1984).

\section{Sexualhormon-bindendes Globulin (SHBG):}

Ein weiterer durch Schilddrüsenhormone beeinflussbarer und in die Studie aufgenommener Parameter ist das SHBG. SHBG ist ein Glykoprotein, welches in der Leber synthetisiert wird. Es stellt das wichtigste Transportprotein für Testosteron dar und bindet alle 17- betahydroxylierenden Steroide (einschließlich der Östrogene) (Klinikleitfaden Labordiagnostik 2000).

$\mathrm{Zu}$ Testosteron und 5- Alphadihydroxytestosteron besteht eine hohe Affinität, zu Östradiol eine etwas geringere Affinität (Immulite SHBG Gebrauchsinformation 1999, Bond und Davis 1987, Lindstedt et al. 1985). Es hat eine einzelne steroidhormonbindende Seite, ein 
Molekulargewicht von rund 80000 bis 100000 Dalton und besteht aus zwei Untereinheiten, ungefähr in gleicher Größe. SHBG kommt typischerweise aufgrund des Verhältnisses von Östrogen zu Androgenen bei Frauen in höherer Konzentration als bei Männern vor. Aus demselben Grund sind SHBG-Spiegel in der Spätschwangerschaft oder nach Östrogen-Gaben besonders erhöht. Verabreichungen von Androgenen tendieren dazu mit erniedrigten SHBGSpiegeln assoziiert zu sein.

Testosterone zirkulieren hauptsächlich proteingebunden, in erster Linie an SHBG, aber auch an Albumin und cortisolbindendes Globulin (Immulite SHBG Gebrauchsinformation 1999).

Erniedrigte SHBG-Spiegel werden oft gefunden bei Hirsutismus, Akne vulgaris, polyzystischem Ovarialsyndrom, Hypothyreose, Akromegalie, Morbus Cushing und Hyperprolaktinämie (Bond und Davis 1987, Lindstedt et al.1985). SHBG tendiert ebenfalls zur Erniedrigung bei Adipositas und nach der Gabe von Androgenen (Immulite SHBG Gebrauchsinformation 1999, Bond und Davis 1987, Cunningham et al. 1985, Lapidius et al. 1986, Lindstedt et al. 1985, Pearce 1988).

Glukokortikoide und Wachstumhormone sind ebenso mit erniedrigten SHBG-Spiegeln assoziert (Lindstedt et al. 1985, Immulite SHBG Gebrauchsinformation 1999). Erhöhte SHBG-Spiegel kann man bei Hyperthyreose und Leberzirrhose antreffen (Immulite SHBG Gebrauchsinformation 1999, Bond und Davis 1987, Cunningham et al. 1985). Hohe Spiegel sind außerdem bei Schwangerschaft, nach Gabe von Östrogenen (z.B. bestimmte Sorten oraler Kontrazeptiva) oder als Konsequenz der Leberenzyminduktion bei Substanzen wie Phenytoin zu finden (Immulite SHBG Gebrauchsinformation 1999, Bond und Davis 1987, Cullberg et al. 1982, Lindstedt et al. 1985, Pearce 1988).

Zwischen TSH, fT4, fT3 und SHBG besteht folgende Korrelation: Bei steigendem TSH sinkt der SHBG-Spiegel, bei steigendem fT4 und fT3 steigt auch die SHBG-Konzentration. Daraus lässt sich schließen, dass bei Hyperthyreose erhöhte und bei Hypothyreose erniedrigte SHBGSpiegel resultieren (Loviselli et al. 1997, Newnham et al. 1988).

Insgesamt ist jedoch festzustellen, dass SHBG ein sehr unspezifischer Parameter ist, da wie oben dargestellt eine Vielzahl von Faktoren die SHBG-Werte beeinflussen.

\section{Eisenstoffwechel:}

Ferritin wurde als Parameter des Eisenstoffwechsels in die Studie aufgenommen. Ferritin ist ein ubiquitäres Protein mit einem Molekulargewicht von 450 Kilodalton. Die insgesamt 24 Protein-Untereinheiten bilden eine hohle Kugel. Im Inneren werden Eisenatome in Form von Eisenoxyhydrophosphat gespeichert. Der eisenfreie Zustand der Kugel wird als Apoferritin bezeichnet. Ferritin bildet zusammen mit Haemosiderin (entspricht Kondensat aus 
Ferritinmolekülen) die spezifische Eisenreserve des Organismus. Je größer die Eisenspeicherung des Organismus, desto höher ist die Plasmaferritinkonzentration.

Die Funktion besteht in der Speicherung von Eisen und dem Schutz der Zellen gegen toxische Effekte ionisierten Eisens durch Proteinumhüllung. Das Serumferritin wird von der Leber aufgenommen. Die Plasmahalbwertszeit beträgt 4 bis 40 Minuten. Die Serumferritinkonzentration umfasst bei Erwachsenen 20 bis 500 Mikrogramm pro Liter, wobei bei Männern in jüngerem Alter (< 50 Jahre $)$ durchschnittlich höhere Ferritinkonzentrationen als bei gleichaltrigen Frauen auftreten. Dies gleicht sich jedoch nach der Menopause aus (Kaltwasser 2000). Bei Kindern sind die Ferritinkonzentrationen geringer als bei Erwachsenen. Ein Serumferritinspiegel von kleiner als 15 Mikrogramm pro Liter ist diagnostisch der sicherste Beweis für einen Eisenmangel. Dies kann bedingt sein durch: Eisenverlust (Blutungen unterschiedlicher Genese), Transferrinmangel, Nephrotisches Syndrom, exsudative Enteropathie, Eisenresorptionsstörungen (zum Beispiel Sprue), alimentären Eisenmangel (z.B. Fehlernährung) oder erhöhten Bedarf z.B. in Schwangerschaft und Wachstumsphase.

Erhöhte Werte kommen vor bei: Eisenüberladung (z.B. bei Hämochromatose), Eisenverteilungsstörungen (bei Infektionen, chronischen Entzündungen, Tumoren) oder Hämolyse, bzw. Hämoglobin-Synthesestörungen bei hämolytischen oder sideroplastischen Anämien (Vitamin B 12, Folsäuremangel), Porphyrie oder Blei-Intoxikation. (Klinikleitfaden Labordiagnostik 2000). Bei Hyperthyreose kommt es zu einer Zunahme des Ferritinspiegels (Seymen et al. 1999, Takamatsu et al. 1985).

\subsubsection{KNOCHEN UND BINDEGEWEBE}

\section{KNOCHENABBAU}

Bei Hyperthyreose überwiegt insgesamt der Knochenabbau. Beim Abbau von Knochensubstanz durch die Osteoklasten kommt es zur Freisetzung von spezifischen Abbauprodukten in den Urin oder den Blutkreislauf. $\mathrm{Zu}$ den Abbauparametern der Knochenmatrix im Urin oder Serum gehören die Pyridinoline, die Telopeptide und das Hydroxyprolin. Als Parameter des Knochenabbaus wurde in der Studie ICTP untersucht. Diese als Telopeptide bezeichneten terminalen Kollagenabschnitte gelten als sehr gute Parameter zur Feststellung einer erhöhten Knochenresorption, da sie nicht weiter metabolisiert werden (Eriksen et al. 1995).

Man unterscheidet den amino- (= N) und carboxy- (= C) terminalen Kollagenabschnitt und demzufolge das carboxyterminale Typ-I-Kollagen-Telopeptid (= ICTP) und das 
aminoterminale Typ-I-Kollagen-Telopeptid (= I NTP) (Klinikleitfaden Labordiagnostik 2000).

ICTP kommt in durch Pyridinolin-Kreuzverbindungen vernetzter Struktur oder frei während des Abbaus von Typ-I-Kollagen vor. Deshalb korrelieren die Serumspiegel mit Prozessen, welche mit vermehrter Knochenresorption einhergehen. Daher kommt es zu einer Steigerung der Serumkonzentration von ICTP bei gesteigertem Knochenabbau, wie z.B. bei multiplem Myelom (Elomaa et al. 1992), osteolytischen Metastasen (Kylmälä et al. 1993), rheumatoider Arthritis ( Hakala et al. 1993) oder Immobilisation (Telopeptide ICTP, Kit instructions 1995). Bezüglich der Schilddrüsenfunktion verhält sich der Serum ICTP-Spiegel proportional zu fT3 und fT4 und negativ proportional zu TSH (Conti et al. 1994, Loviselli et al. 1997). Dies bedeutet, dass bei Hypothyreose ein Absinken des ICTP-Spiegels zu erwarten wäre.

\section{KNOCHENAUFBAU}

Auch der Knochenaufbau wird durch Schilddrüsenhormone beeinflusst. Die Bildung von Knochensubstanz wird durch die Tätigkeit von Osteoblasten vorgenommen. Die neu gebildete Knochenmatrix wird als Osteoidmatrix bezeichnet und besteht zu 90\% aus Kollagen. Je nach Reifungsprozess werden drei wichtige Parameter in den Blutkreislauf freigesetzt: Typ-IProkollagen-Propeptide (PINP, CICP) Knochenspezifische alkalische Phosphatase und Osteocalcin (Eriksen et al. 1995). 97\% des Kollagens bestehen aus Typ-I-Kollagen. Es wird zunächst als Typ-I-Prokollagen synthetisiert, von welchem die beiden terminalen Propeptide durch spezifische Endopeptidasen abgespalten werden. Diese terminalen Propeptide sind das N(amino)- terminale Propeptid (PINP) und das C (carboxy)- terminale Propeptid (PICP oder CICP). Bei Typ-I-Kollagen bilden zwei Alpha -1-Ketten und eine Alpha-2-Kette eine Tripelhelix (Rossert und de Crombrugghe 2002) (Abb. 3).

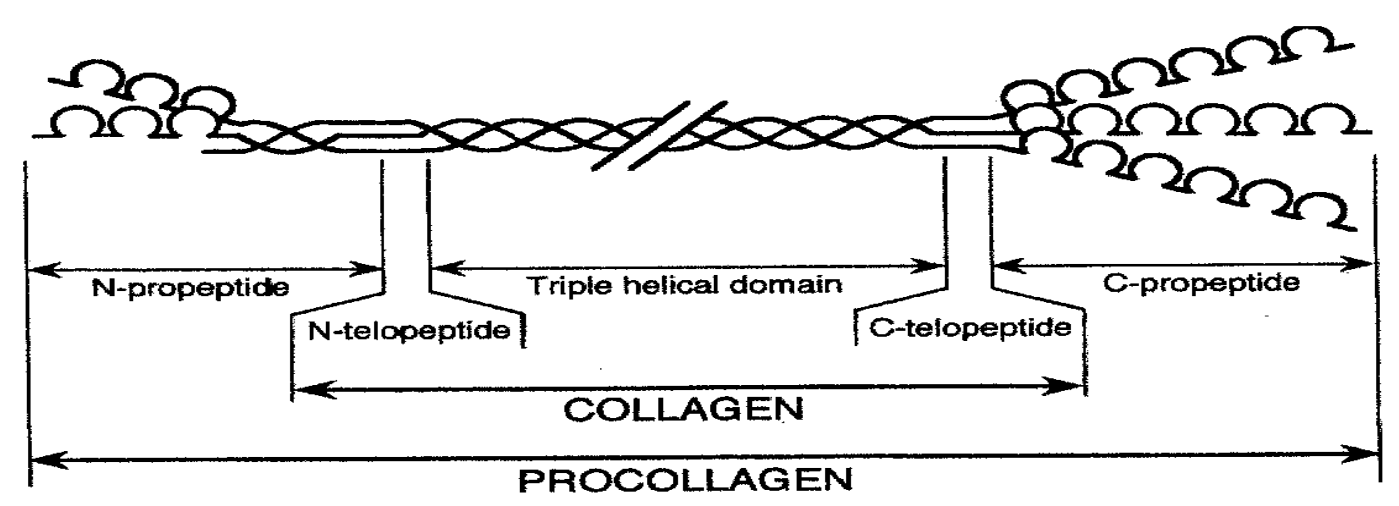

Abb. 3: Schematische Darstellung des Typ-I-Kollagenmoleküls (nach Rossert und de Crombrugghe 2002 S. 190) 
Das C-terminale Propeptid ist ein Glykoprotein, welches nach der Abspaltung als Molekül frei im Blut zirkuliert. Die Freisetzung dieses Peptids in den Blutkreislauf liefert Rückschlüsse auf die Produktion von Kollagen und damit über den Knochenaufbau (Kaspar et al. 2000, Eriksen et al. 1995, Melkko et al. 1990, Parfitt et al. 1987).

Erhöhte Werte von CICP entstehen bei Knochenaufbau, wie er auch bei Osteoporose mit pathologisch gesteigertem Knochenmetabolismus vorkommt (Risteli et al. 1991). Weitere Krankheiten mit erhöhtem CICP sind der Morbus Paget (Simon et al. 1984), Szirrhöses Magen-Ca. (Kohda et al. 1991, Ogawa et al. 1994); metastasierendes Prostata-Ca. (Rudnicki et al. 1995, Imai et al. 1998, Yoshida et al. 1997); metastasierendes Mamma-Ca. mit Knochenmetastasen (Blomqvist et al. 1996); Kolorektales Karzinom (im fortgeschrittenen Stadium mehr als im Frühstadium und abhängig vom Schweregrad) (Eroglu et al. 2000). Außerdem wurden erhöhte Werte bei Wundheilung festgestellt (Haukipuro et al. 1991).

Bezüglich der Schilddrüsenfunktion wurden erhöhte Werte von CICP bei Hyperthyreose gemessen. Dies spiegelt eine vermehrte Knochenbildung wider. Diese Stimulanz kann jedoch den Netto-Knochenabbau bei Hyperthyreose nicht ausgleichen (Takacs et al. 1996).

Osteocalcin ist ein kalziumbindendes und damit knochenaufbauendes Protein der extrazellulären Knochenmatrix. Es stellt ein nicht-kollagenes Knochenprotein dar. Es wird von Osteoblasten und Odontoblasten gebildet. Sowohl eine Erhöhung als auch eine Verminderung des Osteocalcins im Serum sind pathologisch. Osteocalcin ist knochenspezifisch. Eine Erhöhung beruht meist auf einem vermehrten Knochenaufbau. Der human-type besteht aus 49 Aminosäureresten mit einem Molekulargewicht von 5800 Dalton. Osteocalcin macht den größten Anteil der Nicht-Kollagen-Proteine der organischen Knochenmatrix aus. Über $80 \%$ des Osteocalcins werden nach Freisetzung aus den Osteoblasten in die Knochenmatrix eingebaut (Stracke 2000).

Osteocalcin besitzt bis zu 3 Gammacarboxyglutaminsäurereste, welche Vitamin K-abhängig durch Carboxylierung gebildet werden, und befähigen das Protein, Kalzium und Hydroxylapatit zu binden (IMMULITE Osteocalcin - Gebrauchsinformation 1999, Poser et al. 1980, Price et al. 1981). Die Bildung wird beeinflusst von kalziumregulierenden Hormonen wie Calcitonin, Parathormon oder Vitamin D (Civitelli et al. 1988, Zerwekh et al. 1985). Es besteht ein circadianer Rhythmus des Osteocalcin mit hohen Werten in den frühen Morgenstunden. Ein Maximalwert wird zwischen Mitternacht und 4 Uhr morgens erreicht (Stracke 2000, Gundberg et al. 1985).

Die Osteocalcinkonzentration steigt im Alter an, wobei Frauen höhere Konzentrationen als Männer aufweisen. Außerdem kommt Osteocalcin auch in extraossären 
Verkalkungsformationen in der frühen Mineralisationsphase und in atherosklerotischen Plaques vor (Stracke 2000). Erhöhte Osteocalcinspiegel findet man bei folgenden Erkrankungen: Osteomalazie (Demiaux et al. 1992); Morbus Paget (Merle und Delmas 1990); primärer Hyperparathyreoidismus, renale Osteodystrophie (Charhon et al. 1986) und postmenopausaler Osteoporose (Griesmacher et al. 1997). Erniedrigte Osteocalcinspiegel kommen bei Hypoparathyreoidismus (Duda et al. 1988, Kruse et al. 1989) sowie bei Langzeitsteroidtherapie (Ekenstam et al. 1986) vor.

Bezüglich der Schilddrüse wurden erhöhte Werte bei Hyperthyreose gemessen (Lukert et al. 1986, Garnero et al. 1994).

Neben Osteocalcin und CICP sind die alkalische Phosphatase bzw. die alkalische Knochenphosphatase weitere Indikatoren für einen erhöhten Knochenumsatz, insbesondere den Knochenaufbau. Phosphatasen sind zur Gruppe der Hydrolasen gehörende Enzyme. Man unterscheidet saure und alkalische Phosphatasen. Von der alkalischen Phosphatase mit einem pH-Optimum bei pH 7 bis 8 existieren mehrere Isoenzyme im Serum (Vorkommen in Leber, Knochen, Dünndarmschleimhaut und Gallenwegsepithel). Die alkalische Knochenphosphatase ist erhöht bei Knochenerkrankungen, wie z.B. Knochenmetastasen mit gesteigerter Aktivität der Osteoblasten.

Bezüglich einer Korrelation zur Schilddrüsenfunktion wurden bereits Untersuchungen durchgeführt. Hier zeigte sich bei verändertem Knochenmetabolismus bei Patienten mit Hyperthyreose eine nur passagere Erhöhung der alkalischen Phosphatase (Garnero et al. 1994, Sabuncu et al. 2001) und Knochenphosphatase (Akalin et al. 2002). Oren et al. erbrachte den Nachweis einer sinkenden AP bei hypothyreoter Stoffwechsellage (Oren et al. 2000).

\section{BINDEGEWEBE}

Da sich Schilddrüsenhormone auch auf die Bildung von Bindegewebe auswirken, wurde Prokollagen-III (PIIINP) in die Studie aufgenommen. Typ-III-Kollagen ist ein wichtiger Bestandteil von Bindegewebe, es wird von Fibroblasten in straffem Bindegewebe, wie der Haut, der Lunge oder des Gefäßsystems produziert. Typ-III-Kollagen kommt nicht in Knochen, Sehnen oder Knorpel vor. Typ-III-Kollagen wird zunächst als ein Prokollagen synthetisiert, welches Propeptide -Verlängerungen an beiden Enden des Moleküls besitzt (Fessler JH und Fessler LI 1978). Bei der Synthese von Typ-III-Kollagen, aber auch beim Abbau bereits existierender Kollagenfasern werden aminoterminale Propeptide freigesetzt.

Der Metabolismus von PIIINP ist im Einzelnen nicht bekannt. Kleinere Abbauprodukte finden sich im Serum und im Urin (Rhode et al. 1983). Die Referenzwerte für PIIINP im Serum betragen für Erwachsene 1,7 bis $4,2 \mu \mathrm{g} / \mathrm{l}$ (Orion Diagnostica: PIIINP Radioimmunoassay Kit instructions 1999). Hierbei gibt es allerdings geringfügige 
Geschlechtsunterschiede. Außerdem scheint PIIINP altersabhängig zu sein. Bei Kindern ist die Konzentration von PIIINP höher (Orion Diagnostica: PIIINP Radioimmunoassay Kit instructions 1999).

Erhöhte Konzentrationen von PIIINP finden sich dort, wo es Anhäufungen oder Degenerationen von Bindegewebe gibt, z.B. bei fibroproliferativen, hämatologischen, endokrinologischen und malignen Erkrankungen. Folglich sind Schwankungen von PIIINPSpiegeln nicht spezifisch für eine einzelne Krankheit, sondern sie reflektieren die Beteiligung bzw. einen veränderten Metabolismus von Typ-III-Kollagen (Orion Diagnostica: PIIINP Radioimmunoassay Kit instructions 1999). Leberfibrose und -zirrhose verschiedener Ätiologien erhöhen die Serumkonzentration von PIIINP. Das Ausmaß der Veränderungen in der Konzentration scheint bei einer Entzündung größer zu sein als bei einer nur stillen Ansammlung von Bindegewebe. So kommt es bei fibrotischen Prozessen der Lunge, wie bei idiopathischer Lungenfibrose oder Lungensarkoidose, mitunter nur zu geringen Erhöhungen oder keinen Erhöhungen von PIII NP-Spiegeln, wohingegen höhere Konzentrationen bei einer broncheoalveolären Lavage gefunden werden können (Orion Diagnostica: PIIINP Radioimmunoassay Kit instructions 1999, Rojkind 1984, Eriksson und Zettervall 1986, Colombo et al. 1985, Ristelli et al. 1988 a, Low et al. 1983).

Weiterhin ist PIII NP erhöht bei myeloproliferativen Erkrankungen insbesondere während der aktiven Phase der Myelofibrose. Bei der Polycythaemia vera kann ein hoher Wert die Umwandlung in eine myeloische Metaplasie voraussagen (Orion Diagnostica: PIIINP Radioimmunoassay Kit instructions 1999, Hochweiss et al.1983, Arrago et al. 1986).

Auch bei verschiedenen malignen Erkrankungen, z.B. bei Krebsbeteiligung der Leber oder Ovarial-Ca., sind erhöhte PIIINP-Werte nachgewiesen (Orion Diagnostica: PIIINP Radioimmunoassay Kit instructions 1999, Bolarin et al.1982, Blomqvist et al. 1987, Risteli et al. 1988 b, Kauppila et al. 1989).

Bezüglich der Schilddrüse liefert die Literatur keine eindeutigen Aussagen. In einigen Studien ist PIIINP ein Indikator für die peripheren Effekte der Schilddrüsenhormone mit erniedrigten Werten bei Hypothyreose und erhöhten Werten bei Hyperthyreose (Charrie et al. 1986, Kucharz et al. 1994, Nyström et al. 1988, Földes et al. 1992). Eine Korrelation zwischen Serum - PIIINP und T4 oder TSH konnte von Zulewski et al. nicht bestätigt werden (Zulewski et al. 1999). 


\subsubsection{MUSKEL UND HERZ}

Der Einfluss von Schilddrüsenhormonen auf den Muskelstoffwechsel wurde in Untersuchungen u.a. von Beyer et al. und Burnett et al. an Patienten mit manifester und latenter Hypothyreose vorgenommen. Sie kamen zu dem Ergebnis, dass eine CK-Erhöhung mit einer hypothyreoten Stoffwechsellage einhergeht (Beyer et al. 1998, Burnett et al. 1994). Es bestand eine positive Korrelation zwischen CK und TSH sowie eine umgekehrte Proportionalität zwischen CK und fT4.

Kreatinkinase ist ein intrazelluläres Enzym, bestehend aus 2 Untereinheiten, der CK-M und der CK-B. Es gibt 3 Isoenzyme: CK-BB, CK-MB, CK-MM. CK-MB ist im Myokard enthalten, aber auch in der Skelettmuskulatur. Der CK-MB/CK-Index zeigt erhöhte Spezifität für Herzmuskelschädigung. In hoher Aktivität kommt die CK in der Skelettmuskulatur, im Herzmuskel und im Gehirn vor. Außerdem ist geringere Aktivität in Lunge, Uterus, Urogenitalsystem und Gastrointestinaltrakt zu verzeichnen.

Da die CK-MB im Myokard ihre höchste Konzentration erreicht, ist sie als spezifischer Marker in die Untersuchungen mit aufgenommen worden. Erhöhte Werte kommen vor bei Herzinfarkt, aber auch bei anderen Herzmuskelerkrankungen, wie Myokarditis, Endokarditis, Perikarditis. Der Aktivitätsanstieg der Gesamt-CK bei Herzinfarkt beginnt frühestens nach 4 Stunden und erreicht sein Maximum nach ca. 20 Stunden. Auch bei Skelettmuskelerkrankungen, z.B. progressiver Muskeldystrophie (Typ Duchenne), Myositis, auch bei Traumen, intramuskulären Injektionen oder operativen Eingriffen kommt es zu einer Erhöhung der Gesamt-CK (Puschendorf und Mair 2000, Stein 2000, Klinikleitfaden Labordiagnostik 2000). 


\subsubsection{ABHÄNGIGKEIT DER GEMESSENEN PARAMETER VON DER}

\section{SCHILDDRÜSENFUNKTION (ZUSAMMENFASSUNG)}

\begin{tabular}{|c|c|c|}
\hline Untersuchte Parameter & Hyperthyreose & Hypothyreose \\
\hline \multicolumn{3}{|l|}{ Leber und Lipide } \\
\hline Ferritin & $\uparrow$ & $\downarrow$ \\
\hline SHBG & $\uparrow$ & $\downarrow$ \\
\hline GGT & $\uparrow$ & $\downarrow$ \\
\hline Cholesterin & $\downarrow$ & $\uparrow$ \\
\hline Albumin & $\uparrow$ & $\downarrow$ \\
\hline \multicolumn{3}{|c|}{ Knochen und Bindegewebe } \\
\hline \multicolumn{3}{|l|}{ - $\quad$ Knochenaufbau } \\
\hline$\overline{\mathrm{CICP}}$ & $\uparrow$ & $\downarrow$ \\
\hline Osteocalcin & $\uparrow$ & $\downarrow$ \\
\hline Alk.Phosphatase & $\uparrow$ & $\downarrow$ \\
\hline Bone AP & $\uparrow$ & \\
\hline \multicolumn{3}{|l|}{ - Knochenabbau } \\
\hline ICTP & $\uparrow$ & $\downarrow$ \\
\hline \multicolumn{3}{|l|}{ - $\quad$ Bindegewebe } \\
\hline PIIINP & $\uparrow$ & $\downarrow$ \\
\hline \multicolumn{3}{|l|}{ Muskel und Herz } \\
\hline $\mathrm{CK}$ & $\downarrow$ & $\uparrow$ \\
\hline CK-MB & $\downarrow$ & $\uparrow$ \\
\hline
\end{tabular}

$\uparrow \quad$ bedeutet Anstieg

$\downarrow \quad$ bedeutet Abfall

Tab.1 Verhalten der untersuchten Parameter bei Schilddrüsenunter- bzw. überfunktion 


\section{MATERIAL UND METHODEN}

\subsection{Patientenauswahl und Probenentnahme}

Es wurden 22 ambulante Patienten in die Studie aufgenommen, welche mindestens seit 3 Monaten mit Amiodaron behandelt wurden. Die Dosis lag dabei in einer üblichen Dosierung mit $200 \mathrm{mg}$ pro Tag. Alle Patienten wurden mit einem AICD (automatic implantable cardioverter defibrillator) therapiert. Als Vergleichsgruppe dienten ebenfalls 22 ambulante Patienten aus der AICD-Sprechstunde, die jedoch kein Amiodaron in der Medikation hatten. Die Teilnahme der Patienten an der Studie erfolgte nach ausführlicher Aufklärung und Einverständniserklärung der Patienten auch unter dem Hinweis, dass keine Nachteile in der weiteren Behandlung bei Ablehnung der Teilnahme entstehen. Ein genehmigter Antrag bei der Ethik- Kommission der Medizinischen Fakultät der Universität Göttingen zum Ausschluss rechtlicher und ethischer Bedenken gegen die Durchführung der Studie liegt vor. Das Durchschnittsalter lag bei 67 Jahren, wobei der jüngste Teilnehmer 33 Jahre und der älteste 81 Jahre alt waren. Aus beiden Patientengruppen wurden Paare gebildet, wobei sich die Partner jeweils in Alter, Gewicht, Größe und Diagnosen ähnlich waren. Insbesondere wurde Wert gelegt auf den Body-mass-Index und auf gleichartige Herzrhythmusstörungen bei gleichartiger Grunderkrankung. So hatten 16 Patientenpaare als Grunderkrankung für die rezidivierenden, ventrikulären Tachykardien eine KHK und 6 Patientenpaare eine dilatative Kardiomyopathie. Um geschlechtsspezifische Unterschiede auszuschließen, wurden nur Männer in die Studie eingeschlossen.

Als Ausschlusskriterien galten: Schilddrüsenfunktionsstörungen mit manifester Hyper- oder Hypothyreose bzw. die Einnahme von Thyreostatika oder Schilddrüsenhormonen. Weiterhin wurden schwere Zweiterkrankungen als Ausschlusskriterium gewertet. Hierunter wurden Tumorerkrankungen, akute oder chronische Niereninsuffizienz, Leberfunktionstörungen (Leberzirrhose, Hepatitis, Cholangitis) und ausgeprägte Lipidstoffwechselstörungen sowie Anämie, Skelettmuskelerkrankungen, Elektrolytentgleisungen und Osteoporose gerechnet. Auch die Einnahme von Medikamenten, welche in den Knochenstoffwechsel eingreifen, wie Bisphosphonate, war für die Teilnahme an der Studie nicht zugelassen.

In Tabelle 2 sind Referenzbereiche, deren Abweichung zum Ausschluss aus der Studie führte, zuammenfassend dargestellt. 
Tabelle 2 : Labordiagnostische Referenzbereiche zum Ausschluss schwerer Begleiterkrankungen

\begin{tabular}{|l|l|l|}
\hline $\begin{array}{l}\text { Mögliche } \\
\text { Zweiterkrankung }\end{array}$ & Laborparameter & $\begin{array}{l}\text { Referenzbereich zum } \\
\text { Studienausschluss }\end{array}$ \\
\hline Nierenerkrankung & Kreatinin im Serum & $>2 \mathrm{mg} / \mathrm{dl}$ \\
\hline Leberfunktionsstörung & Albumin & $<3,5 \mathrm{~g} / \mathrm{dl}$ \\
\hline & Cholesterin & $>300 \mathrm{mg} / \mathrm{dl}$ \\
\hline & ALT & $>30 \mathrm{U} / \mathrm{l}$ \\
\hline & AST & $>30 \mathrm{U} / \mathrm{l}$ \\
\hline & GGT & $>40 \mathrm{U} / \mathrm{l}$ \\
\hline & AP & $>200 \mathrm{U} / 1$ \\
\hline Anämie & $\begin{array}{l}\text { Bilirubin } \\
\text { ges. }\end{array}$ & $>1,2 \mathrm{mg} / \mathrm{dl}$ \\
\hline Schilddrüsenfunktionsstörung & Hämoglobin & $<11 \mathrm{~g} / \mathrm{dl}$ \\
\hline & TSH & $<0,1 \mu \mathrm{U} / \mathrm{ml} *$ \\
& & $>3,3 \mu \mathrm{U} / \mathrm{ml}$ \\
\hline
\end{tabular}

* 1 Patient aus der Amiodarongruppe mit TSH 0,07 $\mu \mathrm{U} / \mathrm{ml}$ bei peripher euthyreoter Stoffwechsellage,

Es wurden von allen Patienten einmalig venöse Blutproben entnommen und auf verschiedene Parameter untersucht. Zunächst wurde eine Routinediagnostik durchgeführt mit aktuellem Status des Schilddrüsenstoffwechsels (TSH, T3, fT4 bzw. fT4-Index, AP, GGT, Albumin, Elektrolyte, Transaminasen). Weitere Proben zur Bestimmung von SHBG, CICP, PIIINP, Osteocalcin, ICTP, Cholesterin, CK, CK-MB, bone-AP und Ferritin wurden nach Zentrifugation bei $-20^{\circ} \mathrm{C}$ zunächst tiefgefroren. 


\subsection{Probenbestimmung}

\subsubsection{QUANTITATIVE BESTIMMUNG VON SHBG}

SHBG wurde durch einen Radioimmunoassay bestimmt. Im Prinzip handelt es sich dabei um eine Antigen-Antikörper-Komplexbildung, bei welcher radioaktiv markierte Antigene mit den nicht markierten Antigenen des Probantenserums um die Komplexbildung mit den Antikörpern konkurieren. Die durch die kompetitive Verdrängung durch die nicht markierten Antigene in die Lösung frei werdende Radioaktivität wird quantitativ bestimmt und ist der Menge des zugesetzten Proteins, in diesem Fall des SHBG, proportional (Buddecke 1984). Das Labor-Kit war ein Produkt der Firma Zen Tech.

Referenzwert für Männer: 13-71 nmol/1

Sensitivität: $0,2 \mathrm{nmol} / \mathrm{l}$

\subsubsection{QUANTITATIVE BESTIMMUNG VON OSTEOCALCIN}

Hier wurde das Chemilumineszenz-Assay angewendet. Es entspricht im Prinzip dem kompetitiven Radioimmunoassay. Es wird jedoch keine radioaktive Markierung eingesetzt, sondern ein chemilumineszierendes Enzymsubstrat.

Die Messungen wurden mit Hilfe des automatischen Random Access Immunoassay Analyzer IMMULITE der Firma DPC Biermann, Bad Nauheim, durchgeführt. Als Festphase werden mit monoklonalen Anti-Osteocalcin-Maus-Antikörpern beschichtete Kunststoffkugeln verwendet. Die Probe und das mit alkalischer Phosphatase enzymmarkierte Reagenz werden inkubiert. Nach einem Waschvorgang mit Wasser und Trennung der Rückstände mit noch evtl. vorhandenen ungebundenen Markern werden die Kunststoffkugeln mit den markierten Antikörper-Antigen-Komplexen mit einem lumineszierenden Dioxetansubstrat in Verbindung gebracht. Das nun emittierte Licht wird mit einem Luminometer gemessen. Das emittierte Licht ist direkt proportional zur Menge der gebundenen alkalischen Phosphatase (Immulite Osteocalcin 1999).

Referenzwert: 3,1-13,7 ng/ml

Sensitivität: $0,1 \mathrm{ng} / \mathrm{ml}$

\subsubsection{QUANTITATIVE BESTIMMUNG VON I CTP (TELOPEPTID)}

Zur quantitativen Bestimmung des ICTP (Telopeptid) wurde ein Labor-Kit der Firma Orion Diagnostika verwendet. Es handelt sich um ein Radioimmunoassay wie oben beschrieben. 
Zur Markierung der Antigene wurde ebenfalls J 125 verwendet (Telopeptide ICTP, Kit Instructions 1995).

Referenzwert: $1,8-5,0 \mu \mathrm{g} / 1$

Sensitivität: $0,5 \mu \mathrm{g} / 1$

\subsubsection{Quantitative Bestimmung Von CICP (C-Terminal PRopeptide of TYPE I-COLLAGEN)}

Hierbei wurde ein Prolagen-C-Assay der Firma Metra Biosystems angewendet. Dabei handelt es sich um einen Sandwich-Enzym-Immunoassay. Das Prinzip funktioniert folgendermaßen: Es werden monoklonale Maus CICP-Antikörper auf einer Mikrotiterplatte aufgetragen. Danach wird die Probe hinzugegeben. Die in der Probe befindlichen CICP-Antigene bilden mit den an der Platte befindlichen Antikörpern einen Antikörper-Antigen-Komplex. Um diese nun quantifizieren zu können, wird ein zweiter Antikörper, welcher zum Nachweis der Komplexe enzymgekoppelt ist, hinzugegeben. Als Enzym dient hier alkalische Phosphatase, welche mit einem Ziegenantikörper (hergestellt durch Immunisierung mit Kaninchenantikörpern) gekoppelt wurde. Die enzymgekoppelten Antikörper binden nun an einen anderen Epitop des Antigens und können nun durch eine Farbreagenz nachgewiesen werden.

Referenzwert für Männer: 76-163 ng/ml

Sensitivität: $0,2 \mathrm{ng} / \mathrm{ml}$

(Gebrauchsinformation: Prolagen C 1999)

\subsubsection{QUantitative Bestimmung Von Prokollagen III}

PIIINP wurde durch einen Radioimmunoassay-Kit der Firma Orion Diagnostica bestimmt.

Als radioaktives Isotop zur Markierung der Antigene wird J 125 verwendet (Orion Diagnostica: PIIINP Radioimmunoassay Kit instructions 1999).

Referenzwert für Männer: 1,7-4,2 $\mu \mathrm{g} / 1$

Sensitivität: $0,2 \mu \mathrm{g} / \mathrm{l}$

\subsubsection{QUANTITATIVE BESTIMMUNG DER SCHILDDRÜSENPARAMETER}

\section{TSH}

Das Testverfahren für TSH ist ein chemiluminometrischer (Sandwich-)Immunoassay. Es handelt sich um ein TSH-Assay von Ciba Corning ACS ${ }^{\mathrm{TM}}$. Die Referenzwerte liegen zwischen 0,45 und $3,20 \mu \mathrm{U} / \mathrm{ml}$.

Sensitivität: $0,011 \mu \mathrm{U} / \mathrm{ml}$ 
(Ciba Corning ACS ${ }^{\mathrm{TM}}$ TSH 1995)

\section{GESAMT T3}

Es wurde ein kompetitiver Immunoassay nach dem SPALT-Prinzip verwendet (Ciba Corning ACS $^{\text {TM }}$ T3 Assay). Es ist ebenfalls ein Chemilumineszenz-System. Die Referenzwerte liegen zwischen 89 und $185 \mathrm{ng} / \mathrm{dl}$.

Sensitivität: $0,2 \mathrm{ng} / \mathrm{ml}$

(Ciba Corning ACS ${ }^{\mathrm{TM}}$ T3 Gebrauchsinformation 1994)

\section{FT4}

Der Ciba Corning ACS ${ }^{\mathrm{TM}}$ FT4 Assay ist ebenfalls ein kompetitiver Immunoassay.

Die Referenzwerte liegen zwischen 0,77 und 1,53 ng/dl.

Sensitivität: $0,1 \mathrm{ng} / \mathrm{dl}$

(Ciba Corning ACS ${ }^{\text {TM }}$ FT4 Gebrauchsinformation 1994)

Die ersten Werte wurden mit Hilfe eines bis dahin üblichen FT4-Indexes berechnet. Hierbei handelt es sich um die Ermittlung eines Äquivalents für freies T4. Es errechnet sich aus Gesamt-T4 und dem Ergebnis einer T4-Uptake-Messung zur Bestimmung der freien Bindungskapazität von Thyroxin-Bindungsproteinen im Serum (Magic T3-Uptake J 125 Radioassay).

Diese Zahlenwerte sind in die Berechnung der Grafik Abb. 7 nicht mit eingegangen.

\subsubsection{QUANTITATIVE BESTIMMUNG VON FERRITIN}

Bei der Bestimmung des Ferritins im Serum wurde ein Elektrochemilumineszenz-Immunoassay „ECLIA“ der Firma Roche verwendet. Die Bestimmung wurde im Zentrallabor der Universität Göttingen durchgeführt. Es handelt sich bei einem ElektrochemilumineszenzImmunoassay um eine Chemilumineszenz durch elektrochemische Reaktion (Lee 1997). Es kommt zur Bildung eines Sandwich-Komplexes mit einem durch lumineszenzauslösenden Stoff (Ruthenium) markierten ferritinspezifischen Antikörper und einem nicht markierten ferritinspezifischen Antikörper. Nach Zugabe von Mikropartikeln als Festphase wird das Reaktionsgemisch in eine Messzelle überführt, wo die Mikropartikel durch magnetische Wirkung auf eine Elektrode fixiert werden. Durch Anlegen einer Spannung wird die Chemilumineszenz-Emission induziert und mit dem Photomultiplier gemessen (Roche Produktinformation Elcsys ${ }^{\circledR}$ Ferritin 2004).

Der Referenzbereich liegt bei Männern zwischen 30 und $400 \mu \mathrm{g} / \mathrm{l}$.

Sensitivität: $0,5 \mu \mathrm{g} / \mathrm{l}$ 


\subsubsection{Quantitative BeStimmung von CreatinkinaSe (GeSAMT-CK)}

Die Bestimmung wurde im Zentrallabor der Universität Göttingen durchgeführt. Es wurde ein kinetischer Test nach den Empfehlungen der Deutschen Gesellschaft für Klinische Chemie und der International Federation of Clinical Chemistry (IFCC) eingesetzt. Es handelt sich um eine standardisierte Methode mit Creatinphosphat und ADP, mit Rückreaktion und Aktivierung durch NAC. Die entstehende NADPH-Bildung ist der CK-Aktivität proportional und wird photometrisch gemessen (Roche/Hitachi Produktinformation Creatinkinase 2004, Thomas 2000).

\subsubsection{QUANTITATIVE BESTIMMUNG VON CK-MB}

Bei der ebenfalls im Zentrallabor der Universität Göttingen quantitativ bestimmten CK-MB wurde ein In-vitro-Immuninhibitionstest angewendet. Es handelt sich dabei um einen UVTest mit immunologischer Inhibierung von CK-M. Es wird die Restaktivität der CK nach Immuninhibition aller CK-M-Untereinheiten mit CK-M-Antikörpern gemessen (Roche Diagnostics GmbH Produktinformation CK-MB 2003, Thomas 2000).

Referenzwerte für Männer: CK < 190 U/1

$$
\mathrm{CK}-\mathrm{MB}<24 \mathrm{U} / 1
$$

Anteil der CK-MB Aktivität an der Aktivität der Gesamt-CK liegt zwischen 6 und 25\% Sensitivität: 3 U/1

\subsubsection{Quantitative Bestimmung Der alkalischen Phosphatase (AP)}

Die alkalische Phosphatase wurde im Zentrallabor der Universität Göttingen quantitativ bestimmt. Es diente dazu ein von der International Federation of Clinical Chemistry (IFCC) empfohlene und standardisierte Farb-Test-Methode. Das unter der Einwirkung von AP aus einer Reaktion von p- Nitrophenylphosphat freigesetzte p-Nitrophenol ist proportional der AP-Aktivität und wird photometrisch gemessen (Roche/Hitachi Diagnostics GmbH Produktinformation AP 2001).

Die Referenzwerte für Männer liegen zwischen 40 und 129 U/l.

Die Sensitivität beträgt $0,67 \mathrm{U} / \mathrm{l}$.

\subsubsection{Quantitative BeSTIMMUng DER AlKalischen SKELETT-PHOSPHATASE (BONE AP)}

Zur Bestimmung der Knochen-AP wurde ein immunoradiometrischer Festphasen-Assay im Zweischrittverfahren verwendet. Es handelt sich dabei um eine direkte nicht kompetitive 
Nachweismethode (Sandwichverfahren), bei der ein radioaktiv markierter Antikörper (J 125) mit dem Antigen-Antikörper-Komplex (Antigen der bone AP-Probe mit Antikörper der Festphase) eine Bindung eingeht. Nach Waschung, d.h. nach Entfernung der ungebundenen markierten Antikörper, wird die Radioaktivität der an der Festphase gebundenen Antikörper im Gammazähler gemessen. Die Menge der gemessenen Radioaktivität ist dem AlkalischenSkelett-Phosphatase-Spiegel direkt proportional (Tandem ${ }^{\circledR}-$ R Ostase ${ }^{\circledR}$ Produktinformation 2003).

Die Referenzwerte für Erwachsene: 2.3-20 $\mu \mathrm{g} / \mathrm{l}$

Sensitivität: $2 \mu \mathrm{g} / \mathrm{l}$

\subsubsection{QUANTITATIVE BESTIMMUNG DER GAMMA-GLUTAMYL-TRANSFERASE (GGT)}

Zur Bestimmung der GGT im Zentrallabor der Universität Göttingen wurde ein enzymatischer Farbtest verwendet. Die GGT überträgt den Gamma-Glutamylrest von LGamma-Glutamyl-3-Carboxy-4-Nitroanilid auf Glycylglycin. Dabei wird 5-Amino-2Nitrobenzoat freigesetzt und photometrisch gemessen. Es verhält sich proportional zur GGTAktivität (Roche/Hitachi Produktinformation GGT 2004).

Referenzwerte für Männer: 8-61 U/1

Sensitivität: 3 U/1

\subsubsection{QUANTITATIVE BESTIMMUNG VON Albumin}

Albumin wurde im Zentrallabor der Universität Göttingen mit Hilfe eines Farbtestes mit Bromcresolgrün bestimmt. Albumin geht mit dem Anionenfarbstoff Bromcresolgrün (BCG) unter Bildung eines blaugrünen Komplexes eine Bindung ein. Die Farbintensität ist direkt proportional zur Albuminkonzentration und wird photometrisch gemessen (Roche/Hitachi Produktinformation ALB plus 2004).

Referenzwerte bei Erwachsenen: 3,4- 4,8 g/dl

Sensitivität : $0,2 \mathrm{~g} / \mathrm{dl}$

\subsubsection{QUANTITATIVE BESTIMMUNG VON CHOLESTERIN}

Zum quantitativen Nachweis von Cholesterin wurde ein enzymatischer Farbtest (CHODPAP) verwendet. Die Bestimmung wurde im Zentrallabor der Universität Göttingen durchgeführt. 
Das Prinzip besteht in der enzymatischen Bestimmung von Cholesterin mit Cholesterinesterase und Cholesterinoxidase. Dabei entsteht Wasserstoffperoxid, welches mittels Peroxidase mit Phenol und Aminophenazon einen roten Farbstoff bildet. Dieser wird photometrisch gemessen und ist der Cholesterinkonzentration direkt proportional (Roche/Hitachi Produktinformation CHOL 2004).

Referenzwerte: Idealbereich < $200 \mathrm{mg} / \mathrm{dl}$

Grenzwertig hohes Cholesterin 200-240 mg/dl

Sensitivität: $3 \mathrm{mg} / \mathrm{dl}$

\subsection{Statistische AUSWERTUNG}

Die gemessenen Daten wurden in Microsoft-Excel-Tabellen gesammelt, bis die statistische Auswertung mit Hilfe des Statistikprogramms STATISTICA durchgeführt wurde. Es kam der verbundene T-Test zur Anwendung. Das Signifikanzniveau liegt bei $p<0,05$. Die statistische Beratung erfolgte durch die Abteilung Medizinische Statistik der Georg-August-Universität Göttingen. 


\section{ERGEBNISSE}

Die Untersuchungsergebnisse sind schematisch in Tabelle 5 und graphisch in den Abbildungen 4-21 in Form von Box-Plots dargestellt. In den Graphiken werden jeweils die Unterschiede zwischen der Patientengruppe mit Amiodarontherapie (jeweils linkes Box-Plot) und der Patientengruppe ohne Amiodaron (jeweils rechtes Box-Plot) zum Vergleich abgebildet. Die Gruppe der Amiodaron-therapierten Männer (N=22) war der Gruppe von männlichen Patienten ohne Amiodaron in Bezug auf Alter (Abb. 4), Body-mass-Index (Abb. 5), die kardiale Grunderkrankung (16 Patientenpaare mit KHK, 6 Patientenpaare mit DCM) sowie die Begleitmedikation (Tabelle 3 ) vergleichbar.

Insbesondere in Hinblick auf die Begleitmedikation aus Tabelle 3 waren bei geringfügigen Differenzen keine signifikanten Unterschiede $\mathrm{zu}$ verzeichnen. Hinsichtlich der Begleiterkrankungen (Tabelle 4) zeigte sich eine signifikant ungleiche Verteilung nur bei der Häufigkeit von Vorhofflimmern ( $\mathrm{p}=0,021$ in Fisher`s exact test). So wiesen Patienten mit Amiodaron in der Vorgeschichte häufiger ein Vorhofflimmern auf.

In beiden Gruppen war die Schilddrüsenfunktion laborchemisch euthyreot und zeigte ein vergleichbares basales TSH (Abb.6). Hinsichtlich des fT4 und des T3 fand sich dagegen ein signifikanter Unterschied. So war das fT4 unter Amiodaron-Therapie signifikant erhöht (Abb. 7) und das T3 signifikant erniedrigt (Abb. 8).

Die im Folgenden untersuchten Parameter betrafen den Stoffwechsel von Leber und Lipiden, Knochen und Bindegewebe sowie Muskulatur und Herz. Es handelt sich um insgesamt 13 Stoffwechselparameter, dargestellt in Tabelle 5 sowie in den Abbildungen 9-21. Von den hier untersuchten 13 Parametern zeigte nur das Typ-I-Kollagen-carboxyterminale- Propeptid (CICP) einen signifikanten Unterschied mit einem Signifikanzniveau von $p=0,0216$ (Abb.14). 
Tab. 3: Tabellarische Übersicht über die Verteilung von Begleitmedikation in beiden Probandengruppen

\begin{tabular}{|l|c|c|}
\hline & \multicolumn{2}{|c|}{ Probanden } \\
\hline Wirkstoffgruppe & $\begin{array}{c}\text { mit Amiodarontherapie } \\
(\mathbf{n = 2 2})\end{array}$ & $\begin{array}{c}\text { ohne Amiodarontherapie } \\
(\mathbf{n = 2 2})\end{array}$ \\
\hline Fettsenker & 3 & 7 \\
\hline ACE-Hemmer & 18 & 18 \\
\hline B-Blocker & 4 & 10 \\
\hline Digitalis & 13 & 3 \\
\hline Kalziumantagonist & 3 & 2 \\
\hline Orale Antidiabetika & 1 & 0 \\
\hline Prednisolon $(<10 \mathrm{mg})$ & 3 & 9 \\
\hline
\end{tabular}

Tab.4: Verteilung häufiger Begleiterkrankungen in beiden Probandengruppen

\begin{tabular}{|l|c|c|}
\hline Begleiterkrankung & \multicolumn{2}{|c|}{ Probanden } \\
\hline & $\begin{array}{c}\text { mit Amiodarontherapie } \\
(\mathbf{n = 2 2})\end{array}$ & $\begin{array}{c}\text { ohne Amiodarontherapie } \\
(\mathbf{n = 2 2})\end{array}$ \\
\hline Vorhofflimmern & 8 & 1 \\
\hline Diabetes mellitus Typ II & 1 & 2 \\
\hline COPD & 4 & 4 \\
\hline arterielle Hypertonie & 13 & 14 \\
\hline
\end{tabular}


Tab. 5 Schematische Darstellung der Untersuchungsergebnisse

\begin{tabular}{|c|c|c|c|}
\hline \multirow[b]{2}{*}{ Untersuchte Parameter } & \multicolumn{2}{|c|}{ Erwartete Veränderungen bei } & \multirow{2}{*}{$\begin{array}{l}\text { Gemessene } \\
\text { Veränderungen } \\
\text { unter Amiodarontherapie }\end{array}$} \\
\hline & Hyperthyreose & Hypothyreose & \\
\hline \multicolumn{4}{|l|}{ Leber und Lipide } \\
\hline Ferritin & $\uparrow$ & $\downarrow$ & $\leftrightarrow$ \\
\hline SHBG & $\uparrow$ & $\downarrow$ & $\leftrightarrow$ \\
\hline GGT & $\uparrow$ & $\downarrow$ & $\leftrightarrow$ \\
\hline Cholesterin & $\downarrow$ & $\uparrow$ & $\leftrightarrow$ \\
\hline Albumin & $\uparrow$ & $\downarrow$ & $\leftrightarrow$ \\
\hline \multicolumn{4}{|c|}{ Knochen und Bindegewebe } \\
\hline \multicolumn{4}{|l|}{ - $\quad$ Knochenaufbau } \\
\hline $\mathrm{CICP}$ & $\uparrow$ & $\downarrow$ & $\downarrow$ \\
\hline Osteocalcin & $\uparrow$ & $\downarrow$ & $\leftrightarrow$ \\
\hline Alk.Phosphatase & $\uparrow$ & $\downarrow$ & $\leftrightarrow$ \\
\hline Bone AP & $\uparrow$ & & $\leftrightarrow$ \\
\hline \multicolumn{4}{|l|}{ - $\quad$ Knochenabbau } \\
\hline ICTP & $\uparrow$ & $\downarrow$ & $\leftrightarrow$ \\
\hline \multicolumn{4}{|l|}{ - $\quad$ Bindegewebe } \\
\hline PIIINP & $\uparrow$ & $\downarrow$ & $\leftrightarrow$ \\
\hline \multicolumn{4}{|l|}{ Muskel und Herz } \\
\hline CK & $\downarrow$ & $\uparrow$ & $\leftrightarrow$ \\
\hline CK-MB & $\downarrow$ & $\uparrow$ & $\leftrightarrow$ \\
\hline
\end{tabular}

\author{
$\uparrow \quad$ bedeutet Anstieg \\ $\downarrow$ bedeutet Abfall \\ $\leftrightarrow$ bedeutet keine signifikante Veränderung
}




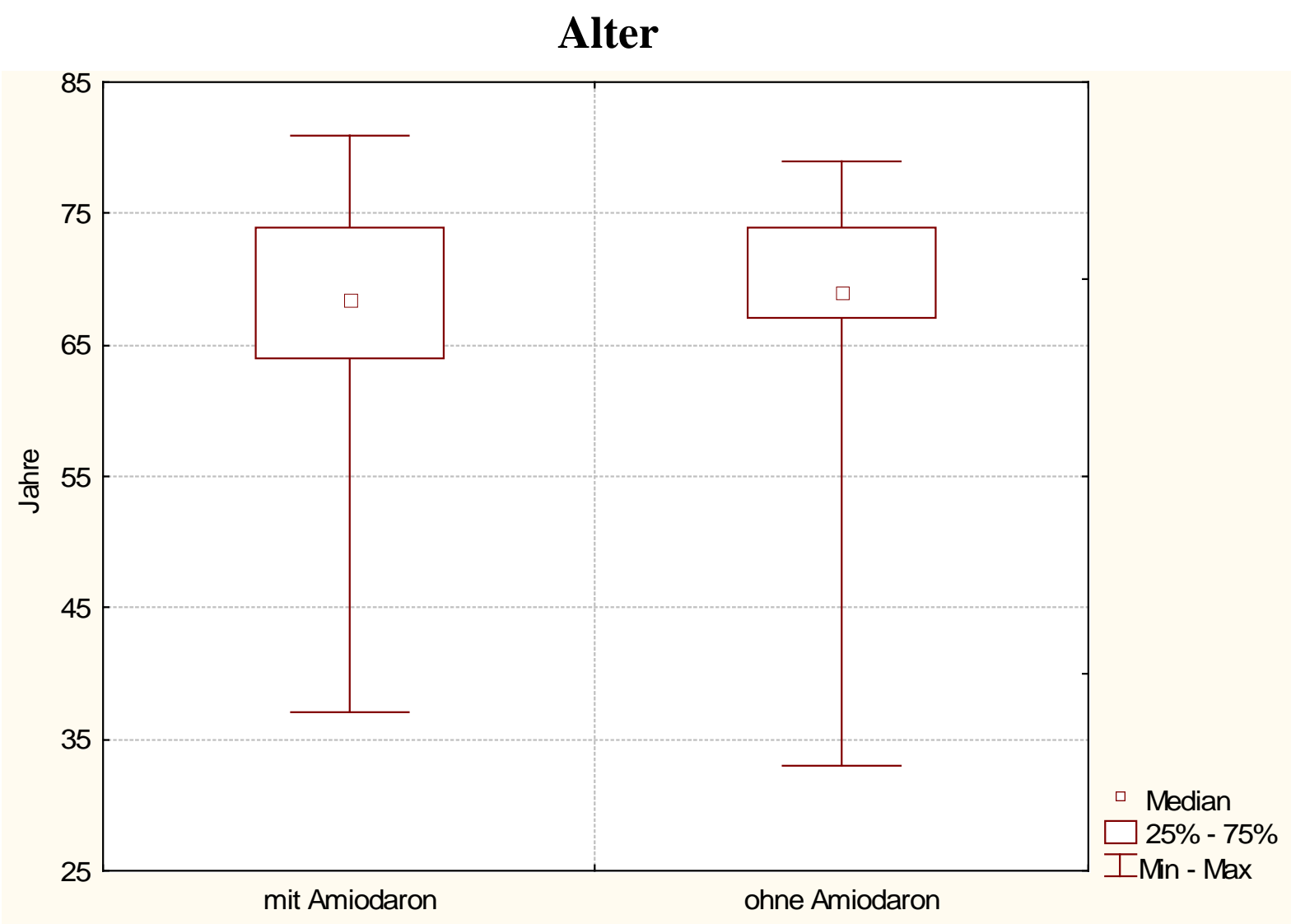

\begin{tabular}{|l|l|l|l|l|l|l|}
\hline & Mittelwert & Median & Minimum & Maximum & $\begin{array}{l}\text { Unteres } \\
\text { Quartil }\end{array}$ & $\begin{array}{l}\text { Oberes } \\
\text { Quartil }\end{array}$ \\
\hline $\begin{array}{l}\text { mit } \\
\text { Amiodaron }\end{array}$ & 67,1 & 68,5 & 37 & 81 & 64 & 74 \\
\hline $\begin{array}{l}\text { ohne } \\
\text { Amiodaron }\end{array}$ & 67,2 & 69 & 33 & 79 & 67 & 74 \\
\hline
\end{tabular}

Abb. 4 Vergleich zwischen den Patientengruppen mit Amiodaron- und ohne Amiodarontherapie in Bezug auf das Alter der Patienten.

Es ergibt sich im verbundenen $t$-Test bei einem Signifikanzniveau von $p=0,931$ kein signifikanter Altersunterschied zwischen beiden Gruppen. Dies galt als Voraussetzung für die Berechnung der Ergebnisse der Untersuchungen. 


\section{BMI}

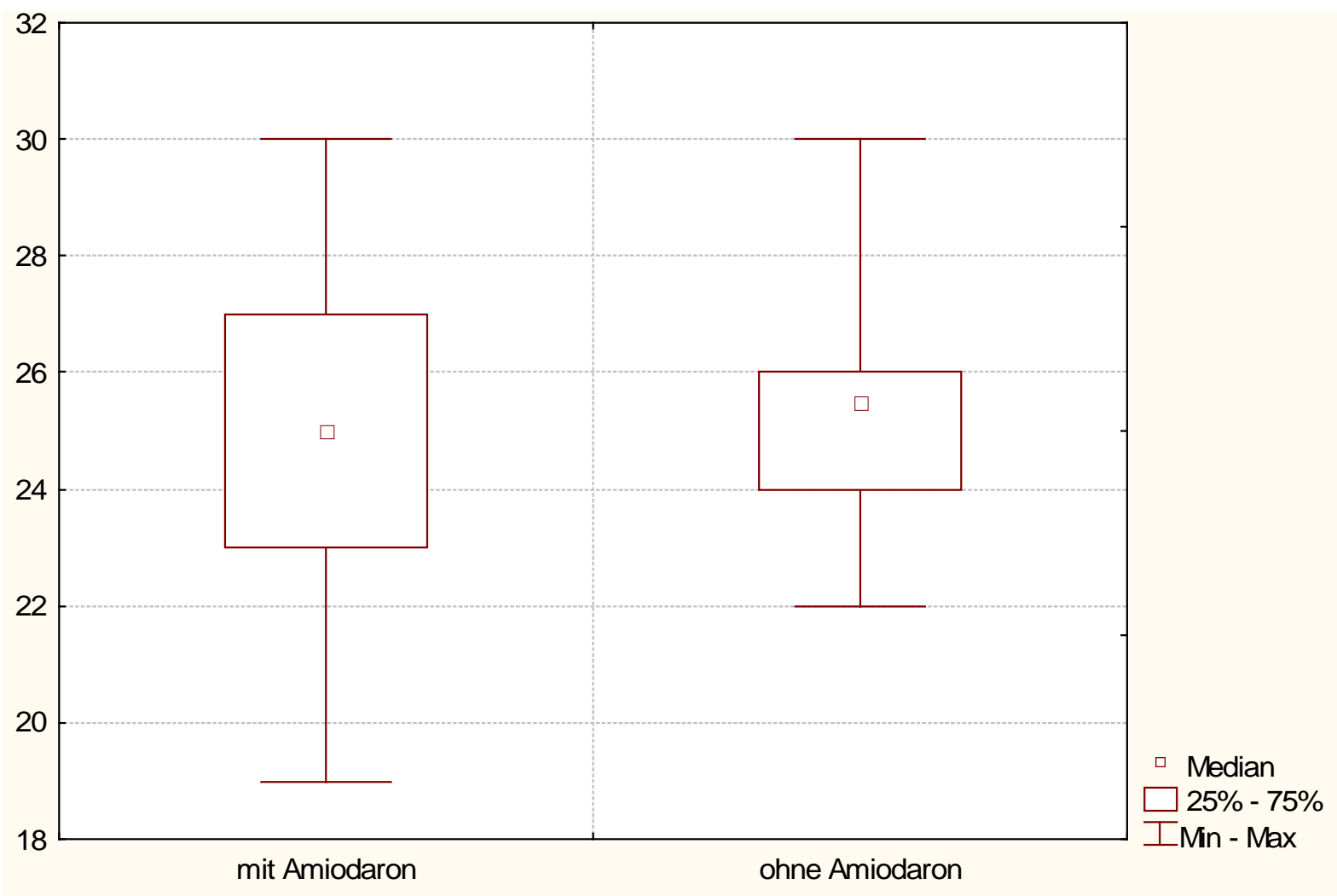

\begin{tabular}{|l|l|l|l|l|l|l|}
\hline & Mittelwert & Median & Minimum & Maximum & $\begin{array}{l}\text { Unteres } \\
\text { Quartil }\end{array}$ & $\begin{array}{l}\text { Oberes } \\
\text { Quartil }\end{array}$ \\
\hline $\begin{array}{l}\text { mit } \\
\text { Amiodaron }\end{array}$ & 25,04 & 24,5 & 19 & 30 & 23 & 28 \\
\hline $\begin{array}{l}\text { ohne } \\
\text { Amiodaron }\end{array}$ & 25,36 & 25,5 & 22 & 30 & 24 & 26 \\
\hline
\end{tabular}

Abb. 5 Vergleich zwischen Patientengruppen mit Amiodaron- und ohne Amiodarontherapie in Bezug auf den Body-mass-Index.

Es ergibt sich bei der Durchführung des verbundenen t-Testes bei einem Signifikanzniveau von $\mathbf{p}=\mathbf{0 , 4 8}$ kein signifikanter Unterschied zwischen beiden Gruppen.

Dies gilt als Voraussetzung für die Studie. 


\section{TSH}

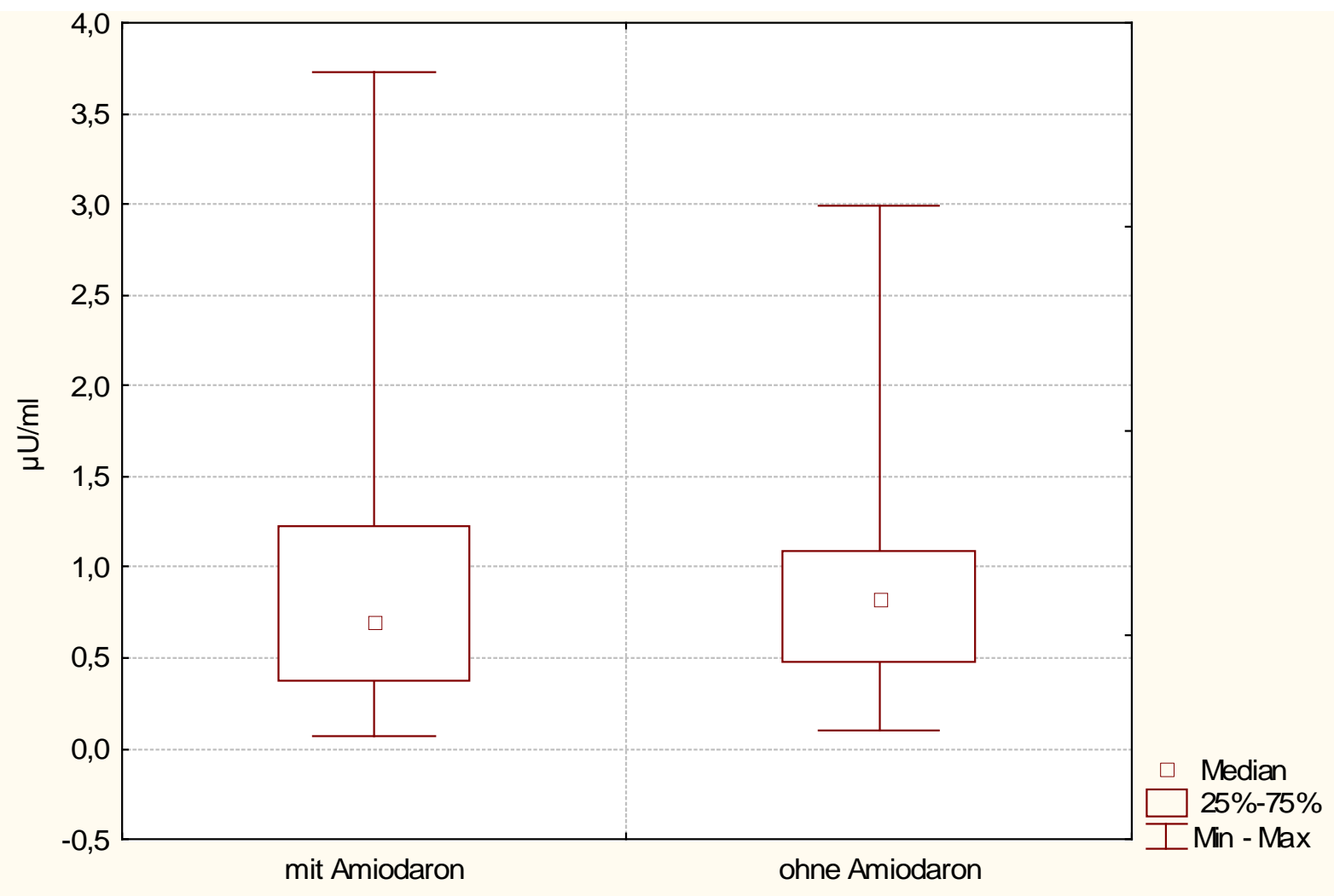

\begin{tabular}{|l|l|l|l|l|l|l|}
\hline & Mittelwert & Median & Minimum & Maximum & $\begin{array}{l}\text { Unteres } \\
\text { Quartil }\end{array}$ & $\begin{array}{l}\text { Oberes } \\
\text { Quartil }\end{array}$ \\
\hline $\begin{array}{l}\text { mit } \\
\text { Amiodaron }\end{array}$ & $\mathbf{0 , 9 2}$ & $\mathbf{0 , 6 9}$ & $\mathbf{0 , 0 7}$ & $\mathbf{3 , 7 3}$ & $\mathbf{0 , 3 7}$ & $\mathbf{1 , 2 3}$ \\
\hline $\begin{array}{l}\text { ohne } \\
\text { Amiodaron }\end{array}$ & $\mathbf{1 , 0 1}$ & $\mathbf{0 , 8 2}$ & $\mathbf{0 , 1}$ & $\mathbf{2 , 9 9}$ & $\mathbf{0 , 4 8}$ & $\mathbf{1 , 0 9}$ \\
\hline
\end{tabular}

Abb. 6 Vergleich zwischen den Patientengruppen mit Amiodaron- und ohne Amiodarontherapie bezüglich des TSH im Serum. Bei der Durchführung des verbundenen t-Testes zeigt sich bei einem Signifikanzniveau von $p=0,71$ kein signifikanter Unterschied zwischen beiden Gruppen. 


\section{fT4}

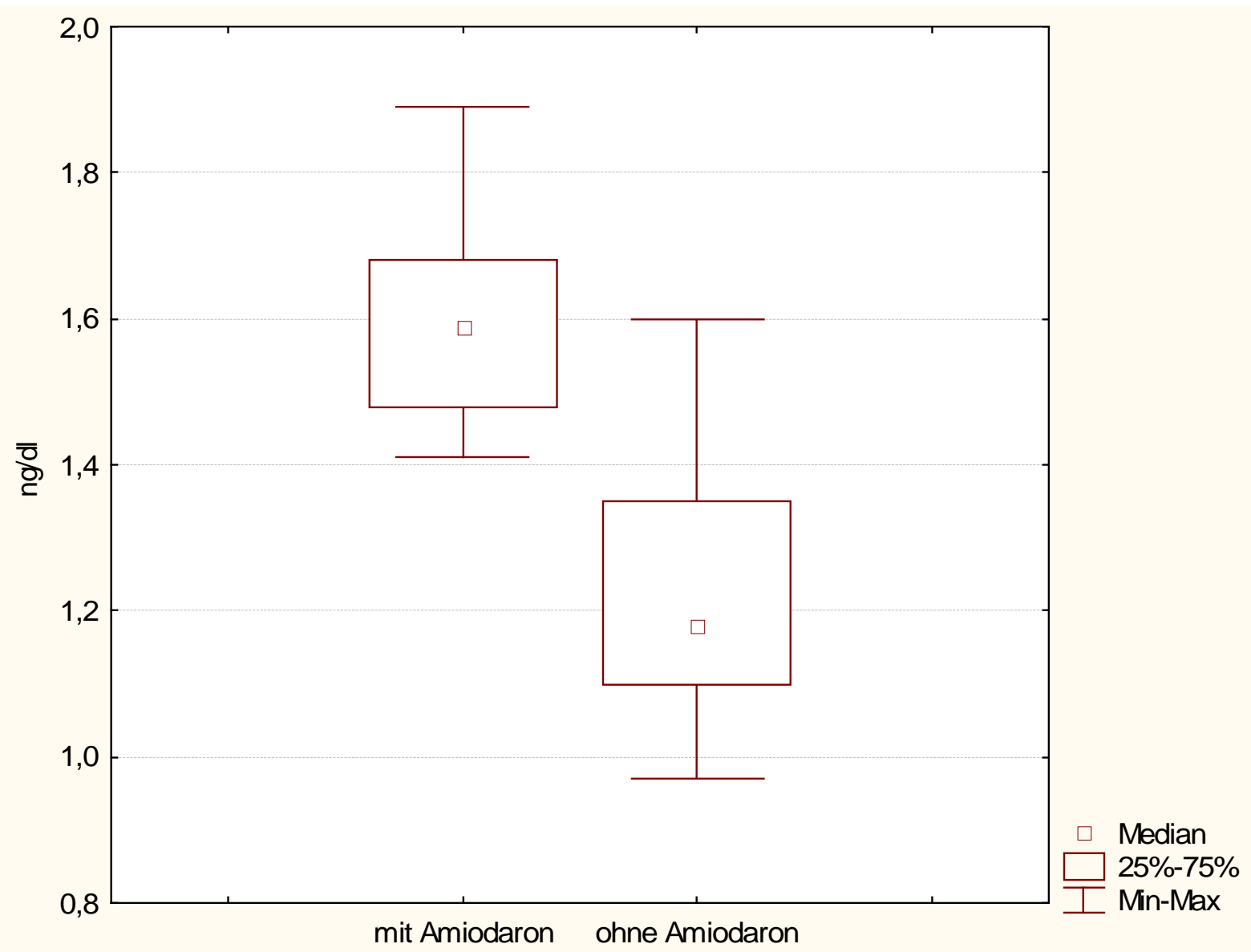

\begin{tabular}{|l|l|l|l|l|l|l|}
\hline & Mittelwert & Median & Minimum & Maximum & $\begin{array}{l}\text { Unteres } \\
\text { Quartil }\end{array}$ & $\begin{array}{l}\text { Oberes } \\
\text { Quartil }\end{array}$ \\
\hline $\begin{array}{l}\text { mit } \\
\text { Amiodaron }\end{array}$ & 1,59 & 1,59 & 1,41 & 1,89 & 1,48 & 1,68 \\
\hline $\begin{array}{l}\text { ohne } \\
\text { Amiodaron }\end{array}$ & 1,22 & 1,18 & 0,97 & 1,6 & 1,1 & 1,35 \\
\hline
\end{tabular}

Abb. 7 Vergleich zwischen Patientengruppen mit Amiodaron- und ohne Amiodarontherapie bezüglich des freien Thyroxins im Serum.

Es zeigt sich bei der Anwendung des verbundenen t-Testes bei einem Signifikanzniveau von 0,000005 ein hochsignifikanter Unterschied zwischen beiden Gruppen. 
T3

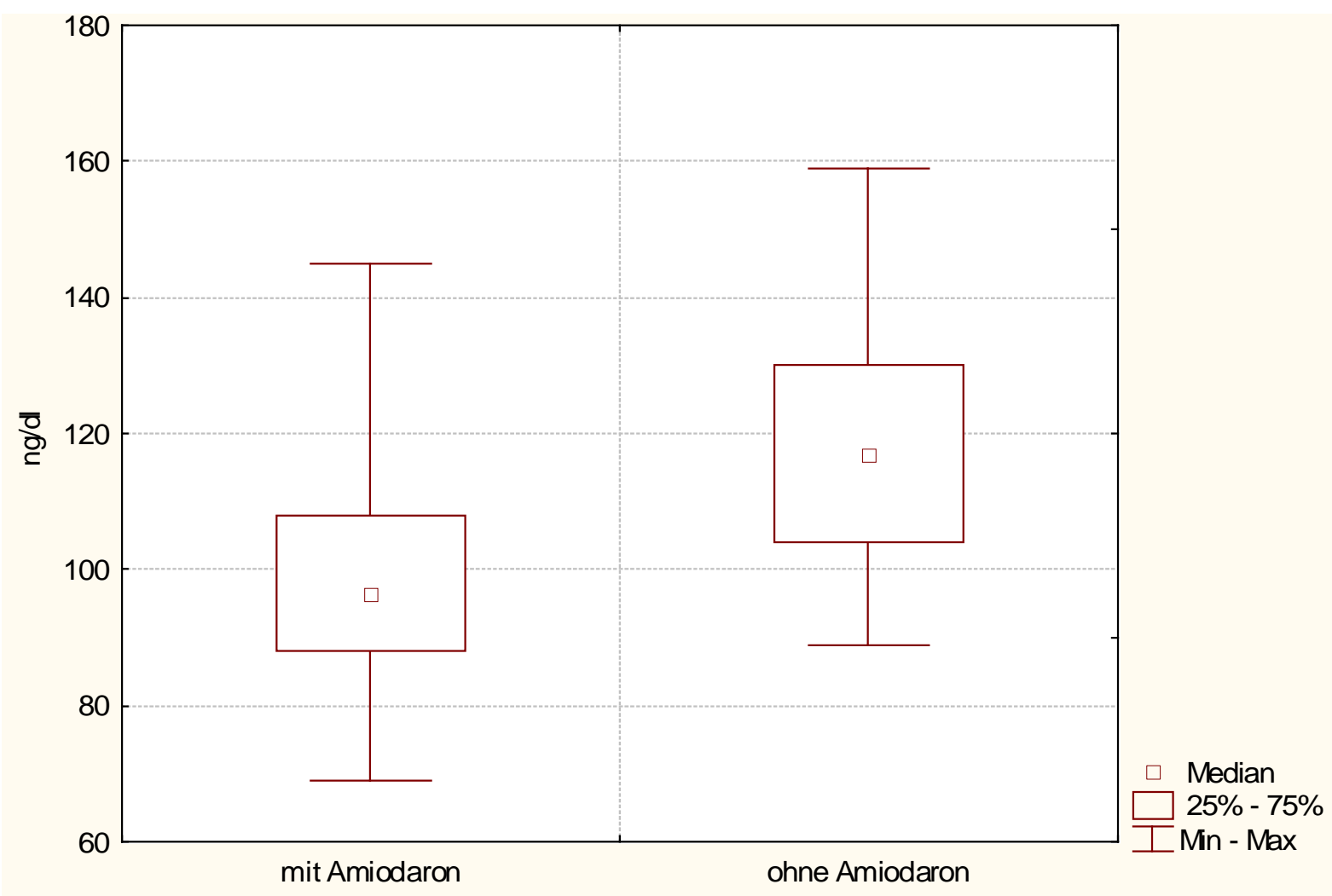

\begin{tabular}{|l|l|l|l|l|l|l|}
\hline & Mittelwert & Median & Minimum & Maximum & $\begin{array}{l}\text { Unteres } \\
\text { Quartil }\end{array}$ & $\begin{array}{l}\text { Oberes } \\
\text { Quartil }\end{array}$ \\
\hline $\begin{array}{l}\text { mit } \\
\text { Amiodaron }\end{array}$ & 99,09 & 96,5 & 69 & 145 & 88 & 108 \\
\hline $\begin{array}{l}\text { ohne } \\
\text { Amiodaron }\end{array}$ & 118,54 & 117 & 89 & 159 & 104 & 130 \\
\hline
\end{tabular}

Abb. 8 Vergleich zwischen den Patientengruppen mit Amiodaron- und ohne Amiodarontherapie in Bezug auf T3 im Serum. Der verbundene t-Test zeigt bei einem Signifikanzniveau von $\mathrm{p}=\mathbf{0 , 0 0 1 9}$ einen signifikanten Unterschied zwischen beiden Gruppen. 


\section{Ferritin}

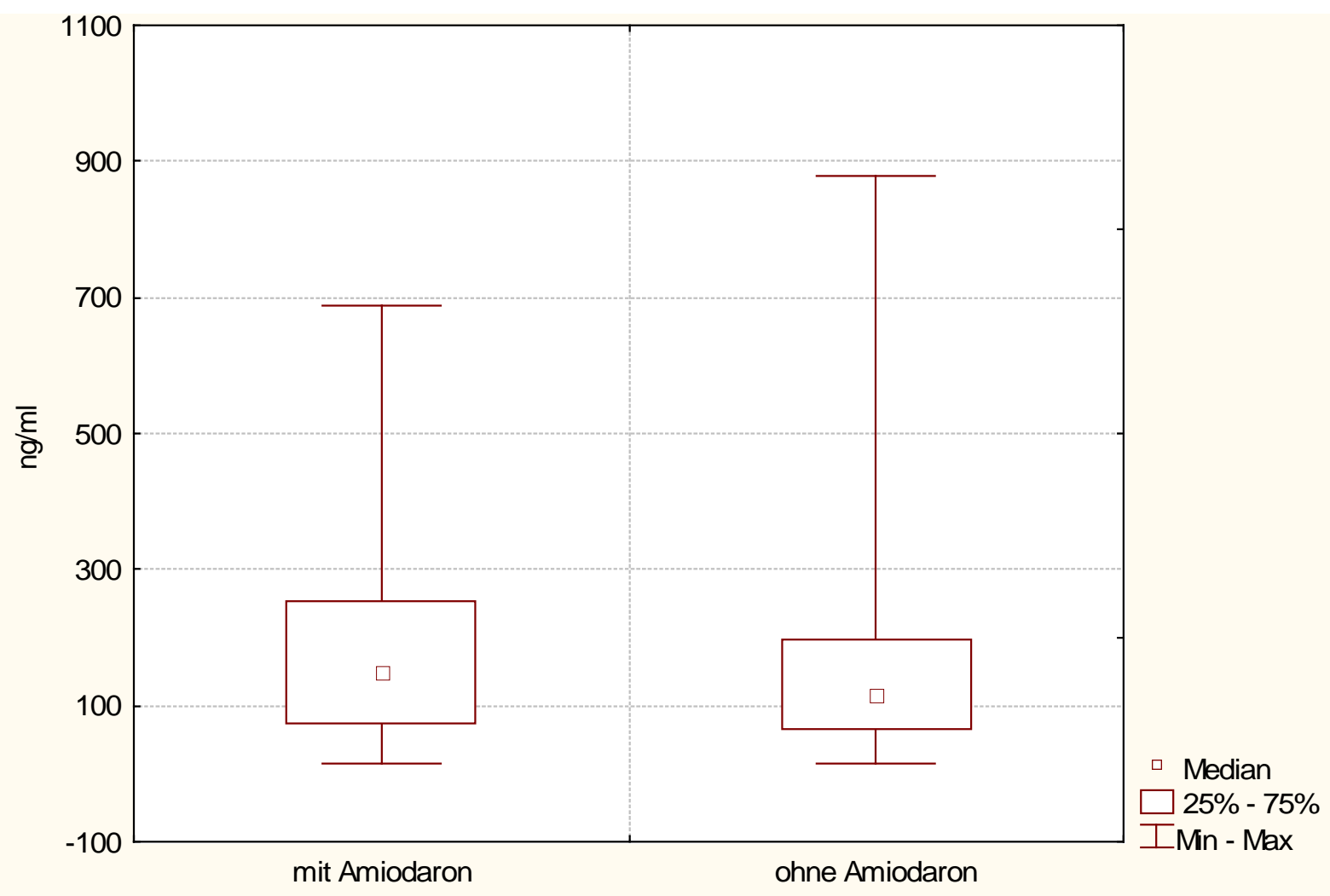

\begin{tabular}{|l|l|l|l|l|l|l|}
\hline & Mittelwert & Median & Minimum & Maximum & $\begin{array}{l}\text { Unteres } \\
\text { Quartil }\end{array}$ & $\begin{array}{l}\text { Oberes } \\
\text { Quartil }\end{array}$ \\
\hline $\begin{array}{l}\text { mit } \\
\text { Amiodaron }\end{array}$ & 188,39 & 150,45 & 14,81 & 688,1 & 74,66 & 253,5 \\
\hline $\begin{array}{l}\text { ohne } \\
\text { Amiodaron }\end{array}$ & 181,62 & 116,8 & 15,06 & 880,0 & 65,66 & 196,8 \\
\hline
\end{tabular}

Abb. 9 Vergleich zwischen Patientengruppen mit Amiodaron- und ohne Amiodarontherapie bezüglich des Ferritins im Serum. Bei der Durchführung des verbundenen t-Testes ergibt sich bei einem Signifikanzniveau von $p=0,526$ kein signifikanter Unterschied zwischen beiden Gruppen. 


\section{SHBG}

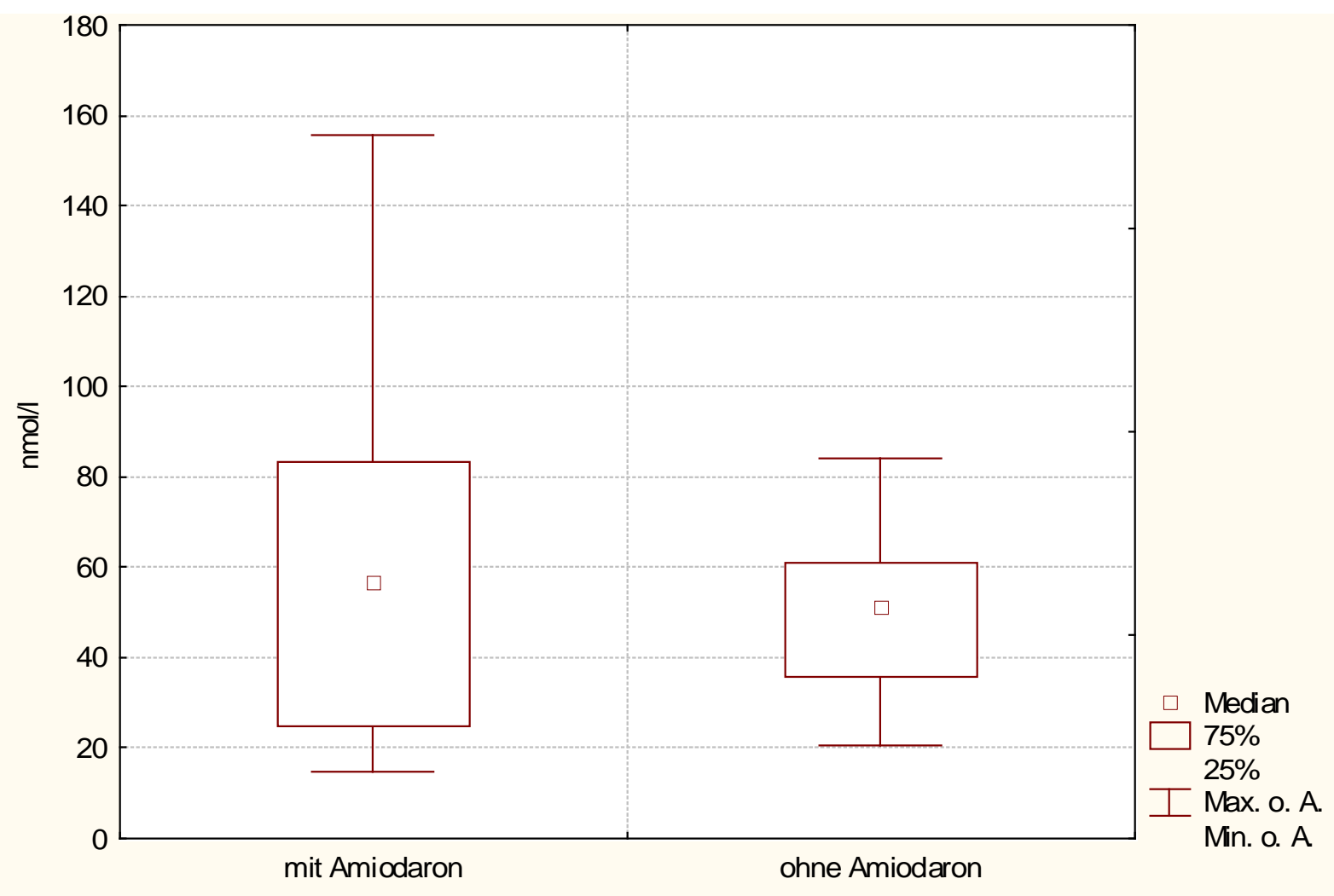

\begin{tabular}{|l|l|l|l|l|l|l|}
\hline & Mittelwert & Median & Minimum & Maximum & $\begin{array}{l}\text { Unteres } \\
\text { Quartil }\end{array}$ & $\begin{array}{l}\text { Oberes } \\
\text { Quartil }\end{array}$ \\
\hline $\begin{array}{l}\text { mit } \\
\text { Amiodaron }\end{array}$ & $\mathbf{6 1 , 5 9}$ & $\mathbf{5 6 , 6}$ & $\mathbf{1 4 , 6}$ & $\mathbf{1 5 5 , 6}$ & $\mathbf{2 5}$ & $\mathbf{8 3 , 4}$ \\
\hline $\begin{array}{l}\text { ohne } \\
\text { Amiodaron }\end{array}$ & $\mathbf{5 0 , 6 8}$ & $\mathbf{5 1 , 2}$ & $\mathbf{2 0 , 6}$ & $\mathbf{8 4}$ & $\mathbf{3 5 , 8}$ & $\mathbf{6 1}$ \\
\hline
\end{tabular}

Abb. 10 Vergleich zwischen Patienten mit Amiodaron- und ohne Amiodarontherapie bezüglich des SHBG im Serum. Bei der Durchführung des verbundenen t-Testes ergibt sich bei einem Signifikanzniveau von $\mathbf{p}=\mathbf{0 , 5 6 9}$ kein signifikanter Unterschied zwischen beiden Gruppen. 


\section{GGT}

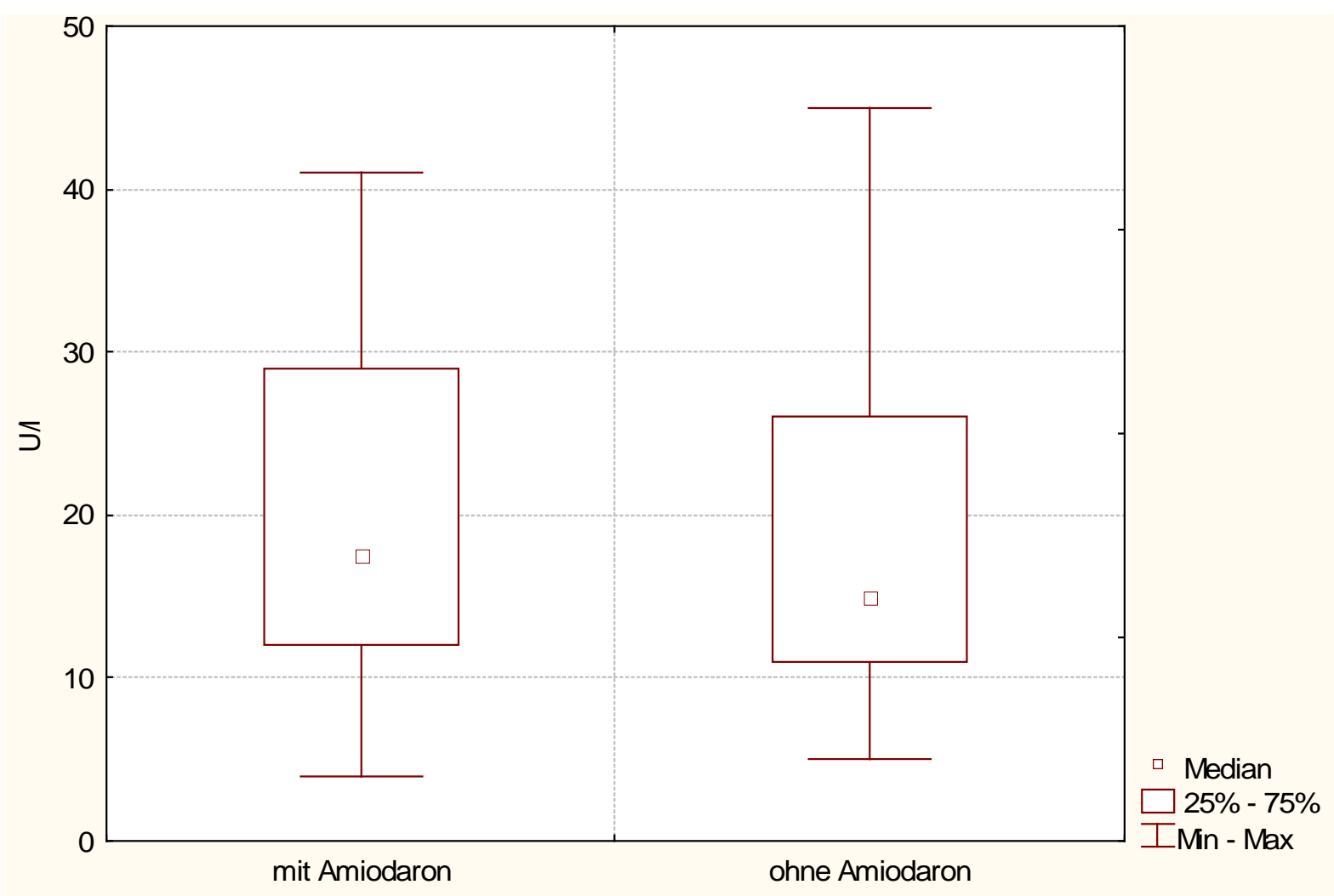

\begin{tabular}{|l|l|l|l|l|l|l|}
\hline & Mittelwert & Median & Minimum & Maximum & $\begin{array}{l}\text { Unteres } \\
\text { Quartil }\end{array}$ & $\begin{array}{l}\text { Oberes } \\
\text { Quartil }\end{array}$ \\
\hline $\begin{array}{l}\text { mit } \\
\text { Amiodaron }\end{array}$ & 20,09 & 17,5 & 4 & 41 & 12 & 29 \\
\hline $\begin{array}{l}\text { ohne } \\
\text { Amiodaron }\end{array}$ & 18,41 & 15 & 5 & 45 & 11 & 26 \\
\hline
\end{tabular}

Abb. 11 Vergleich zwischen Patientengruppen mit Amiodaron- und ohne Amiodarontherapie bezüglich der Gamma-Glutamyl-Transferase im Serum. Bei der Durchführung des verbundenen t-Testes zeigt sich bei einem Signifikanzniveau von $\mathbf{p}=$ 0,635 kein signifikanter Unterschied zwischen beiden Gruppen. 


\section{Cholesterin}

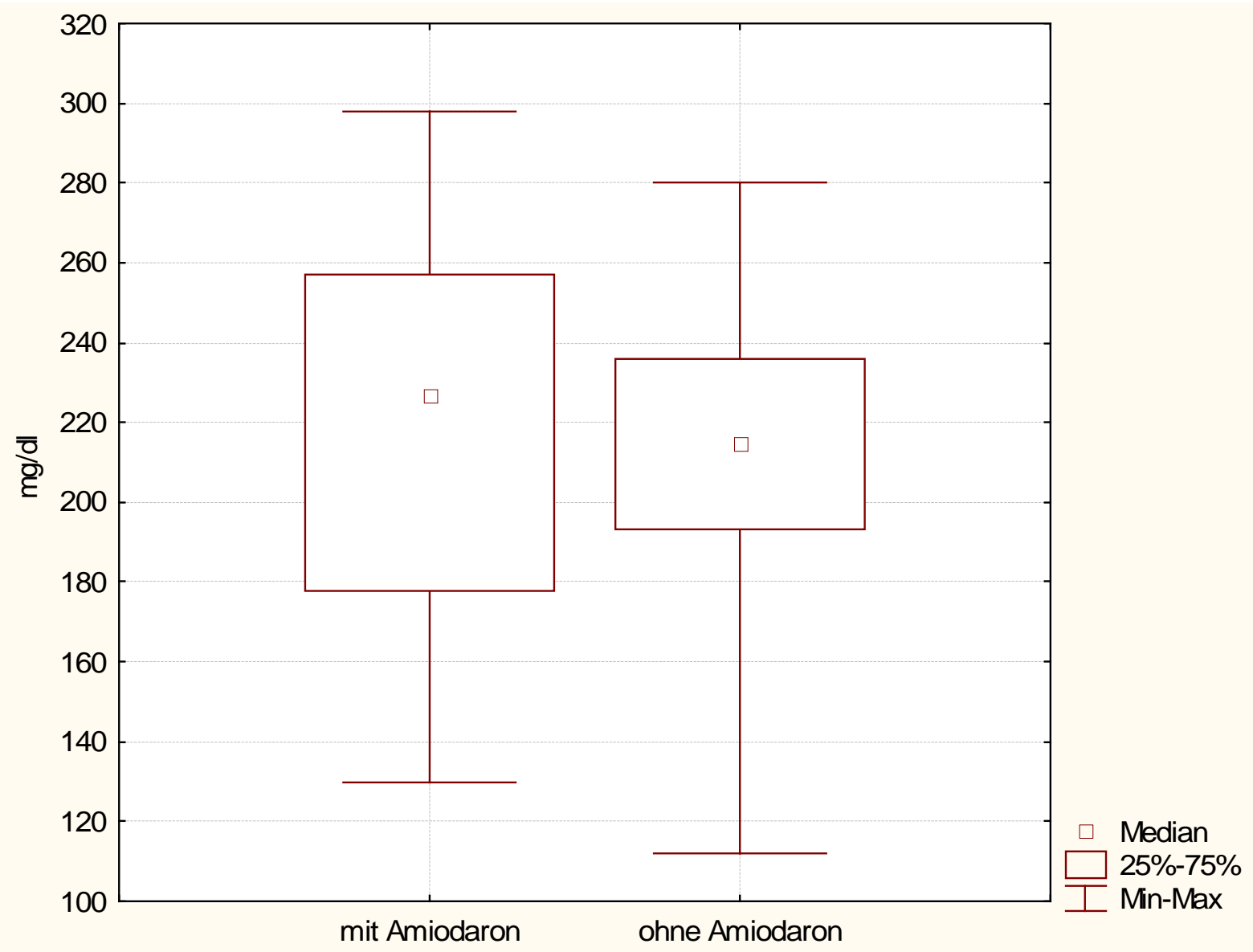

\begin{tabular}{|l|l|l|l|l|l|l|}
\hline & Mittelwert & Median & Minimum & Maximum & $\begin{array}{l}\text { Unteres } \\
\text { Quartil }\end{array}$ & $\begin{array}{l}\text { Oberes } \\
\text { Quartil }\end{array}$ \\
\hline $\begin{array}{l}\text { mit } \\
\text { Amiodaron }\end{array}$ & 220,9 & 227 & 130 & 298 & 178 & 257 \\
\hline $\begin{array}{l}\text { ohne } \\
\text { Amiodaron }\end{array}$ & 212,2 & 215 & 112 & 280 & 193 & 236 \\
\hline
\end{tabular}

Abb.12 Vergleich zwischen den Patientengruppen mit Amiodaron- und ohne Amiodarontherapie in Bezug auf Cholesterin im Serum. Bei der Auswertung des verbundenen $t$-Testes kommt es bei einem Signifikanzniveau von $p=0,325 \mathrm{zu}$ keinem signifikanten Unterschied zwischen beiden Gruppen. 


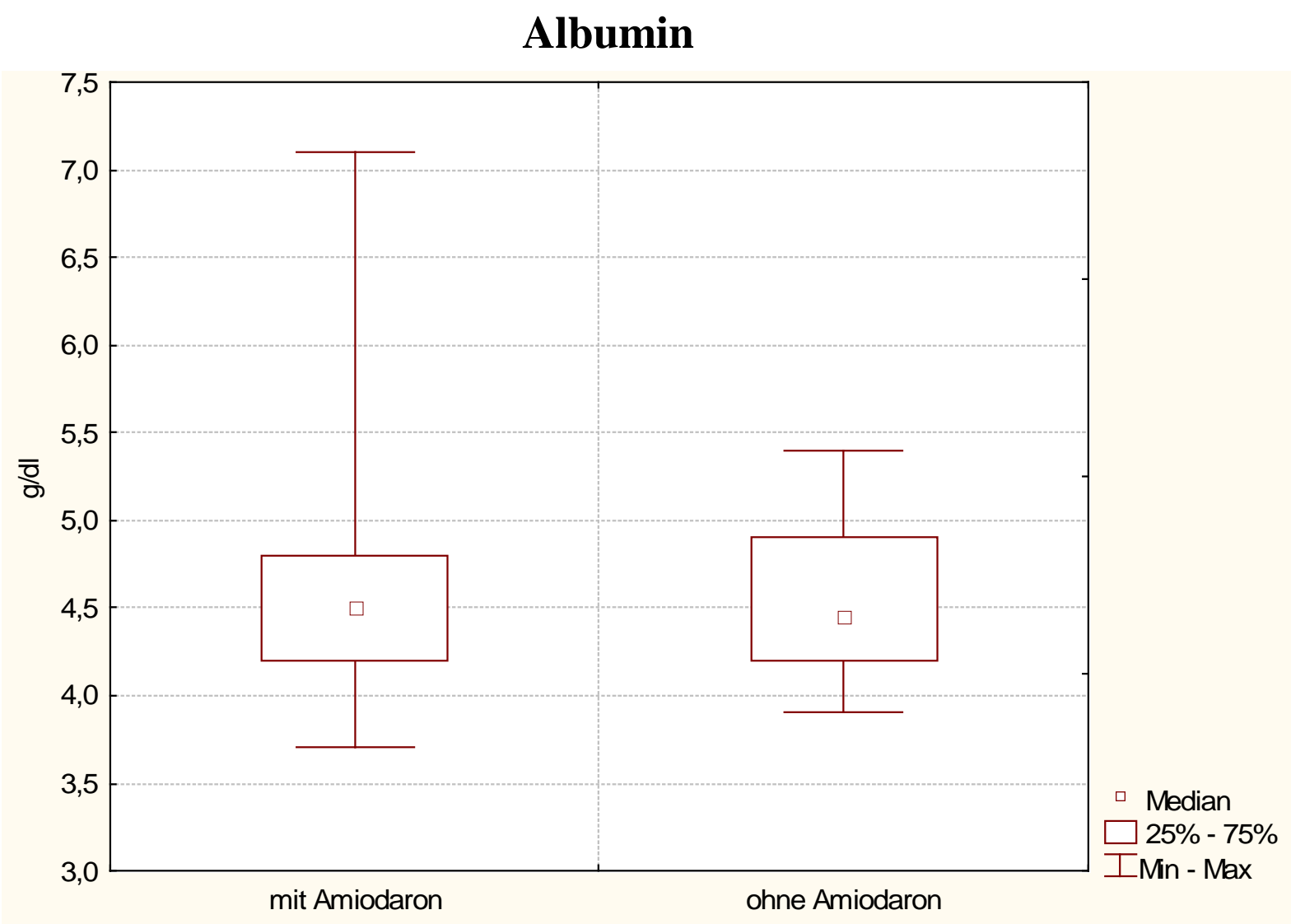

\begin{tabular}{|l|l|l|l|l|l|l|}
\hline & Mittelwert & Median & Minimum & Maximum & $\begin{array}{l}\text { Unteres } \\
\text { Quartil }\end{array}$ & $\begin{array}{l}\text { Oberes } \\
\text { Quartil }\end{array}$ \\
\hline $\begin{array}{l}\text { mit } \\
\text { Amiodaron }\end{array}$ & $\mathbf{4 , 5 7 7}$ & $\mathbf{4 , 5}$ & 3,7 & $\mathbf{7 , 1}$ & $\mathbf{4 , 2}$ & $\mathbf{4 , 8}$ \\
\hline $\begin{array}{l}\text { ohne } \\
\text { Amiodaron }\end{array}$ & $\mathbf{4 , 5 8 6}$ & $\mathbf{4 , 4 5}$ & $\mathbf{3 , 9}$ & $\mathbf{5 , 4}$ & $\mathbf{4 , 2}$ & $\mathbf{4 , 9}$ \\
\hline
\end{tabular}

Abb. 13 Vergleich zwischen Patientengruppen mit Amiodaron- und ohne Amiodarontherapie bezüglich des Albumins im Serum. Die Durchführung des verbundenen $t$-Testes ergibt bei einem Signifikanzniveau von $p=0,507$ keinen signifikanten Unterschied zwischen beiden Gruppen. 


\section{CICP}

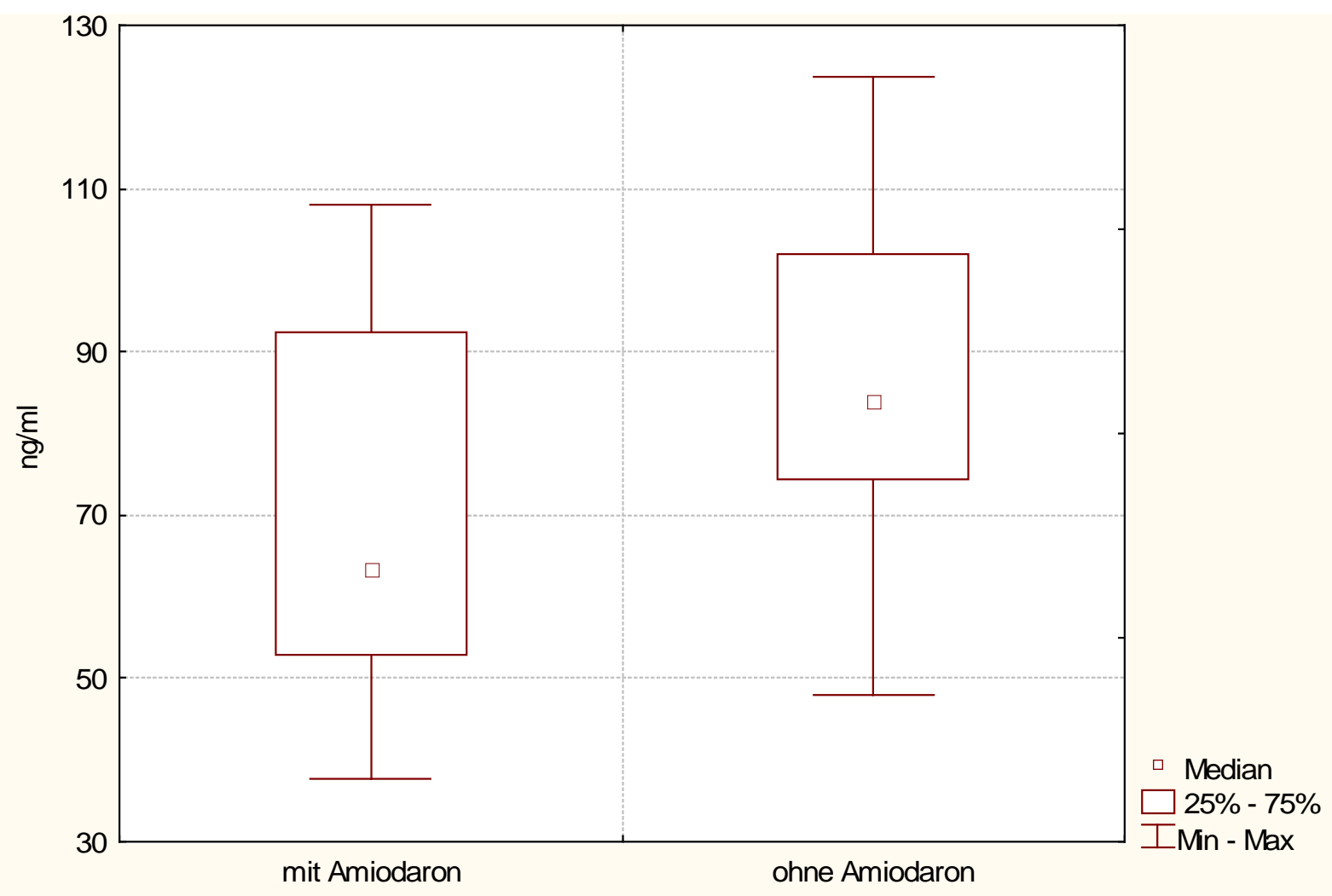

\begin{tabular}{|l|l|l|l|l|l|l|}
\hline & Mittelwert & Median & Minimum & Maximum & $\begin{array}{l}\text { Unteres } \\
\text { Quartil }\end{array}$ & $\begin{array}{l}\text { Oberes } \\
\text { Quartil }\end{array}$ \\
\hline $\begin{array}{l}\text { mit } \\
\text { Amiodaron }\end{array}$ & 69,63 & 63,35 & 37,8 & 108 & 52,8 & 92,4 \\
\hline $\begin{array}{l}\text { ohne } \\
\text { Amiodaron }\end{array}$ & 87,07 & 84 & 48 & 123,6 & 74,4 & 102 \\
\hline
\end{tabular}

Abb.14 Vergleich zwischen Patienten mit Amiodaron- und ohne Amiodarontherapie bezüglich des CICP (Typ I collagen carboxyterminal propeptide) im Serum. Bei Anwendung des verbundenen t-Testes ergibt sich bei einem Signifikanzniveau von 0,0216 ein signifikanter Unterschied zwischen beiden Gruppen. 


\section{Osteocalcin}

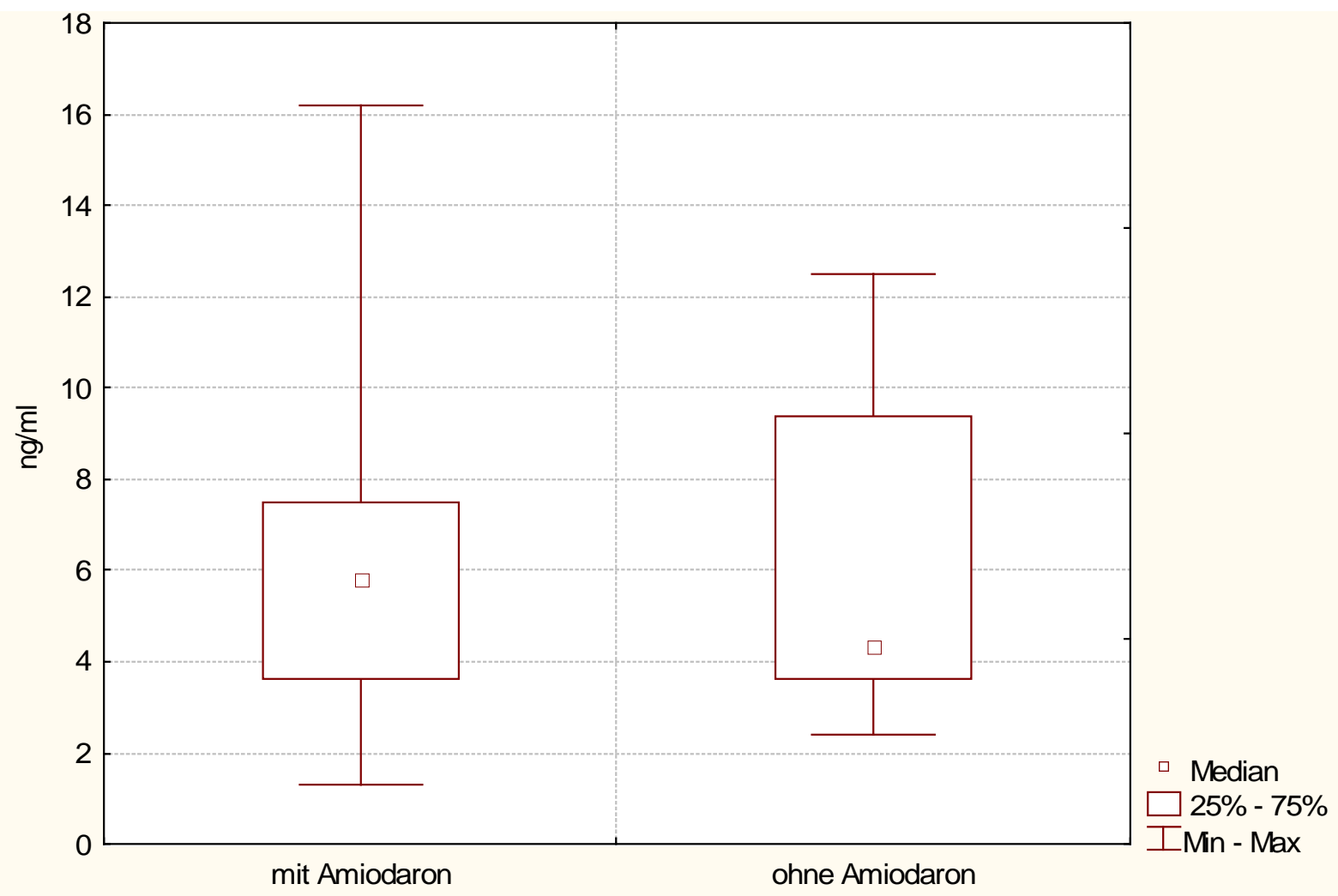

\begin{tabular}{|l|l|l|l|l|l|l|}
\hline & Mittelwert & Median & Minimum & Maximum & $\begin{array}{l}\text { Unteres } \\
\text { Quartil }\end{array}$ & $\begin{array}{l}\text { Oberes } \\
\text { Quartil }\end{array}$ \\
\hline $\begin{array}{l}\text { mit } \\
\text { Amiodaron }\end{array}$ & 6,24 & 5,8 & 1,3 & 16,2 & 3,6 & 7,5 \\
\hline $\begin{array}{l}\text { ohne } \\
\text { Amiodaron }\end{array}$ & 6,09 & 4,35 & 2,4 & 12,5 & 3,6 & 9,4 \\
\hline
\end{tabular}

Abb. 15 Vergleich zwischen Patienten mit Amiodaron- und ohne Amiodarontherapie bezüglich des Osteocalcins im Serum. Es zeigt sich bei der Durchführung des verbundenen t-Testes mit einem Signifikanzniveau von $p=0,913$ kein signifikanter Unterschied zwischen beiden Gruppen. 


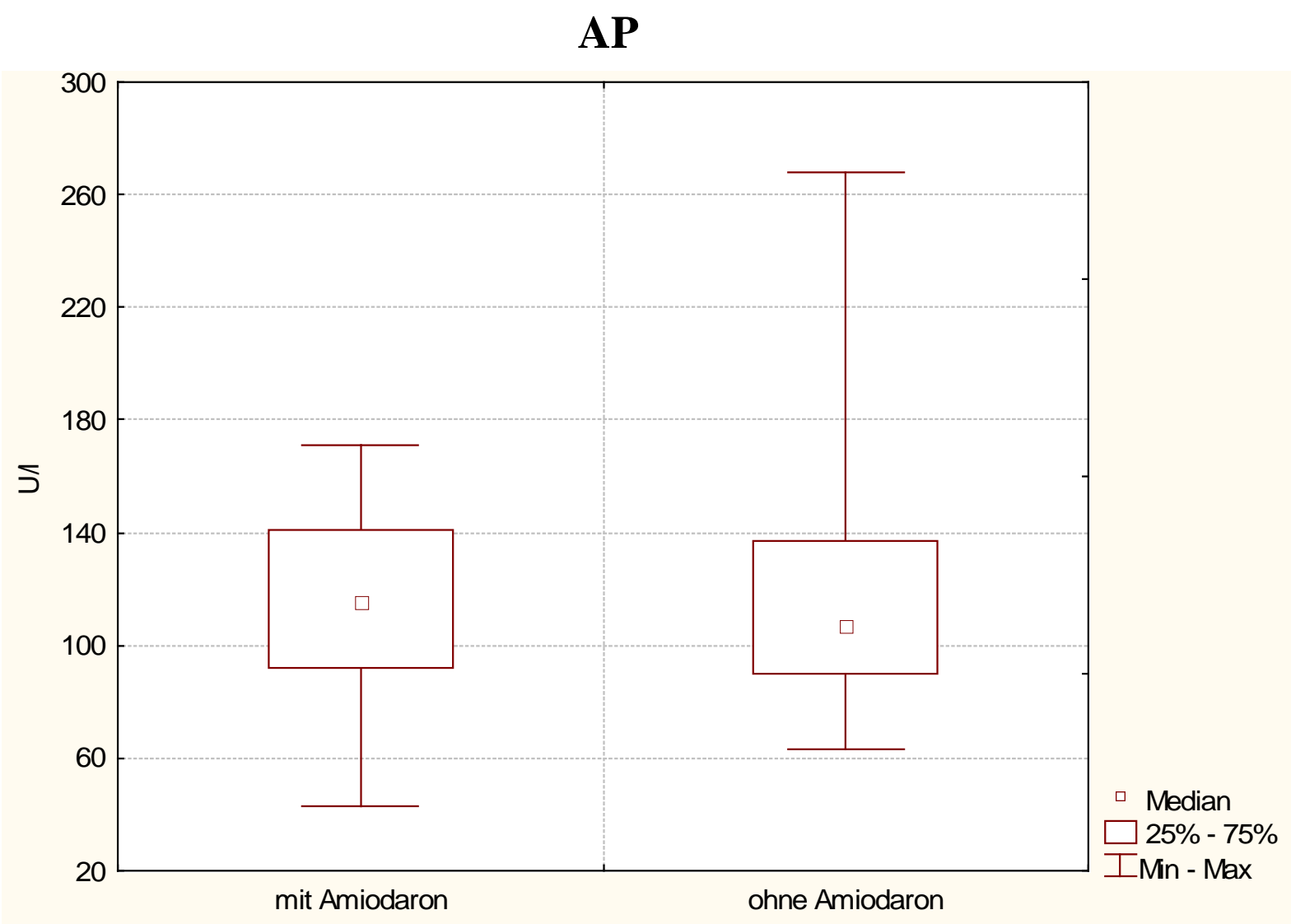

\begin{tabular}{|l|l|l|l|l|l|l|}
\hline & Mittelwert & Median & Minimum & Maximum & $\begin{array}{l}\text { Unteres } \\
\text { Quartil }\end{array}$ & $\begin{array}{l}\text { Oberes } \\
\text { Quartil }\end{array}$ \\
\hline $\begin{array}{l}\text { mit } \\
\text { Amiodaron }\end{array}$ & 117,09 & 115,5 & 43 & 171 & 92 & 141 \\
\hline $\begin{array}{l}\text { ohne } \\
\text { Amiodaron }\end{array}$ & 114,27 & 107 & 63 & 268 & 90 & 137 \\
\hline
\end{tabular}

Abb.16 Vergleich zwischen Patientengruppen mit Amiodaron- und ohne Amiodarontherapie bezüglich der Alkalischen Phosphatase im Serum. Es zeigt sich bei der Durchführung des verbundenen t-Testes bei einem Signifikanzniveau von $p=0,264$ kein signifikanter Unterschied zwischen beiden Gruppen. 


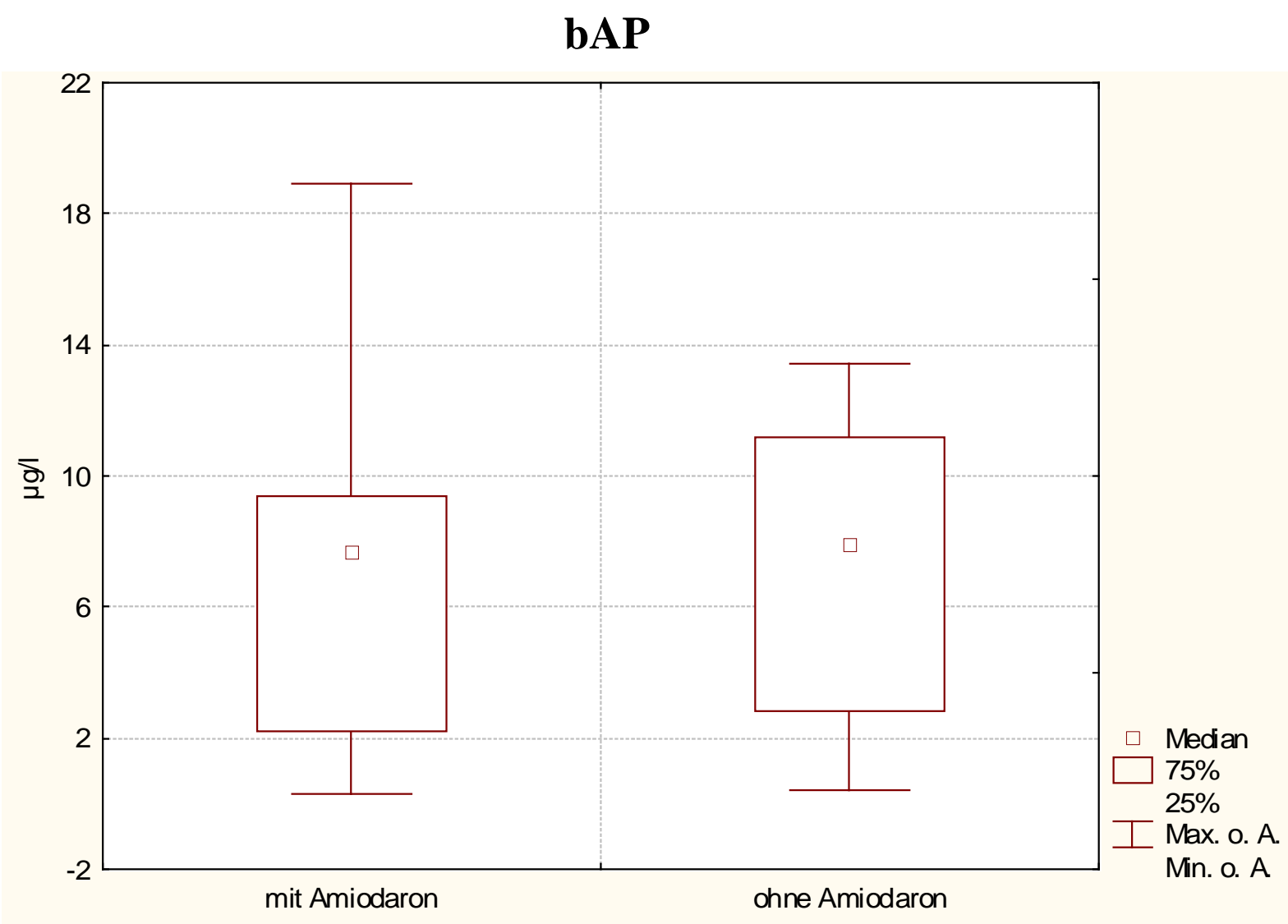

\begin{tabular}{|l|l|l|l|l|l|l|}
\hline & Mittelwert & Median & Minimum & Maximum & $\begin{array}{l}\text { Unteres } \\
\text { Quartil }\end{array}$ & $\begin{array}{l}\text { Oberes } \\
\text { Quartil }\end{array}$ \\
\hline $\begin{array}{l}\text { mit } \\
\text { Amiodaron }\end{array}$ & 7,61 & 7,7 & 0,3 & 18,9 & 2,2 & 9,4 \\
\hline $\begin{array}{l}\text { ohne } \\
\text { Amiodaron }\end{array}$ & 7,19 & 7,95 & 0,4 & 13,4 & 2,8 & 11,2 \\
\hline
\end{tabular}

Abb. 17 Vergleich zwischen Patientengruppen mit Amiodaron- und ohne Amiodarontherapie in Bezug auf Alkalische Knochenphosphatase (bone alkaline phosphatase).

Bei der Durchführung des verbundenen t-Testes ergab sich bei einem Signifikanzniveau von $\mathbf{p}=1,0$ kein signifikanter Unterschied zwischen beiden Gruppen. 


\section{ICTP}

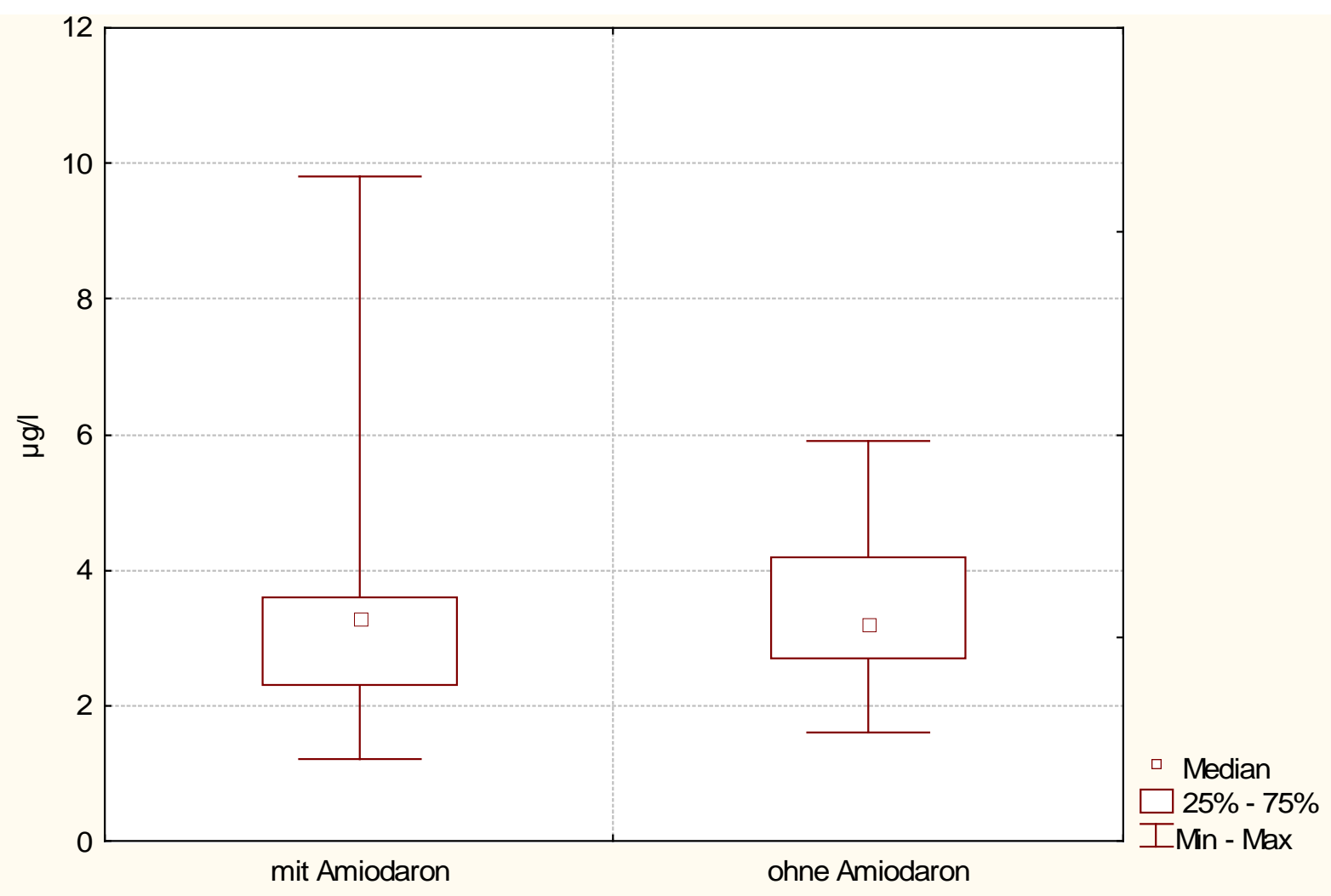

\begin{tabular}{|l|l|l|l|l|l|l|}
\hline & Mittelwert & Median & Minimum & Maximum & $\begin{array}{l}\text { Unteres } \\
\text { Quartil }\end{array}$ & $\begin{array}{l}\text { Oberes } \\
\text { Quartil }\end{array}$ \\
\hline $\begin{array}{l}\text { mit } \\
\text { Amiodaron }\end{array}$ & $\mathbf{3 , 3 2}$ & $\mathbf{3 , 3}$ & 1,2 & 9,8 & 2,3 & $\mathbf{3 , 6}$ \\
\hline $\begin{array}{l}\text { ohne } \\
\text { Amiodaron }\end{array}$ & $\mathbf{3 , 4 2}$ & $\mathbf{3 , 2}$ & 1,6 & $\mathbf{5 , 9}$ & $\mathbf{2 , 7}$ & $\mathbf{4 , 2}$ \\
\hline
\end{tabular}

Abb. 18 Vergleich zwischen Patienten mit Amiodaron- und ohne Amiodarontherapie bezüglich des ICTP (Kollagen-I-carboxyterminales Telopeptid) im Serum. Bei der Durchführung des verbundenen $t$-Testes ergibt sich bei einem Signifikanzniveau von $p=$ 0,531 kein signifikanter Unterschied zwischen beiden Gruppen. 


\section{PIIINP}

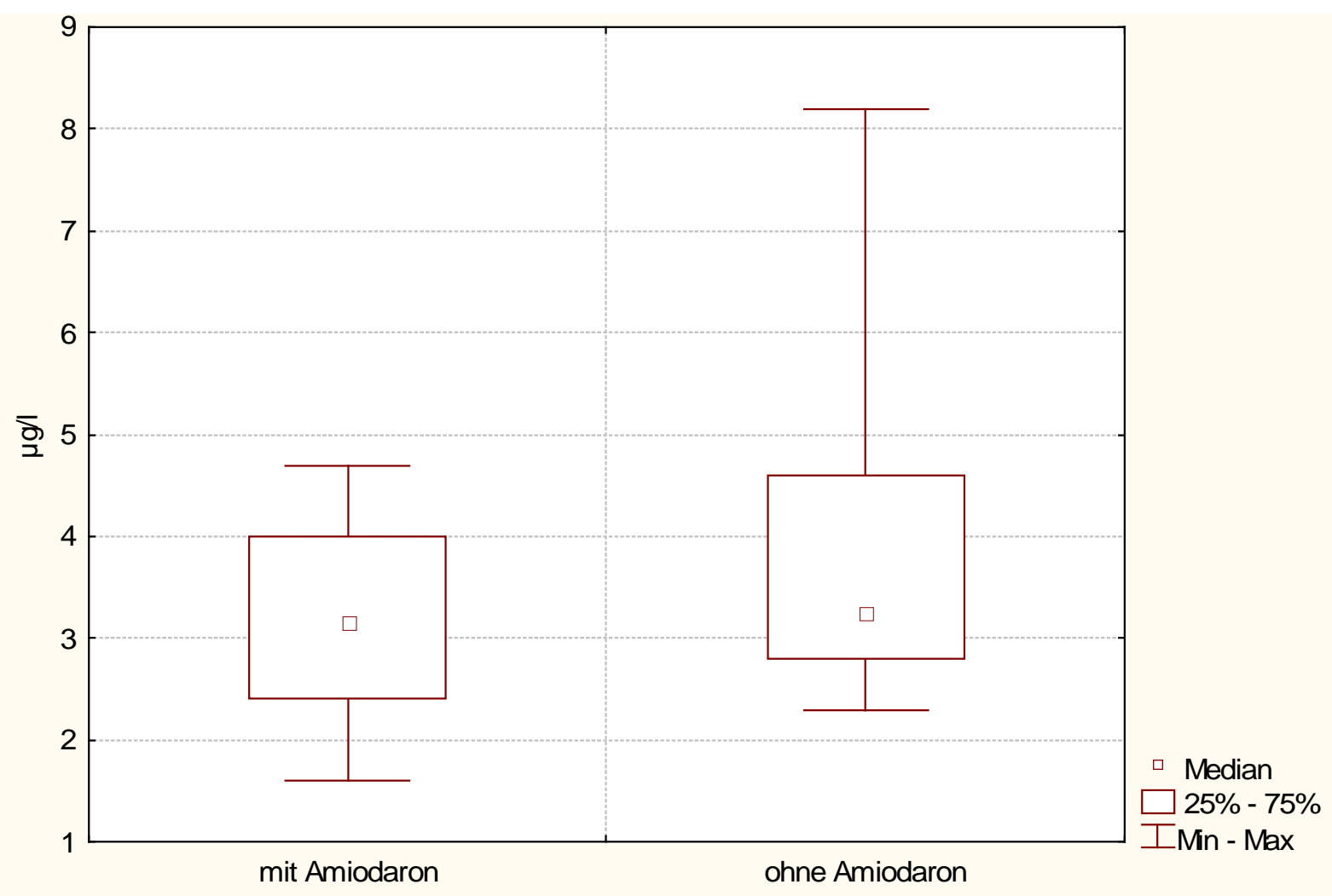

\begin{tabular}{|l|l|l|l|l|l|l|}
\hline & Mittelwert & Median & Minimum & Maximum & $\begin{array}{l}\text { Unteres } \\
\text { Quartil }\end{array}$ & $\begin{array}{l}\text { Oberes } \\
\text { Quartil }\end{array}$ \\
\hline $\begin{array}{l}\text { mit } \\
\text { Amiodaron }\end{array}$ & 3,14 & 3,15 & 1,6 & 4,7 & 2,4 & 4,0 \\
\hline $\begin{array}{l}\text { ohne } \\
\text { Amiodaron }\end{array}$ & 3,74 & 3,25 & 2,3 & 8,2 & 2,8 & 4,6 \\
\hline
\end{tabular}

Abb. 19 Vergleich zwischen Patienten mit Amiodaron- und ohne Amiodarontherapie bezüglich des PIIINP (Prokollagen III)

Bei verbundenem $t$-Test und einem Signifikanzniveau von $p=0,262$ ergibt sich kein signifikanter Unterschied zwischen beiden Gruppen. Es zeigt sich jedoch eine nicht signifikante leichte Tendenz zu sinkendem PIIINP-Werten unter Amiodarontherapie. 


\section{CK}

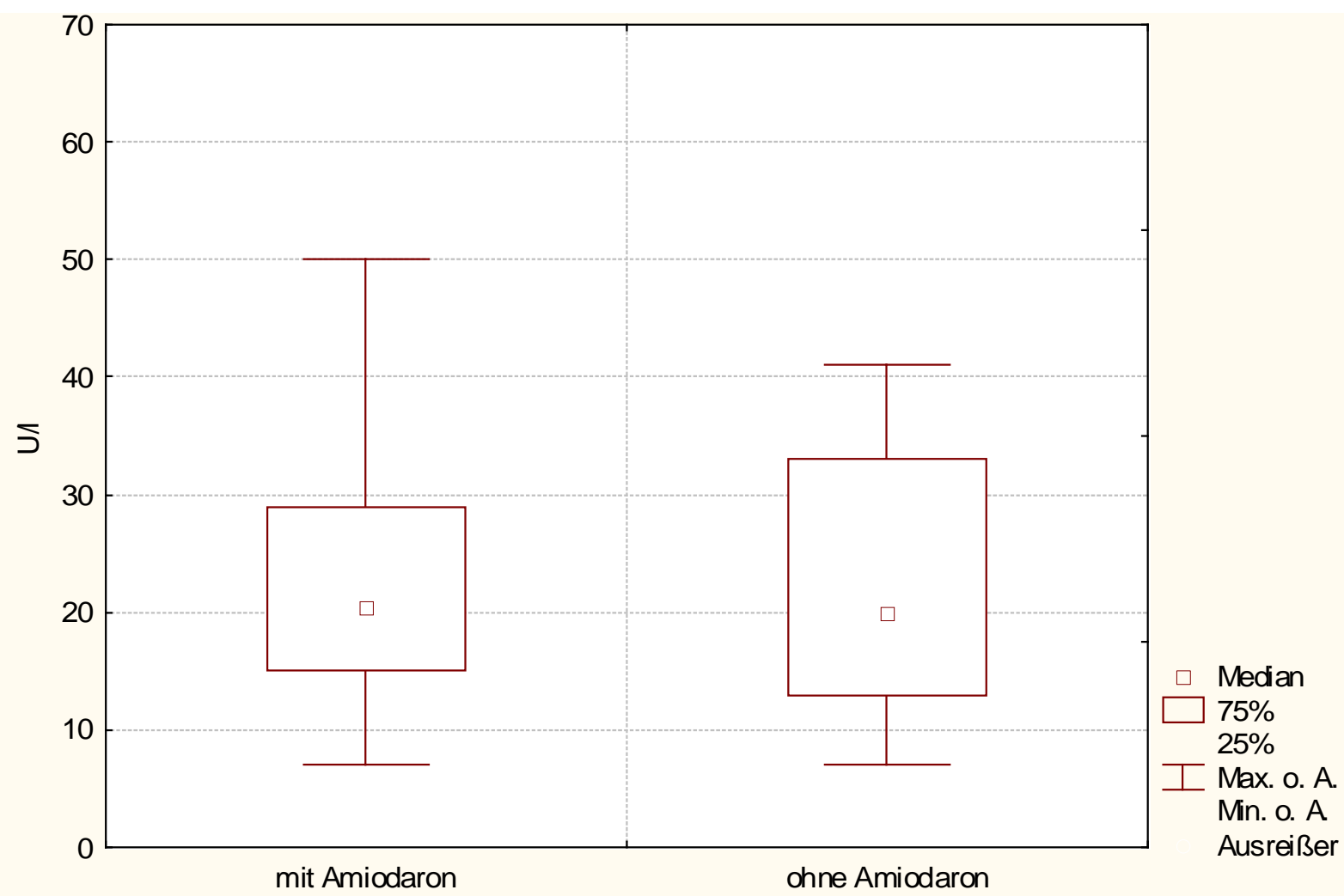

\begin{tabular}{|l|l|l|l|l|l|l|}
\hline & Mittelwert & Median & Minimum & Maximum & $\begin{array}{l}\text { Unteres } \\
\text { Quartil }\end{array}$ & $\begin{array}{l}\text { Oberes } \\
\text { Quartil }\end{array}$ \\
\hline $\begin{array}{l}\text { mit } \\
\text { Amiodaron }\end{array}$ & 23,7 & 20,5 & 7 & 61 & 15 & 29 \\
\hline $\begin{array}{l}\text { ohne } \\
\text { Amiodaron }\end{array}$ & 23,7 & 20 & 7 & 41 & 13 & 33 \\
\hline
\end{tabular}

Abb. 20 Vergleich zwischen Patientengruppen mit Amiodaron- und ohne Amiodarontherapie in Bezug auf die Gesamt-Creatinkinase im Serum. Bei der Auswertung mit Hilfe des verbundenen t-Testes ergibt sich ein Signifikanzniveau von $p=$ 0,98 und somit kein signifikanter Unterschied zwischen beiden Gruppen. 
CK-MB

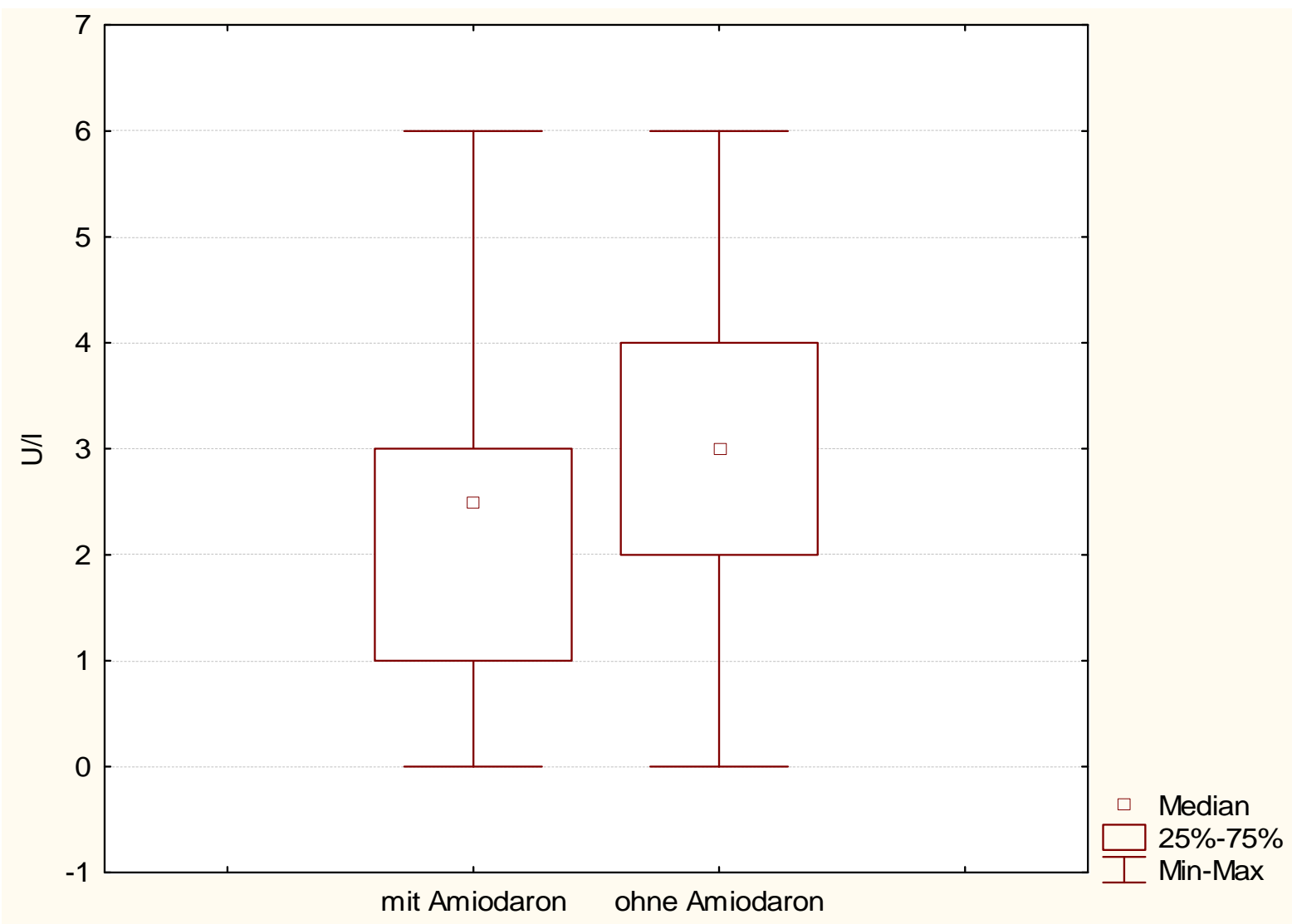

\begin{tabular}{|l|l|l|l|l|l|l|}
\hline & Mittelwert & Median & Minimum & Maximum & $\begin{array}{l}\text { Unteres } \\
\text { Quartil }\end{array}$ & $\begin{array}{l}\text { Oberes } \\
\text { Quartil }\end{array}$ \\
\hline $\begin{array}{l}\text { mit } \\
\text { Amiodaron }\end{array}$ & 2,59 & 2,5 & 0 & 6 & 1 & 3 \\
\hline $\begin{array}{l}\text { ohne } \\
\text { Amiodaron }\end{array}$ & 2,77 & 3 & 0 & 6 & 2 & 4 \\
\hline
\end{tabular}

Abb. 21 Vergleich zwischen Patientengruppen mit Amiodaron- und ohne Amiodarontherapie in Bezug auf CK-MB im Serum. Die Durchführung des verbundenen t-Testes erbringt bei einem Signifikanzniveau von $p=0,61$ keinen signifikanten Unterschied zwischen beiden Gruppen. 


\section{DISKUSSION}

Die vorliegende Arbeit untersuchte den Einfluss einer Amiodaron-Erhaltungstherapie auf organ- und gewebespezifische Antwortparameter der Schilddrüsenhormonwirkung. Anhand von Gewebekulturen und tierexperimentellen Untersuchungen wurde postuliert, dass Amiodaron und sein Hauptmetabolit Desethylamiodaron die Bindung von T3 an den nukleären Hormonrezeptor hemmen und auf diese Weise in der Peripherie eine der Hypothyreose entsprechende Wirkung entfalten (Wiersinga 2008, Paradies et al. 1991, van Beeren et al. 1995). Unsere Messergebnisse, die sich auf die Bestimmung von 13 repräsentativen Markern stützen, können diese Hypothese in der klinischen Praxis nicht überzeugend bestätigen. Im Ergebnis kam es zu keinen signifikanten Veränderungen bis auf CICP, welches wie bei hypothyreoter Stoffwechsellage reagierte und unter Amiodaronbehandlung signifikant erniedrigt war.

Knochenstoffwechsel und Bindegewebe:

CICP, ICTP, Osteocalcin und AP bzw. bone AP sind Parameter des Knochenstoffwechsels.

Dabei war es wichtig, dass Faktoren, wie das Vorkommen von Erkrankungen, welche den Knochenstoffwechsel beeinflussen, in beiden Patientengruppen ausgeschlossen wurden. So wurden Patienten mit Osteoporose sowie generell mit malignen Erkrankungen und möglichen Knochenmetastasen nicht in die Studie aufgenommen. Auch die Einnahme von Medikamenten, welche in den Knochenstoffwechsel eingreifen, wie z.B. Bisphosphonate, war in beiden Patientengruppen nicht erfolgt.

In einer Studie von Tziakas et al. von 2007 wurde festgestellt, dass ICTP bei Patienten mit Vorhofflimmern signifikant erhöht war (Tziakas et al. 2007). In unserer Studie besteht ein Übergewicht bezüglich des Vorhofflimmerns in der Patientengruppe mit Amiodaron. So gaben 8 Patienten aus der Amiodarongruppe gegenüber 1 Patienten aus der Gruppe ohne Amiodaron Vorhofflimmern in der Anamnese an. Es hätte also in Hinsicht auf das Vorhofflimmern am ehesten zu höheren Werten von ICTP in der Amiodarongruppe kommen müssen. Dies war jdoch in unserer Studie nicht der Fall, sondern es kam im Gegenteil zu tendenziell eher niedrigeren Werten in dieser Gruppe, wie dies auch bei Hypothyreose vorkommt. Denkbar wäre hier, dass das Vorhandensein von Vorhofflimmern ein signifikantes Abfallen von ICTP eher verhindert hat. Es ist hierbei allerdings zu beachten, dass bei der Angabe des Vorhofflimmerns auch intermittierendes Vorhofflimmern berücksichtigt wurde, welches möglicherweise zum Zeitpunkt unserer Untersuchung und auch durch die Therapie mit Amiodaron aktuell gar nicht vorhanden war. Ein Kontroll-EKG ist zum Zeitpunkt unserer Untersuchung nicht vorgenommen worden. 
Der einzige signifilkant veränderte Parameter war CICP, welcher in der Amiodarongruppe wie bei Hypothyreose entsprechend erniedrigt ausfiel. Die den Parameter verändernden Erkrankungen wurden in den Ausschlusskriterien berücksichtigt. Dies betraf insbesondere Faktoren die den Knochenmetabolismus beeinflussen, wie Osteoporose, M. Paget oder (metastasierende) Tumorerkrankungen. Ein Einfluss des Alters der Patienten, wie in einer Studie von Melkko et al. 1990 festgestellt wurde, konnte durch eine ausgeglichene Altersstruktur in beiden Patientengruppen ebenfalls ausgeschlossen werden. In einer Arbeit über den myokardialen Kollagen-Stoffwechsel wurde 2003 von Lombardi et al. eine Abhängigkeit von CICP von dem Vorhandensein einer HCM (hypertrophe Kardiomyopathie) festgestellt (umgekehrte Proportionalität von CICP zur diastolischen Funktion) (Lombardi et al. 2003). In unserer Studie kamen 6 Patientenpaare mit Kardiomyopathie als Grunderkrankung vor mit gleichmäßiger Verteilung über beide Patientengruppen. Es handelte sich bei diesen Studienteilnehmern jedoch nicht um eine hypertrophische Kardiomyopathie, sondern um eine dilatative Kardiomyopathie. Die dokumentierte Ejektionsfraktion zeigte für beide Gruppen vergleichbare Werte. Weitere Funktionsparameter wie der LVEDD (linksventrikuläre enddiastol. Durchmesser) wurden nicht dokumentiert.

PIIINP ist Bestandteil von Bindegewebe. Bekanntermaßen haben Geschlechts- und Altersunterschiede einen Einfluss auf PIIINP, wie sie in unserer Studie ausgeschlossen wurden. Hinsichtlich der Antwortparameter CICP, ICTP Osteocalcin und PIIINP gibt es bezüglich des Einflusses von Amiodaron keine Literatur.

\section{Leber und Lipide:}

Beim SHBG ist in der Literatur bereits eine Untersuchung von Bambini et al. mit Amiodaron durchgeführt worden (Bambini et al. 1987). Dabei kam es unter Amiodaron zu einem signifikanten Anstieg. Dieser Anstieg ging allerdings mit dem Auftreten einer Hyperthyreose einher, wie sie in unserer Studie ausgeschlossen wurde.

Bezüglich der Alkalischen Phosphatase sowie des Albumins und Cholesterins sind ebenfalls bereits Untersuchungen mit Amiodaron sowohl als Tierversuch an Ratten als auch am Menschen durchgeführt worden. In einer Untersuchung von Pollak und Shafer von 2004 wurden Patienten mit einer Amiodaron-Dauermedikation von 200-400 mg/d, also der üblichen Erhaltungsdosis, über einen Zeitraum von 5 Jahren auf hepatische Effekte geprüft. Es wurden dabei auch AP und Albumin als Kontrollparameter in die Studie aufgenommen. Ein signifikantes Ergebnis erbrachten diese Parameter allerdings auch nicht. Lediglich ALT und AST reagierten signifikant, was auf toxische Effekte von Amiodaron zurückzuführen ist (Pollak und Shafer 2004). 
In einem In-vivo-Versuch mit Ratten hingegen wurden in der Arbeitsgruppe von Morales et al. renal-toxische Effekte von Amiodaron untersucht. Hier kam es unter hoher Dosierung von $50 \mathrm{mg} / \mathrm{kg} \mathrm{KG} \mathrm{zu} \mathrm{Nierenschädigungen} \mathrm{mit} \mathrm{deutlichem} \mathrm{Kreatinin-Anstieg.} \mathrm{Unter} \mathrm{diesen} \mathrm{hohen}$ Dosen von Amiodaron war dann auch ein signifikanter AP-Anstieg zu verzeichnen (Morales et al. 2003). Auch hier mögen toxische Einflüsse überwogen haben.

Auch die Auswirkungen einer Amiodarontherapie auf das Cholesterin im Plasma wurden bereits in Studien untersucht. In einer Studie von Hudig et al. an Ratten wurde eine Cholesterinerhöhung im Plasma von $69 \%$ festgestellt. Es wurde auch hier mit hohen Dosierungen von $100 \mathrm{mg} / \mathrm{kg} \mathrm{KG}$ gearbeitet (Hudig et al. 1998).

In einer entsprechenden Untersuchungen am Menschen durch Pollak und Tan sowie Lakhdar et al. wurden jedoch ebenfalls signifikante Anstiege des Gesamtcholesterins gemessen. Bei Pollak und Tan wurde eine Amiodaron-Dosierung von $400 \mathrm{mg} / \mathrm{d}$ verabreicht, also eine doppelt so hohe Dosierung im Vergleich zu unserer Studie. Der Untersuchungszeitraum lag bei 18 Monaten und es waren 18 Patienten beteiligt. Die Studienbedingungen waren vergleichbar mit unserer Studie. Die Patienten lagen vorher bezüglich des Cholesterins und auch bezüglich der Schilddrüsenwerte im Normbereich (Pollak und Tan 1999).

Lakhdar et al. verwendeten bei ebenfalls vergleichbaren Versuchsbedingungen Dosierungen von nur 100-200 mg/d, was einer Dosierung wie in unserer Studie entspricht. Beachtenswert ist, dass auch hier in der Patientengruppe mit Amiodarontherapie signifikant erhöhte Cholesterinwerte gemessen wurden. Eine mögliche Ursache für die Diskrepanz zu unserer Untersuchung besteht in der Tatsache, dass unsere Probanden bei Blutabnahme nicht nüchtern waren. Die von Lakhdar et al. gemessenen Unterschiede zwischen den Patientengruppen waren zwar signifikant aber doch eher gering, so das diese Unterschiede bei unseren Patienten nicht mehr signifikant ausfielen. $\mathrm{Zu}$ beachten ist auch, dass bei Lakhdar et al. die signifikant ausgefallenen Ergebnisse nach Amiodaroneinnahmedauer von 6 Monaten bereits nach einer Einnahmedauer von 9 Monaten wieder deutlich sinkend waren. Messungen zu noch späteren Zeitpunkten wurden dabei nicht vorgenommen. Möglicherweise lässt der Effekt des steigenden Cholesterinspiegels bei langfristiger Einnahme von Amiodaron wieder nach und folglich ein Anstieg des Cholesterins in signifikanter Ausprägung nur kurzfristig besteht. (Lakhdar et al. 1991).

Vom Ferritin im Serum in Verbindung mit einer Amiodarontherapie existieren in der Literatur keine relevanten Untersuchungen.

\section{Herz und Muskelstoffwechsel:}

Die Creatinkinaseaktivität im Serum spiegelt insbesondere Erkrankungen der Skelettmuskulatur und des Herzens wider. In Bezug auf die Wirkung von Amiodaron auf den 
Muskelstoffwechsel, einschließlich des Herzmuskels, in Zusammenhang mit einer erhöhten CK-Aktivität ist in der Literatur nur wenig beschrieben. Es handelt sich dabei um die Ausbildung einer Myopathie oder Rhabdomyolyse durch HMG-CoA-Reduktase-Inhibitoren, meist in Verbindung mit Statinen oder mit sehr hohen Amiodarondosierungen (400 mg /d) (Itoh et al. 1998, McKelvie et Dennett 2002, Roten et al. 2004). Die CK wäre in solch einem Fall deutlich erhöht, was bei unseren Studienteilnehmern nicht der Fall war. Ein zu erwartender Aktivitätsanstieg der CK oder CK-MB, wie es auch bei hypothyreoter Stoffwechsellage vorkommt, war in der Patientenguppe mit Amiodaron nicht zu verzeichnen. Da das Ergebnis unserer Studie insgesamt eher nicht den Erwartungen aus bisherigen Untersuchungen entspricht, ist es hilfreich, die bisher durchgeführten Untersuchungen zum kompetitiven und nicht-kompetitiven Antagonismus von Amiodaron bzw. DEA am T3Rezeptor zu betrachten. Dies waren Gewebekulturen und Tierexperimente, hauptsächlich an Ratten. Dabei sind bezüglich des geringen Körpergewichts der Ratten sehr hohe Dosierungen verabreicht worden. Es wurden Ratten mit Amiodarondosierungen von mind. $50 \mathrm{mg} / \mathrm{kg} \mathrm{KG}$ in die Studien einbezogen. Eine niedrigere Dosierung in einer Studie von Wiegand et al. von 1986 zeigte den hypothyreose-ähnlichen Effekt durch die Einwirkung von Amiodaron am Herzmuskel von Ratten. Es wurde dabei Isomyosin gemessen, welches bereits unter einer Amiodarondosierung von $15 \mathrm{mg} / \mathrm{kg} \mathrm{KG}$ signifikant reagierte. Aber auch diese Dosierung entspricht immer noch mindestens der fünffachen Dosis, gemessen an der Amiodarondosierung, welche unsere Probanden erhielten.

Auch die wenigen Untersuchungen, welche an Probanden durchgeführt wurden (Studie von Pollak und Tan mit 400 mg Amiodaron/Tag), waren bis auf die Studie von Lakhdar et al. deutlich höher mit Amiodaron dosiert, als unsere Probanden.

Wie von Bogazzi et al. 2001 festgestellt wurde, antagonisiert nicht Amiodaron selbst, sondern der Metabolit Desethylamiodaron in hohen Konzentrationen die Aktivität von T3 auf molekularer Ebene in Bezug auf eine Bindung am peripheren Schilddrüsenhormonrezeptor (Bogazzi et al. 2001).

Auch Bakker et al. stellten bereits 1994 fest, dass Desethylamiodaron und nicht Amiodaron selbst als ein nicht-kompetitiver Antagonist auf die Beta-T3-Rezeptoren wirkt (Bakker et al.1994).

Es ist nun wichtig zu wissen, in welchem Maße Amiodaron zu Desethylamiodaron im menschlichen Organismus im Vergleich zur Ratte metabolisiert wird. In einer Studie von Plomp et al. von 1987 erhielten Ratten eine Einmaldosis von 100 mg / kg KG oral. Der nach 
24 h gemessene Desethylamiodaronspiegel im Serum ergab 30-60 ng/ml. Im Vergleich dazu existiert eine Studie ebenfalls von Plomp et al. von 1984, in welcher Probanden eine einmalige orale Dosis von $400 \mathrm{mg} / \mathrm{d}$ verabreicht bekamen. Der danach gemessene Desethylamiodaronspiegel betrug nur $10 \mathrm{ng} / \mathrm{ml}$. Dies zeigt, dass bei Ratten unter einer höheren Amiodarondosierung auch tatächlich mehr Desethylamiodaron im Organismus und damit auch am peripheren Schilddrüsenhormonrezeptor zur Verfügung steht. Es zeigt aber auch, dass quanitative Unterschiede in der Metabolisierung von Amiodaron zwischen Ratte und Mensch bestehen (Plomp et al. 1984, Plomp et al. 1987).

Dass ein Effekt am Herzen über den Mechanismus des T3-Antagonismus abläuft, wurde auch in einer Untersuchung von Wiersinga von 2008 nachgewiesen. Die T3-Konzentrationen im Herzen der Ratten lagen bei den mit Amiodaron behandelten Tieren um das 4fache niedriger als in der Vergleichsgruppe ohne Amiodaron. Auch diese Untersuchung wurden mit Ratten durchgeführt, welche im Vergleich zu unserer Studie deutlich höhere AmiodaronDosierungen erhielten (100mg/kg/d per os) (Wiersinga 2008).

Eine sichere Klärung der Hypothese, dass der klinische Effekt von Amiodaron am Herzen über den Mechanismus des T3-Antagonismus verläuft, würde direkte intrakardiale Untersuchungen der T3-Konzentrationen sowie der T3-Bindung am Rezeptor erfordern.

Das Fehlen signifikanter Reaktionen der gemessenen Surrogat-Parameter in der vorliegenden Studie widerspricht nicht dem bereits bekannten Antagonismus von Amiodaron bzw. DEA an den T3-Rezeptoren. Möglicherweise waren die Dosierungen von Amiodaron in der vorliegenden Studie nicht hoch genug, um einen Antagonismus und damit Hypothyreoseähnliche Stoffwechsellagen an peripheren Zellen messbar zu machen. 


\section{ZUSAMMENFASSUNG}

Amiodaron ist ein hochpotentes Antiarrhythmikum, welches bei schweren, therapieresistenten ventrikulären Arrhythmien, aber auch bei Vorhofflimmern und Reentrytachykardien eingesetzt wird.

Bezüglich des antiarrhythmogenen Effektes findet sich eine Verlängerung der Repolarisationszeit, wie bei Hypothyreose. Da das Molekül von Amiodaron und das seines Hauptmetaboliten Desethylamiodaron in seiner räumlichen Struktur eine gewisse Ähnlichkeit mit Thyroxin bzw. Trijodthyronin haben, besteht die Hypothese, dass Amiodaron und Desethylamiodaron als Antagonisten an den peripheren Schilddrüsenhormonrezeptoren wirken und den antiarrhythmogenen Effekt sozusagen über eine Organhypothyreose verursachen. Tierexperimentelle Untersuchungen unterstützen diese Hypothese.

Es wurde nun in einer Querschnittsstudie an insgesamt 44 männlichen ambulanten Patienten mit einem AICD-Aggregat untersucht, ob sich Veränderungen an organ- oder gewebsspezifischen Antwortparametern der Schilddrüsenhormonwirkung nachweisen lassen. Einer Gruppe von 22 Patienten mit Amiodarontherapie (200mg/d Erhaltungstherapie) wurde eine vergleichbare Gruppe von 22 Patienten ohne Amiodarontherapie gegenübergestellt. Untersucht wurden 13 Laborparameter, welche den Stoffwechsel der unterschiedlichen Gewebe repräsentieren. Diese waren für das Knochen- und Bindegewebe: CICP, ICTP, AP, bAP, Osteokalzin, PIIINP, für Leber und Lipide: SHBG, GGT, Ferritin, Albumin, Cholesterin und für Muskel bzw. Herz: CK, CK-MB.

Im Ergebnis erbrachte der Knochenaufbauparameter CICP als einziger Antwortparameter einen signifikanten, für die hypothyreote Stoffwechsellage typischen Unterschied zur Kontrollgruppe $(\mathrm{p}=0,02)$. Alle übrigen Parameter zeigten keine signifikanten Veränderungen. Schlussfolgerung: Unter einer Erhaltungstherapie mit $200 \mathrm{mg}$ Amiodaron konnte in der klinischen Praxis anhand der verwendeten Surrogat-Parameter keine überzeugende Veränderung des peripheren Schilddrüsenhormonstoffwechsels gefunden werden. 


\section{LITERATURVERZEICHNIS}

ABRAMS JJ, GRUNDY SM (1981): Cholesterol metabolism in hypothyroidism and hyperthyroidism in man. J Lipid Res $\underline{22}$ (2), 323-338

Adams PC, Holt DW, Storey GC, Morley AR, Callaghan J, Campbell RW (1985): Amiodarone and its desethyl metabolite: tissue distribution and morphologic changes during long-term therapy. Circulation $\underline{72}, 1064-75$

Akalin A, Colak O, Alatas O, EFe B (2002): Bone remodelling markers and serum cytokines in patients with hyperthyroidism. Clin Endocrinol (Oxf) $\underline{57}$ (1), 125-9

Arrago JP, Poirier O, Chomienne C, D’Agay MF, Najean Y (1986): Type III aminoterminal propeptide procollagen in some haematological malignancies. Scand J Haematol $\underline{36}$, 288-294

AZIZI F (1982): Gamma-glutamyl-transpeptidase levels in thyroid disease. Arch Intern Med $\underline{142}(1), 79-81$

BAKKER O, VAN BEEREN HC, WIERSINGA WM (1994): Desethylamiodarone is a noncompetitive inhibitor of the binding of thyroid hormone to the thyroid hormone 1-receptor protein. Endocrinology 134, 1665-1670

Bambini G, Aghini-Lombardi F, Rosner W, Khan MS, Martino E, Pinchera A, BRAVERMAN LE, SAFRAN M (1987): Serum sex hormone-binding globulin in amiodaronetreated patients. A marker for tissue thyrotoxicosis. Arch Intern Med 147(10), 1781-5

BAstenie PA (1972): Thyroide et Lipides Plasmatiques. Acta Cardiol. Suppl. XV , 50

BEEREN VAN HC, BAKKER O, WIERSINGA WM (1995): Desethylamiodarone is a competitive inhibitor of the binding of thyroid hormone to the thyroid hormone alpha 1-receptor protein. Mol Cell Endocrinol 112(1), 15-19

BEEREN VAN HC, BAKKER O, CHATTERJEE VK, WIERSINGA WM (1999): Effect of mutations in the beta 1-thyroid hormone receptor on the inhibition of T3 binding by desethylamiodarone. FEBS Lett. $\underline{450}$ (1-2), 35-38

BEEREN VAN HC, BAKKER O, WIERSINGA WM (2000): Desethylamiodarone interferes with the binding of co-activator GRIP-1 to the beta1-thyroid hormone receptor. FEBS Lett $\underline{481}(3)$, 213-216

Beyer IW, Karmali R, Demeester-Mirkine N, Cogan E, Fuss MJ (1998): Serum creatine kinase levels in overt und subclinical hypothyroidism. Thyroid $\underline{8}$ (11), 1029-31

Blomqvist C, ElomaA I, VirkKunen P, PorkKa L, Karonen S-L, Risteli L, Risteli J (1987): Response evaluation of bone metastases in mammary carcinoma. The value of radiology, scintigraphy und biochemical markers of bone metabolism. Canner $\underline{60}, 2907$

BlomQVist C, Risteli L, Risteli J, VirkKunen P, SARna S, ElomaA I (1996): Markers of type I collagen degradation und synthesis in the monitoring of treatment response in bone metastases from breast carcinoma. Br J Cancer 73(9), 1074-9

Bogazzi F, Bartalena L, Brogioni S, Burelli A, Raggi F, Ultimieri F, Cosci C, Vitale M, FenZi G, MARTINo E (2001): Desethylamiodarone antagonizes the effect of thyroid hormone at the molecular level. Eur J Endocrinol 145 (1), 59-64

BOLARIN DM, SAVOLAINEN E-R, KIVIRIKKo Kl (1982): Enzymes of collagen biosynthesis and type III procollagen aminopropeptide in serum from Nigerians with hepatocellular carcinoma and other malignant diseases. Int J Cancer $\underline{29}$, 401-405 
Bond A, DAVIS C (1987): Sex hormone binding globulin in clinical perspektive. Acta Obstet Gynecol Scand $\underline{66}, 255-262$

BRENT GA (1994): The molecular basis of thyroid hormone action. New Engl J Med $\underline{331}$, $847-854$

BudDECKE E: Grundriß der Biochemie: für Studierende der Medizin, Zahnmedizin und Naturwissenschaften. 7. Auflage; Walter de Gruyter Verlag, Berlin 1984; S.331 f./ S.236 ff

Burger A, Dinicheret D, Nicod P, JENny M, LEMARCHAND-Beraud T, VALloton MB (1976): Effect of amiodarone on serum triiodothyronine, reverse triiodothyronine, thyroxin and thyrotropin. J Clin Invest $\underline{58}$, 255-59

Burnett JR, CRoOKe MJ, Delahunt JN, FeEK CM (1994): Serum enzymes in hypothyroidism. N Z Med J 107(985), 355-6

Charhon SA, Delmas PD, Malaval L, Chavassieux PM, Arlot M, Chapuy MC, MeUNIER PJ (1986): Serum bone Gla-protein in renal osteodystrophy: comparison with bone histomorphometry. J Clin Endocrinol Metab $\underline{63}$, 892-897

CHARLIER R (1962): Recherche dans la serie des benzfurannes.VII.Etude pharmacologique preliminaire du butyl-2(diiodo-3`,5-B-N-diethylaminoethoxy-4`benzoyl)-3-benzfuranne. Arch Int Pharmacodyn 139, 255-62

ChArrie AM, Fleury-Goyon MC, Dutey P, Tourniaire J (1986): Procollagen-III peptide and hyperthyroidism. Lancet 1986, II, 1221

Ciba Corning ACS ${ }^{\text {TM }}$ T3 Gebrauchsinformation, Ciba Corning, Fernwald 1994

Ciba Corning ACS ${ }^{\text {TM }}$ FT4 Gebrauchsinformation, Ciba Corning, Fernwald 1994

Ciba Corning ACS ${ }^{\mathrm{TM}}$ TSH Gebrauchsinformation, Ciba Corning, Fernwald 1995

Civitelli R, Gonnelli S, Zacchei F, Bigazzi S, Vattimo A, Avioli LV, Gennari C (1988): Bone turnover in postmenopausal osteoporosis: effect of calcitonin treatment. J Clin Invest $\underline{82}, 1268-74$

Colombo M, Annoni G, Donato MF, Conte D, Martines D, Zaramella MG, Bianchi PA, PIPERNO A, TIRIBELLI C (1985): Serum type III procollagen peptide in alcoholic liver disease and idiopathic hemocroma- tosis: its relationship hepatic fibrosis, activity ot the disease and iron overload. Hepatology $\underline{5}, 475-479$.

Conti A, Monzani M, Persani L, SARTorio A (1994): Serum levels of the carboxyterminal telopeptide of type I collagen in patients with thyroid disorders. Minerva Endocrinol 19 (3), 127-31

Couzigou P, latapie Jl, Fleury B, Climas mt, Le Moigne F, Crockett E, Sauneron MF, Richard-MOLARD B, AMOURETTI M, BERAUd C (1984): [Evolution of serum gammaglutamyl transpeptidase activity in treated hyperthyroid and hypothyroid patients] Gastroenterol Clin Biol $\underline{8}$ (5), 458-63

Cullberg G, Dovre PA, Lindstedt G, StefFensen K (1982): On the use of plasma proteins as indikators of the metabolic effects of combined oral contraceptives. Acta Obstet Gynecol Scand Suppl 111, 47-54.

Cunningham SK, Loughlin T, Culliton M, McKenna TJ (1985): The relationship between sex steroids und sex-hormone-binding globulin in plasma in physiological und pathological conditions. Ann Clin Biochem 22, 489-97 
DARling DS, BeEbe JS, BuRnside J, Winslow ER, ChIN WW (1991): 3,5,3`triiodthyronine (T3) receptor auxiliary protein (TRAP) binds DNAand forms heterodimers with the T3 receptor. Mol Endocrinol $\underline{5}$ (1), 73-84

Demiaux B, Arlot ME, Chapuy MC, Meunier PJ, Delmas PD (1992): Serum osteocalcin is increased in patients with osteomalacia: correlations with biochemical and histomorphometric findings. J Clin Endocrinol Metab 74, 1146-51

Drvota V, Carlsson B, Haggblad J, Sylven C (1995): Amiodarone is a dose-dependent noncompetitive und competitive inhibitor of $\mathrm{T} 3$ binding to thyroid hormone receptor subtype beta 1 , whereas disopyramide, lignocaine, propafenone, metoprolol dl-sotalol and verapamil have no inhibitory effect. J Cardiovasc Pharmacol 26(2), 222-226

Duda RJ, O’Brien JF, Katzmann JA, Peterson JM, Mann KG, Riggs BL (1988): Concurrent assays of circulating bone Gla- protein and bone alkaline phosphatase: effects of sex, age, and metabolic bone disease. J Clin Endocrinol Metab 6, 951-967

ECKERTH HU: Schilddrüsenhormone und Lipidstoffwechsel: Eine Übersicht und neue Ergebnisse. Med. Diss. Düsseldorf 1982

EKENSTAM EA, LJUNGHALL S, HÄLLGREN R (1986): Serum osteocalcin in rheumatoid arthritis and other inflammatory arthritides: relation between inflammatory activity and the effect of glucocorticoids and remission inducing drugs. Ann Rheum Dis $\underline{45}, 484-490$

ElomaA I., VirkKunEN P., Risteli L., Risteli, J.(1992): Serum concentration of the crosslinked carboxyterminal telopeptide of type I collagen (ICTP) is useful prognostic indicator in multiple myeloma. Br J Cancer 66, 337-341

ERIKSEN EF, BRIXEN K, CHARLES P (1995): New markers of bone metabolism: clinical use in metabolic bone disease. Eur J Endocrinol 132, 251-63

ERIKSSON S and ZETTERVALL O (1986): The N-terminal propeptide of collagen type III in serum as a prognostic indikator in primary billiary cirrhosis. $\mathrm{J}$ Hepatol $\underline{2}, 370-378$

Eroglu A, Demirci S, Akbay A, Sungurroglu K (2000): Correlation between tissue levels of carboxy-terminal propeptide of Type I procollagen and clinicopathological characteristics in human colorectal cancer. Hepatogastroenterology 47 (34), 1006-10

EVANS RM (1988): The steroid and thyroid hormone receptor superfamily. Science 240, 889895

Fachinformation Sanofi Cordarex Infusionslösung, Berlin 1998

FESSLER JH, FESSLER LI (1978): Biosynthesis of Collagen. Ann Rev Biochem 47, 129-162

Földes J, TARJan G, Banos CS, Nemeth J, VARGa F, BÜKi B (1992): Biologie markers in blood reflecting thyroid hormone effect at peripheral tissue level in patients receiving levothyroxine replacement for hypothyroidism. Exp Clinical Endocrinol 99, 129-133

FRANKLYN JA, ShEPPARD MC (1993): Amiodarone and Thyroid Dysfunction. Trends Endocrinol Metab $\underline{4}, 128-131$

Franklyn JA, Davis JR, Gammage MD, LitTler WA, RAmsden DB, Sheppard MC (1985): Amiodarone and thyroid hormone action. Clin Endocrinol 22, 257-264

Garnero P, VAssy V, Bertholin A, Riou JP, Delmas PD (1994): Markers of Bone Turnover in Hyperthyroidism and the Effects of Treatment. J Clin Endocrinol Metab $\underline{78}$, 955-959

Gebrauchsinformation: Prolagen C-96 assays for the C-terminal Propeptide of Type 1 Collagen, Metra Biosystems, Inc. 265 North Whisman Road Mountain View, USA 1999 
Griesmacher A, Peichl P, Pointinger P, Mateau R, Broll H, Hartl W, Gruber W (1997): Biochemical markers in menopausal women. Scand J Clin Lab Invest Suppl 227, 6472

GundBerg CM, MARKowitz ME, Mizruchi M, Rosen JF (1985): Osteocalcin in human serum: a circadian rhythm. Clin Endocrinol Metab $\underline{60}, 736-9$

Hakala M, Risteli L, Manelius J, Nieminen P, Risteli J (1993): Increased type I collagen degradation correlates with disease severity in rheumatoid arthritis. Ann Rheum Dis $\underline{52}$ (12), 866-869.

Haukipuro K, MelkKo J, Risteli L, Kairaluoma M, Risteli J (1991): Synthesis of type I collagen in healing wounds in humans. Ann Surg 213(1), 75-80

HEUFELDER AE , WIERSINGA WM (1999): Störungen der Schilddrüsenfunktion durch Amiodaron: Pathogenese, Diagnostik und Therapie. Dtsch Ärztebl 96(13), A-853-860

Hochweiss A, Fruchtman S, Hahn EG, Gilbert H, Donovan PB. Johnson J, Goldberg JD, BERK PD (1983): Increased serum procollagen III aminoterminal peptide in myelofibrosis. Am J Hematol 15, 343-351

HÖRMANN R: Schilddrüsenkrankheiten: Leitfaden für Praxis und Klinik. Blackwell Wissenschafts-Verlag, Berlin 1997

HUdig F, BAKKER O, WIERSINGA WM (1998): Amiodarone decreases gene expression of low-density lipoprotein receptor at both the mRNA and the protein level. Metabolism $\underline{47}$ (9),1052-57

HÜFNER M, GRUSSENDORF M (1980): Studies on the deiodination of 3,3',5'-T3 (reverse T3) to 3,3'-T2 (diiodthyronine) in rat liver. Acta Biol Med Ger 39(2-3), 169-75

Imai T, Honda M, Maeda S, Hosoya Y, Arai T, Sumi S, Umeda H, Yano M, Koga F, ARAI K, YOSHIDA K (1998): [Studies of type I collagen related substances as bone metastatic markets of prostate carcinoma with special regard to serum carboxyterminal propeptide of type I . Procollagen (PICP), cross-linked carboxyterminal telopeptide of type I collagen (ICTP) and Urinary deoxypyridinoline levels ]. Nippon Hinyokika Gakkai Zasshi $\underline{89}$ (4), 48491

IMMULITE Osteocalcin, Diagnostic Products Corporation, Los Angeles 1999

IMMULITE SHBG Gebrauchsinformation EURO/DPC, Los Angeles 1999

IтOH K, KAто R, HotTA N (1998): A case report of myolysis during high- dose amiodarone therapy for uncontrolled ventricular tachycardia. Jpn Circ J 62 (4), 305-308

JANSSEN OE (1998): Resistenz gegen Schilddrüsenhormone. Internist 39, 613-618

KALTWASSER JP: Ferritin. In: Labor und Diagnose. hrsg v. Thomas L; TH-Books Verlagsgesellschaft mbH, Frankfurt/Main 2000, 285-288

Kaspar D, Seidl W, Neidlinger-Wilke C, Iqnatius A, Claes L (2000): Dynamic cell stretching increases human osteoblast proliferation and CICP synthesis but decreases osteocalcin synthesis and alkaline phosphatase activity. J Biomech $\underline{33}$ (1), 45-51

KAtes RE, KANNAN R, Singh BN: Pharmacokinetics of Class III Antiarrhythmic Agents. In: Control of Cardiac Arrhythmias by Lengthening Repolarization. hrsg. v. SINGH BN Futura Pub.Co., New York 1988, 175

Kaufmann C, Cron TA, Meier C, Staub JJ, Oberholzer M, Osswald S (2000): Amiodaron- induzierte Hyperthyreose. Schweiz Med Wochenschr 130, 1610-1617 
KaupPila A, Puistola U, Risteli J, Risteli L (1989): Aminoterminal propeptide of type III procollagen: a new prognosis indicator in ovarian cancer. Cancer Res $\underline{49}, 1885$

Klinikleitfaden Labordiagnostik; Urban \& Fischer Verlag, München 2000

Kohda K, Ito N, Ohwada M, Morita K, Watanabe N, Kohgo Y, Mogi Y, Niitsu $\mathrm{Y}(1991)$ : Diagnostic value of measurement of serum type I procollagen carboxy terminal peptides in patients with scirrhous carcinoma of the stomach. Gut 32(6), 624-9

KrUSE K, KRACHT U,Wohlfart K, KRUSE U (1989): Biochemical markers of bone turnover, intact serum parathyroid hormone and renal calcium excretion in patients with pseudohypoparathyroidism and hypoparathyroidism before and during vitamin D treatrnent. Eur J Point 148, 535-539

Kucharz EJ, Jurecka-Tuleja B, Jonderko G, Marcisz C (1994): Serum amino-terminal propeptide of type III collagen in patients with hyperthyroidism or hypothyroidism during therapy. Thyroid 4 (2),191-194

Kylmälä T, TAmmela T, Risteli J, Risteli L, TAube T, ElomaA I (1993): Evaluation of the effect of oral clodronate on skeletal metastases with type I collagen metabolites. A controlled trial of the Finnish Prostate Cancer Group. Eur J Cancer 29A, 821-825

LAKHDAR AA, FARISH E, HILlis WS, DUNN FG (1991): Long- term amiodarone therapy raises serum cholesterol. Eur J Clin Pharmacol 40, 477-480

LALLOZ MR, BYField PG, GREENWOOd RM, HiMsworTh RL (1984): Binding of amiodarone by serum proteins and the effects of drugs, hormones and other interacting ligands. $\mathrm{J}$ Pharm Pharmacol 36(6), 366-72

LAPidus L, Lindstedt G, LundBerg PA, Bengtsson C, Gredmark T (1986): Concentrations of sex-hormone binding globulin and corticosteroid binding globulin in serum in relation to cardiovascular risk factors and to 12-year incidence of cardiovascular disease and overall mortality in postmenopausal women. Clin Chem $\underline{32}$, 146-52

LATHAM KR, SELLITTI DF, GoldSTEIN RE (1987): Interaction of amiodarone and desethylamiodarone with solubilized nuclear thyroid hormone receptors. J Am Coll Cardiol 9(4), 872876

LAZAR MA (1993): Thyroid hormone receptors: multiple forms, multiple possibilities. Endocrinol Rev $\underline{14}$, 184-93

LEE WY (1997): Tris(2,2-bi-pyridyl)Ruthenium(II)electrogenerated Chemiluminescence in analytical science. Mikrochemica Acta 127, 19-39

LeWAlter T, Schrickel J, SHLEVkov N, LÜDERITZ B (2002): Kardiale Effekte von Amiodaron: Unter besonderer Berücksichtigung der QT- Verlängerung und des Torsade-depointes- Risikos. Dtsch Arztebl 99(30), A2040-2046

Lieberman MW, BARrios R, CARTer BZ, Habib GM, Lebovitz RM, RAJAGOPalan S, SEPUlVEDA AR, SHI ZZ, WAN DF (1995): Y-glutamyl transpeptidase. What does the organisation and expression of a multipromoter gene tell us about its Functions? Am J Pathol 147, $1175-85$

Lindstedt G, Lundberg PA, HAMmOnd GL, Vihko R (1985): Sex hormone-binding globulin - still many questions. Scand J Clin Lab Invest $\underline{45}, 1-6$

LOMBARdi R, Betocchi S, Losi MA, TOCChetTi CG, AVERSA M, Miranda M, D’Alesandro G, CACACE A, Ciampi Q, Chiariello M (2003): Myocardial collagen turnover in hypertrophic cardiomyopathy. Circulation 108, 1455-1460 
Loviselli A, Mastinu R, Rizzolo E, Massa GM, Velluzzi F, Sammartano L, Mela Q, MARIOTTI S (1997): Circulating telopeptide type I is a peripheral marker of thyroid hormone action in hyperthyroidism and during levothyroxine suppressive therapy. Thyroid $\underline{7}$ (4), 5616

Low RB, Cutroneo KE, DAvis GS, Gianicola MS (1983): Lavage type III procollagen Nterminal peptides in human pulmonary fibrosis and sarcoidosis. Lab Invest $\underline{48}$, 755-759.

LUKeRT BP, Higgins JC, StOSKopf MM (1986): Serum osteocalcin is increased in patients with hyperthyroidism and decreased in patients receiving glucocorticoids. J Clin Endocrinol Metab $\underline{62}, 1056-1058$

Martino E, Aghini- Lombardi F, Bartalena L, Grasso L, Lovielli A, Velluzzi F, PinCHERA A, BRAVERMANN LE (1994): Enhanced susceptibility to amiodarone- induced hypothyroidism in patients with thyroid autoimmune disease. Arch Intern Med 154, 2722-6

Martino E, Safran M, Aghini-Lombardi F, Rajatanavin R, LenZiardi M, FAy M, PaCCHIAROtTI A, ARONIN N, MACCHIA E, HAFFAJEE C et al. (1984): Environmental iodine intake and thyroid dysfunction during chronic amiodarone therapy. Ann Intern Med 101(1), 28-34

McKelvie PA, DennetT X (2002): Myopathie Associated With HMG-CoA Reductase Inhibitors (Statins): A Series of 10 Patients and Review of the Literature. J Clin Neuromuscul Dis $\underline{3}(4), 143-8$.

Melkko J, NiEMI S, Risteli L, Risteli J (1990): Radioimmunoassay of the carboxyterminal propeptide of human type I procollagen. Clin Chem 36(7), 1328-32

Merle B, Delmas PD (1990): Normal carboxylation of circulating osteocalcin (bone Glaprotein) in Paget's disease of bone. Bone Miner 11, 237-45

Morales Ai, Barata JD, Bruges M, Arevalo MA, Gonzales de Buitrago JM, Palma P, BRANCO P, PEREZ-BARRIOCANAL F (2003): Acute renal toxic effect of amiodarone in rats. Pharmacol Toxicol 92(1), 39-42

NATTER S, TALAJIC M (1988): Recent Advances in Understanding the Pharmacology of Amiodarone. Drugs 36, 121-131

Newman CM; Price A; Davies DW; Gray TA; WeEtMan AP (1998): Amiodarone und the thyroid: A practical guide to the management of thyroid dysfunction induced by amiodarone therapy. Heart $\underline{79}, 121-127$

Newnham HH, Topliss DJ, Le Grand BA, Chosich N, Harper RW, Stockigt JR (1988): Amiodarone-induced hyperthyroidism: assessment of the predictive value of biochemical testing and response to combined therapy using propylthiouracil and potassium perchlorat. Aust N Z J Med 18 (1), 37-44

Nolte W, MÜller R, HÜFNER M (1995): Treatment of iodine-induced hyperthyroidism. Possibilities and limits of pharmacotherapie. Med Klin $\underline{90}$ (4), 246-53

Nyström E, CAidahl K, Fager G, Wikkelsö C, Lundberg PA, Lindstedt G (1988): A doubble-blind cross-over 12 month study of L-Thyroxine treatment of women with "subclinical" hypothyroism. Clin Endocrinol 29, 63-76

Ogawa K, Naritaka Y, Katsube T, Ohtani Y, Yagawa H, Kajiwara T (1994): Clinical studies of type-I procollagen carboxyterminal peptide in serum of patients with gastric cancer: comparison with CEA and CA19-9. J Gastroenterol 29 (3), 250-6

OPPENHEIMER JH, SCHWARTZ HL, STRAIT KA (1996): The molecular basis of thyroid hormone action. In: Werner and Ingbar's the thyroid: a fundamental- and clinical text. hrsg.v. BRAVERMAN LE, Utiger RD; LiPPINCOTT-RAVEN, Philadelphia, NewYork 1996, 162-184 
OREN R, SiKuler E, Wong F, Blendis LM, HALPERn Z (2000): The effects of hypothyroidism on liver status of cirrhotic patients. J Clin Gastroenterol 31(2), 162-3

Orion Diagnostica: Type III Procollagen, PIIINP , Radioimmunoassay Kit instructions , Espoo/Finland 1999

PARAdies P, LAmbert C, Rouleau J (1991): Amiodarone antagonizes the effects of T3 at the receptor level: an additional mechanism for its in vivo hypothyroid-like effects.Can J Physiol Pharmacol $\underline{69}$ (6), 865-70

ParfitT AM, Simon LS, VillanueVa AR, Krane SM (1987): Procollagen type I carboxyterminal extension peptide in serum as a marker of collagen biosynthesis in bone. Correlation with Iliac bone formation rates and comparison with total alkaline phosphatase. Bone Miner Res 2 $(5), 427-36$

PEARCE S: SHBG: physiological variation and drug effects. In: NEQAS Participant's Meeting. Session Five, Cardiff 1988, 48-56.

PeKary AE, Hershman JM, ReEd AW, KANNON R, WANG YS (1986): Amiodarone Inhibit T4 to T3 Conversion and Alpha-Glycerolphosphate Dehydrogenase and Malic Enzyme Levels in Rat Liver. Horm Metabol Res $\underline{18}, 114-118$

Pfannenstiel P; Hotze L-A; SAller B: Schilddrüsenkrankheiten: Diagnose und Therapie. 4. Auflage, Berliner Med.Verl.-Anst., Berlin 1999 a, 23-33

Pfannenstiel P; Hotze L-A; Saller B: Schilddrüsenkrankheiten: Diagnose und Therapie. 4. Auflage, Berliner Med.Verl.-Anst., Berlin 1999 b, 245-250

PICCINI JP, BERGER JS, O`CONNOR CM (2009): Amiodarone for the prevention of sudden cardiac death: a meta- analysis of randomized controlled trials. Eur Heart J $\underline{30}$ (10), 1245-53

Plomp TA, van Rossum JM, Robles e Medina EO, van Lier T, MAEs RA (1984): Pharmakokinetics and body distribution of amiodarone in man. Arzneimittelforschung $\underline{34}(4), 513-$ 20

Plomp TA, Wiersinga WM, VAN Rossum JM, MAEs RA (1987): Pharmakokinetics and body distribution of amiodarone and desethylamiodarone in rats after oral administration. In Vivo 1 (5), 265-79

PollaK PT, TAN MH (1999): Elevation of high-density lipoprotein cholesterol in humans during long-term therapie with amiodarone. Am. J Cardiol 83 (2), 296-300

POLLAK PT, SHAFER SL (2004): Use of population modeling to define rational monitoring of amiodarone hepatic effects. Clin Pharmacol Ther 75(4), 342-51

Poser JW, Esch FS, LING NC, PRICE PA (1980): Isolation und sequence of the vitamin Kdependent protein from human bone. J Biol Chem 255, 8685-91

PRICE PA, WILLIAMSON MK, LOTHRINGER JW (1981): Origin of the vitamin K-dependent bone protein found in the plasma and its clearance by kidney and bone. J Biol Chem 256 , 12760-6

Puschendorf B, MAIR J: Kardiale Diagnostik; In: Labor und Diagnose. hrsg v. Thomas L; TH-Books Verlagsgesellschaft mbH, Frankfurt/Main 2000, 103-122

RAO RH, MCCREAdY VR, Spathis GS (1986): Iodine kinetic studies during amiodarone treatment. J Clin Endocrinol Metab 62, 563-8

Rhode H, LANGer I, KRIEG T, TIMPel R, (1983): Serum and urine analysis of the aminoterminal procollagen peptide type III by radioimmunoassay with antibody Fab fragments. Coll Rel Res $\underline{3}, 371-379$ 
Risteli J, SogaArd H, Oikarinen A, Risteli L, Karvonen J, Zacharias H (1988) a: Aminoterminal propeptide of type III procollagen in methotrexateinduced liver fibrosis and cirrhosis. Br J Dermatol 119, 321

Risteli L, KAUPPILA A, MÄKILÄ U-M, Risteli J, (1988) b: Aminoterminal propeptide of type III procollagen in serum - an indicator of clinical behaviour of advanced ovarian carcinoma? Int J Cancer $\underline{41}, 409$

Risteli J, MelkKo J, NiEMi S, Risteli L (1991):Use of a marker of collagen formation in osteoporosis studies. Calcif Tissue Int $\underline{49}$ Suppl, 24-25

Roche Diagnostics GmbH Produktinformation CK-MB, Mannheim 2003

Roche/Hitachi Diagnostics GmbH Produktinformation AP, Mannheim 2001

Roche/Hitachi Produktinformation ALB plus, Mannheim 2004

Roche/Hitachi Produktinformation CHOL, Mannheim 2004

Roche/Hitachi Produktinformation Creatinkinase, Mannheim 2004

Roche/Hitachi Produktinformation GGT, Mannheim 2004

Roche Produktinformation Elcsys® Ferritin 2004

ROJKIND M (1984): The blue glass und the predictive value of serum aminoterminal propeptide of type III procollagen as a marker of liver fibrosis. Hepatology $\underline{4}$, 977-978

Rossert J, DE Crombrugghe B: Type I collagen: structures, synthesis and regulation. In: Principles of Bone Biology. hrsg. v. BILEzIKIAN J, Raisz L, RodAn G; Academic Press, San Diego 2002, 189-210

Roten L, SchoenEnberger RA, KRÄHENBÜHL S, Schlienger RG (2004): Rhabdomyolysis in association with simvastatin and amiodarone. Ann Pharmacother $\underline{38}(6), 978-81$

RUDNICKI M, JENSEN LT, IVERSEN P (1995): Collagen derived serum markets in carcinoma of the prostate. Scand J Urol Nephrol 29(3), 317-21

Sabuncu T, Aksoy N, Arikan E, Ugur B, TAsan E, Hatemi H (2001): Early changes in parameters of bone and mineral metabolism during therapy for hyper- and hypothyroidism. Endocr Res 27 (1-2), 203-13

Safran M, Martino E, Aghini- Lombardi F, Bartalena L, Balzano S, Pinchera A (1988): Effect of Amiodarone on circulating antithyroid antibodies. Br Med J 297, 456-457

SCHMIDBERGER HFX: Bindung von Amiodaron und Schilddrüsenhormonen an Proteine. Med. Diss. Tübingen 1988

Seymen HO, Seven A, Civelek S, Yigit G, Hatemi H, Burcak G (1999): Evaluation of antioxidant status in liver tissues: effekt of iron supplementation in experimental hyperthyroidism. J Basic Clin Physiol Pharmacol 10 (4), 315-25

Shimamoto Y, Shimamoto H , NAKAmURA H (1989): Factors influencing serum free T3 and free T4 in elderly euthyroid subjects. Nippon Ronen Igakkai Zasshi $\underline{26}$ (4), 401-406

Simon LS, Krane SM, WorTMAn PD, Krane IM, Kovitz KL (1984): Serum levels of type I und III procollagen fragments in Paget's disease of bone. Clin Endocrinol Metab $\underline{58}$ (1),110120

Sogol PB, Hershman JM, Reed AW, Dillman WH (1983): The effects of Amiodarone on serum thyroid hormones and hepatic thyroxine $5{ }^{`}$-monodeiodination in rats. Endocrinology $\underline{113}, 1464-1469$ 
SPÄTH G: Herzrhythmusstörungen: aktuelle Bedeutung von Amiodaron. 2. Auflage; Beltz Verlag, Weinheim, Basel 1992

Spelsberg F, Negele T, RitTer MM: Die Schilddrüse in Klinik und Praxis. Johann Ambrosius Barth Verlag, Heidelberg 2000, 168- 170

StÄUbli M, StUder H (1981): Behandlung der Arrhythmien mit Amiodaron. Schweiz Med Wochenschr 111, 460-465

STEIN W: Creatinkinase (Gesamtaktivität) Creatinkinase-Isoenzyme und -Varianten. in: Labor und Diagnose. hrsg v. Thomas L; TH-Books Verlagsgesellschaft mbH , Frankfurt/Main 2000, $73-82$

STRACKE H: Osteocalcin; In: Labor und Diagnose, Indikation und Bewertung von Laborbefunden für die medizinische Diagnostik; hrsg. v. Thomas L; TH-Books Verlagsgesellschaft mbH, Frankfurt/M. 2000, 264- 266

STUder H, HunZIKER HR, RUCHTI C (1978): Morphologie and funktional substrate of thyreotoxicosis caused by nodular goiters. Am J Med $\underline{65}$, 227-234

SUlAKHE SJ, TRAN ST, PULGA VB (1990): Modulation of gamma-glutamyltranspeptidase activity in rat liver plasma membranes by thyroid hormone. Int J Biochem $\underline{22}$ (9), 997-1004

Takacs I, Kiss L, Horvath C, Foldes J, Lakatos P. TARJAN G (1996): Serum levels of type I collagen carboxyterminal propeptide and bone metabolism in hyperthyroidism. J Bone Miner Res 11 (Suppl.), 441

Takamatsu J, Majima M, Miki K, Kuma K, Mozai T (1985): Serum ferritin as a marker of thyroid hormone action on peripheral tissues. J Clin Endocrinol Metab $\underline{61}$ (4), 672-676

Tandem ${ }^{\circledR}-R$ Ostase ${ }^{\circledR}$ Produktinformation Beckman Coulter ${ }^{\mathrm{TM}}$, Fullerton/USA 2003

TATA JR, WILLIAMS-ASHMAN HG (1967): Effects of growth hormone and tri-iodthyronine on amino acid incorporation by microsomal subfractions from rat liver. Eur J Biochem $\underline{2}$ (3), 366374

Telopeptide ICTP Radioimmunoassay Kit, Kit Instructions; Orion Diagnostica, Espoo/Finland 1995

THomas L: Gamma-Glutamyl-Transferase; In: Labor und Diagnose. hrsg v. THOMAS L; THBooks Verlagsgesellschaft mbH, Frankfurt/Main 2000 a, 83-88

Thomas L: Albumin; In: Labor und Diagnose. hrsg v. THOMAS L; TH-Books Verlagsgesellschaft mbH, Frankfurt/Main 2000 b, 668-670

Tziakas DN, Chalikias GK, Papanas N, Stakos DA, Chatzikyriakou SV, Maltezos E (2007): Circulating levels of collagen type I degradation marker depend on the Type of atrial fibrillation. Europace $9(8), 589-96$

WiEgand V, WAgner G, KREuZER H (1986): Hypothyroid-like effect of amiodarone in the ventricular myocardium of the rat. Basic Res Cardiol $\underline{81}$, 482-488

WIERSINGA WM: Amiodarone and the thyroid. In: Handbook of Experimental Pharmacology, Vol. 128, Pharmacotherapeutics of the Thyroid Gland; hrsg. v. WEETMAN AP, Grossmann A ; Springer Verlag; Berlin 1997, 225-287.

WIERSINGA WM (2008): The role of thyroid hormone nuclear receptors in the heart: evidence from pharmacological approaches. Heart Fail Rev. (published online 19 December 2008)

Yoshida K, Sumi S, Arai K, Koga F, Umeda H, Hosoya Y, Honda M, Yano M, MORIGUCHI H, KITAHARA S (1997): Serum concentration of type I collagen metabolites as a 
quantitative marker of bone metastasen in patients with prostate carcinama. Cancer $\underline{80}(9)$, 1760-7

ZeRweKh JE, SAKHAEE K, PAK CYC (1985): Short-term 1,25 dihydroxyvitamin D3 administration raises serum osteocalcin in patients with postmenopausal osteoporosis. J Clin Endocrinol Metab $\underline{60}, 615-17$

Zulewski H, Siggelkow H, WALden C, BeCKeR W, HÜFNER M (1999): Evaluation of procollagen III peptide as a marker of tissue hyperthyroidism in long-term treated women with TSH suppressive doses of thyroxine. Exp Clin Endocrinol Diabetes 107, 190-194 


\section{ABKÜRZUNGSVERZEICHNIS}

ACE-Hemmer

AICD

ALT

AP

AST

bAP

CICP

CK

C-terminal

I CTP

DCM

DEA

DIT

DNS

fT4

GGT

$\mathrm{KG}$

KHK

MIT

mRNA

o.A.

PINP

PIIINP

rT3

$\mathrm{T} 2$

T3

$\mathrm{T} 4$

TBG

TPO

TR

TRAP

TRE

TSH
Angiotensin-Converting-Enzym-Hemmer

(engl.) automatic implantable cardioverter defibrillator

Alaninaminotransferase

alkalische Phosphatase

Aspartataminotransferase

bone-AP (alkalische Knochenphosphatase)

Kollagen-I-carboxyterminales Propeptid

Creatinkinase

carboxyterminal

Kollagen-I-carboxyterminales Telopeptid

dilatative Cardiomyopathie

Desethylamiodaron

Dijodthyrosin

Desoxyribonukleinsäure

freies Thyroxin

Gammaglutamyltransferase

Körpergewicht

koronare Herzkrankheit

Monojodthyrosin

(engl.) messenger ribonucleic acid

ohne Ausreißer

Kollagen- I- aminoterminales Propeptid

Kollagen-III- aminoterminales Propeptid = Prokollagen-III

reverses Trijodthyronin

Dijodthyronin

Trijodthyronin

Tetrajodthyronin $=$ Thyroxin

Thyroxinbindendes Globulin

Thyreoidperoxidase

Thyroid-Rezeptor

TR auxiliary protein

thyroid hormone response elements

Thyroidea stimulierendes Hormon 


\section{DANKSAGUNG}

Mein Dank gilt meinem Doktorvater Herrn Prof. Dr. med. M. Hüfner für die Überlassung des interessanten Dissertationsthemas und die langjährige Unterstützung bei der Durchführung der Studie.

Für die geduldige Betreuung bei der wissenschaftlichen Erarbeitung und bei der Darstellung der Ergebnisse möchte ich mich besonders bei Herrn Prof. Dr. med. W. Nolte bedanken. Wissenschaftlich korrektes Arbeiten und problemorientierte Vorgehensweise sind mir durch seine Mitwirkung vermittelt worden.

Weiterhin danke ich Frau Claus und den Mitarbeitern des Hormonlabors der endokrinologischen Abteilung von Prof. Hüfner für die hilfreiche Einarbeitung in Labortechniken. 
